\title{
8 Tagungsberichte/Report on conferences
}

\subsection{Kolleg-Forschergruppe „Religiöse Individualisierung in historischer Perspektive“}

Tagung vom 17. bis 19. September 2012 am Max-Weber-Kolleg: ,Burial Rituals, Ideas of Afterlife, and the Individual in the Hellenistic World and the Roman Empire' (Richard Gordon, Wolfgang Spickermann, Katharina Waldner)

Die internationale Tagung wurde im Rahmen der Kolleg-Forschergruppe ,Religiöse Individualisierung in historischer Perspektive، veranstaltet und finanziell von der Fritz-Thyssen-Stiftung unterstützt. Hierzu trafen sich vom 17. bis 19. September 2012 im Augustinerkloster zwanzig Althistoriker, Archäologen, Altphilologen, Religionswissenschaftler und Ägyptologen, um interdisziplinäre Zugangsweisen zur Thematik $\mathrm{zu}$ entwickeln.

Die Vielfalt der Bestattungspraktiken in antiken und modernen Kulturen hat ihren Ursprung in der einfachen Tatsache der Sterblichkeit des Menschen. Darüber hinaus provoziert Tod in jeder Kultur (und jeder Religion) Vorstellungen darüber, was danach geschieht, also über eine postmortale Existenz. Wenn auch jeder Tod höchst individuell ist, ist die Bestattung der Toten immer ein großes sozio-religiöses Anliegen. In gleicher Weise sind diesbezügliche Praktiken auch in einer bestimmten Kultur nie standardisiert oder homogen, sondern sie beruhen auf kontingenten Schemata und Möglichkeiten. Auf dieser Basis soll eine Verbindung zwischen den drei Bereichen Bestattung, Eschatologie und Individuation fruchtbar gemacht werden.

Die Tagung sollte daher die Wechselbeziehungen zwischen Bestattungspraktiken, Vorstellungen von Leben nach dem Tod und deren Verhältnis zum Individuum in hellenistischer und römischer Zeit untersuchen. Wenn die ersten beiden Begriffe relativ eindeutig sind, gilt dies nicht für den dritten. Wir verstehen den Begriff des Individuums in einem zweifachen Sinn: 1) In dem elementaren Sinne von ,einer Person', die sich der Tatsache ihrer Sterblichkeit bewusst ist und möglicherweise Vorbereitungen für ihre Bestattung trifft (z.B. Auswahl einer bestimmten Art von Grab, Grabstele, Sarkophag etc.) und vielleicht auch versucht, ein Leben nach dem Tod für sich selbst und Angehörige (z.B. durch Initiation in einen oder mehrere Mysterienkulte) zu gewährleisten; 2) als Mittel der Konzeption einer individuellen Identität (Person), die im Laufe der Bestattungsriten eine Transformation erfährt und so in der Lage ist, über den Moment des physischen Todes hinaus zu existieren. Um dieses facettenreiche Feld zu untersuchen, hat die Konferenz drei große Themenkomplexe behandelt: 
1. Archäologie und die Anthropologie von Tod und Sterben,

2. Erinnerung an die Toten: Praktiken des Totengedenkens und Jenseitsvorstellungen,

3. Rituale über den Tod hinaus? Mysterienkulte und Grabriten.

Ein von den drei Veranstaltern herausgegebener Sammelband ist in Vorbereitung.

ESF-LiU Conference vom 10. bis 14. September 2012 in Norrköping (Schweden): ‘Historiography of Religion’ (Jörg Rüpke, Susanne Rau, Bernd-Christian Otto)

The conference focused on the question "How, under which conditions and with which consequences are religions historicized?”. It aimed at furthering the study of religion as of historiography by analysing how religious groups (or their adversaries) employ historical narratives in the construction of their identities. Likewise it asked how such groups were invented by later historiography and are continued in modern research. Thus it also focused on the biases and elisions of current analytical and descriptive frames. Combining disciplinary competences of Religious Studies and History of Religion, Confessional Theologies, History, History of Science, and Literary Studies, the participants initiated a comparative historiography of religion. Furthermore, a history of historical research on religion was stimulated by identifying key steps in the early modern and modern history of research. The agenda of the conference was therefore highly comparative and interdisciplinary.

Numerous scholars from different fields of historical and religious research, from Circum-Mediterranean and European as well as Asian religious traditions from the first millennium BCE to the present came together. The conference was structured by a series of six sessions in three days (including one poster session) which combined impulses from short (10 minutes) and long (20 minutes) lectures with plenary discussions. Here, the impulse of the initial question was driven forward by further questions developed in the opening lecture by the organizers like "Which contexts do provoke processes of historicization and the development of historiography in particular?"; "Which practices to historicize the past, i.e. to acknowledge and sequence the pastness of the past, have been used in historicizing religions?"; "How do religions make themselves immune against historicist claims?” The conference programme included some 26 papers focusing on the above-mentioned questions and covered a variety of topics and religious traditions. A first group of papers dealt with narrations of 'origins and developments'. In this group, among others, specialists on the ancient Mediterranean (Ingvild Gilhus), on Hinduism (Johannes Bronkhorst), Islam (Chase Robinson), Buddhism (Sylvie Hureau; Per Sørensen), the European middle ages (Pekka Tolonen), and Early modern Europe (Yves Krumenacker) presented lectures on their topics. A second group dealt with the topic of 'writing histories' and included papers on Islam (Ulrika Mårtensson, Shahzad Bashir), Hinduism (Jon Keune), Early modern and modern Europe (Susanne Rau; Hannah Schneider; Franziska Metzger), 
and modern China (Philipp Hetmanczyk). Finally, a third group focussed on the interconnectedness between pre-academic and academic discourses dealing with the historiography of religion: 'Transforming narratives: scholars, methods, disciplines'. In this group, papers on Judaism and Jewish Studies (Reinhard G. Kratz, Christiana Facchini), on modern interpretations of ancient polytheism (Renée Koch-Piettre, Gabriella Gustafsson), and on the modern History of Christianity in Italy (Giovanni Filoramo) were presented. A poster session offered the opportunity to present case studies as contributions to the other sessions. It was used by nearly twenty young scholars.

Tagung vom 22. bis 24. November 2012 am Max-Weber-Kolleg im Rahmen der Kolleg-Forschergruppe 'Religiöse Individualisierung in historischer Perspektive' und in Kooperation mit der Forschungsstätte der Evangelischen Studiengemeinschaft (FEST), Heidelberg: ,Metamorphosen des Heiligen. Vergemeinschaftung durch Sakralisierung der Kunst' (Markus Kleinert)

In der Einführung wurden zunächst drei zentrale Aspekte des Tagungsthemas erläutert: erstens, die methodisch grundlegende Thematisierung des Heiligen als Kommunikationsgeschehen, als Zuschreibung von Heiligkeit mittels habitualisierter Deutungsverfahren und Handlungsformen; zweitens, die soziale Funktion solcher Sakralisierungen, die durch sie bewirkte Identitätsstiftung und Vergemeinschaftung; drittens, der Wandel solcher Sakralisierungen, in diesem Fall die tendenzielle Verlagerung der Kommunikation des Heiligen von der Institution der Religion auf die Institution der Kunst, die sich kurz mit dem Begriff der Kunstreligion bezeichnen lässt (Magnus Schlette). Als ein Musterbeispiel für diesen Themenkomplex, für die Vergemeinschaftung durch Sakralisierung der Kunst wie für die Kritik eben dieses Prozesses wurde kurz die Deutungs- und Aufführungsgeschichte von Beethovens letzter Klaviersonate op. 111 vor Augen geführt (Markus Kleinert).

In seinem Eröffnungsvortrag stellte Volkhard Krech das Heilige nach phänomenologischen und begriffs- bzw. wissenschaftsgeschichtlichen Anmerkungen als eine besondere Kommunikation dar, durch die die letztlich paradoxe Verfasstheit sozialer Systeme kommuniziert werden könne und die die Voraussetzung religiöser wie kunstreligiöser Kommunikation bilde (welche sich dann in ihren Gewichtungen, nicht aber grundsätzlich voneinander unterscheiden). Im Hinblick auf die Unterscheidung von religiöser und kunstreligiöser Kommunikation wurde in der Diskussion unter anderem die Frage nach der jeweiligen Verträglichkeit von Ironie aufgeworfen, auf die, wenngleich damit kein Unterscheidungsmerkmal benannt ist, im Tagungsverlauf noch mehrfach zurückgekommen wurde. Stefan Alkier wies mit Bezug auf Diskurse über das Wunder (am Beispiel von Gregor von Nyssas Lebensbeschreibung seiner Schwester Makrina) auf die der religiösen Kommunikation immanente 
Rationalität hin, die mit der bloßen Entgegensetzung von Wunderglauben und Wissenschaft verkannt wird und auf die wechselseitige Abhängigkeit von Wunderdiskursen und Wirklichkeitskonzepten verweist. Dagegen entwickelte Reinhard Brandt unter Bezugnahme auf die Konzepte des Erhabenen bei Pseudo-Longinos und Kant (hier unter besonderer Berücksichtigung der begründungstheoretischen ,Figur des Vierten') einen emphatischen Vernunftbegriff, vor dem eine Sakralisierung als fahrlässige Ermäßigung erscheint, so erkennbar etwa in Burkes Konzept des Erhabenen. Nach diesen grundsätzlichen Beiträgen zum Sakralen wurde die Sakralisierung speziell der Kunst bzw. der Künste und deren soziale Funktion behandelt.

In seiner detaillierten Analyse von Elvis Presleys Bühnenshow in Los Angeles deutete Heinrich Detering diese Auftrittsserie als ein popkulturelles kunstreligiöses Ritual, dessen allmählich perfektionierter Verlauf auf eine universale Kultursynthese abzielt und in dem der Künstler die Funktion eines Schamanen übernimmt.

Wolfgang Braungart deutete anhand von Lessings Minna von Barnhelm und Nathan der Weise einen der Kunst eigenen religiös-utopischen Zug an, der darin besteht, dass das Subjekt in der ritualisierten Auseinandersetzung mit einem autonomen Kunstwerk seiner eigenen Unbedingtheit innewerden könne, und der in der Vorstellung einer künstlerischen Kompensation des schwindenden Einflusses traditioneller Religionen gerade verfehlt wird. Er leitete mit diesen Thesen eine Reihe literaturwissenschaftlicher Beiträge ein. Bernd Auerochs demonstrierte die Spannung zwischen kunstreligiösen Ansätzen und der Kritik einer Ästhetisierung von Religion im Werk Martin Bubers, was nebenbei verdeutlichte, dass das Thema der Vergemeinschaftung durch Sakralisierung der Kunst keinesfalls auf die christliche Tradition beschränkt ist. Danach wurden zwei Extrempositionen innerhalb der christlichen Tradition behandelt: auf der einen Seite die bei aller Differenzierung vorherrschende Reserve gegenüber der Kunst in der Literatur des Pietismus, bei August Hermann Francke und Gottfried Arnold (Joachim Jacob), auf der anderen Seite die in einem emphatischen Wort- und Sprachverständnis begründete Kunstreligion Hölderlins (Johann Kreuzer). Schließlich demonstrierte Günter Häntzschel, wie in den im neunzehnten Jahrhundert außerordentlich populären Lyrikanthologien eine diffuse religiöse Stimmung erzeugt wurde und zu diesem Zweck auch profane Texte (durch strategische Präsentation und mehr oder weniger unauffällige Manipulationen der Herausgeber) sakralisiert wurden.

Neben diese literaturbezogenen Studien traten drei Vorträge, die Anspruch und Wirklichkeit der Sakralisierung von Kunst am Beispiel der Musik untersuchten. Peter Steinacker rekonstruierte Wagners kunstreligiöses Programm und gab einen Ausblick auf dessen Musealisierung im Wagnerismus. Dietrich Korsch deutete Mozarts Cosi fan tutte als Experiment auf die ordnungsstiftende Kraft der Liebe, dessen Ausgang im Kunstwerk als Ambivalenz festgehalten werden könne und gerade darin ein Analogon moderner, nur in Gegensätzen explizierbarer Religiosität bilde. Elisabete M. de Sousa widmete sich in einer detaillierten Analyse dem Mozart-Kapitel in Kier- 
kegaards Entweder/Oder, um unter Hinzuziehung der zeitgenössischen musikkritischen Kontexte (Schumann, Berlioz, Wagner) einen emphatischen Begriff von Virtuosität herauszuarbeiten, als dessen Verkörperung Liszt erscheint und der sich auf Grund der darin enthaltenen Ambivalenzen wiederum in eine Analogie zu moderner Religiosität bringen lässt.

Überblickscharakter hatten die Vorträge von Werner Hofmann, der das Verhältnis von Religion und bildender Kunst in Anlehnung an Hegels Ausführungen über die Auflösung der romantischen Kunstform (die Dialektik von Nachahmung des Objektiven in seiner Kontingenz einerseits und subjektivem Humor andererseits) darstellte, und von Bernhard Schäfers, der aus architektursoziologischer Perspektive die Vorstellung von Transformationsprozessen innerhalb des Verhältnisses von Kunst und Religion - im Gegensatz zu Kompensationsmodellen - stützte.

Der für die Tagung gewählte Ansatz, das vielfach thematisierte Verhältnis von Kunst und Religion auf der Grundlage der Kommunikation des Heiligen, von sozialen, identitätsstiftenden Praktiken der Zuschreibung von Heiligkeit zu untersuchen, erwies sich so insgesamt als sehr produktiv. Zu der Tagung konnte neben den Referenten eine ungefähr gleich große Zahl von Gästen begrüßt werden. Die Tagungsbeiträge sollen in einem Sammelband innerhalb der von der FEST herausgegebenen Reihe Religion und Aufklärung des Tübinger Verlags Mohr Siebeck veröffentlicht werden. Im Hinblick auf eine systematisch vollständige Darstellung des Forschungsansatzes werden in diesen Sammelband einige zusätzliche Beiträge aufgenommen, zum Beispiel zur Vermittlung der die Sakralisierung der Kunst bewirkenden Einstellungsund Handlungsmuster in der Pädagogik (so erscheint darin auch der auf der Tagung wegen Krankheit entfallene Beitrag von Jürgen Oelkers).

Tagung vom 14. bis 16. Februar 2013 am Max-Weber-Kolleg, in Kooperation mit dem Deutschen Literaturarchiv Marbach und im Rahmen der Kolleg-Forschergruppe ,Religiöse Individualisierung in historischer Perspektive‘: Sokratische Ortlosigkeit. Kierkegaards Idee des religiösen Schriftstellers‘ (Markus Kleinert)

In der Einführung wurde die Problematik entwickelt, die in Kierkegaards Selbstverständnis als religiöser Schriftsteller impliziert ist: die Zwiespältigkeit und das Wagnis eines literarischen Unternehmens, das eine ästhetische Existenz religiös begründen und eine religiöse Existenz ästhetisch absichern will, sich dabei aber auf keine kirchlich-religiöse Vollmacht stützt und sich auch nicht dem etablierten Wissenschaftssystem zuordnen lässt, ja insbesondere gegenüber der Universitätsphilosophie und -theologie auf Distanz geht. Die Spannung in Kierkegaards Selbstverständnis zeigt sich zum Beispiel daran, dass er seine Tätigkeit als Schriftsteller einerseits in Anlehnung an die eigene Sokrates- Darstellung und unter Hervorhebung der Sokrates bei Platon zugeschriebenen Ortlosigkeit kennzeichnet, andererseits für sich metaphorisch Poli- 
zeigewalt in Anspruch nimmt. Vor diesem Hintergrund sollte auf der Tagung zunächst Kierkegaards Idee des religiösen Schriftstellers im Spannungsfeld von Religion, Dichtung und Wissenschaft genauer betrachtet werden; dann sollte untersucht werden, welche Paradigmen die literarische und auch die literaturwissenschaftliche Rezeption dieses Schriftstellers bestimmen und ob dabei sein Selbstverständnis von Belang ist; schließlich sollte die Aktualität der Idee des religiösen Schriftstellers im Hinblick auf Religiosität und religiöse Rede in der Moderne thematisiert werden (Markus Kleinert).

In seinem Eröffnungsvortrag arbeitete Heiko Schulz akribisch heraus, wie der religiöse Schriftsteller in Kierkegaards Werk bestimmt ist: Die Spezifizierung nahm ihren Ausgang von wissenschafts-theoretischen Überlegungen zu der von Kierkegaard konzipierten Existenzwissenschaft; die christliche Redekunst, die Kierkegaard im kritischen Anschluss an die antike Rhetorik entwirft, steht im Dienst der Existenzwissenschaft; der religiöse Schriftsteller wiederum bedient sich der christlichen Redekunst auf eine Weise, die philosophische Metaphysik und theologische Dogmatik als für das religiöse Selbstverhältnis des Einzelnen gleichermaßen irrelevant suspendiert. Vor diesem Hintergrund wurde die besondere Problematik des religiösen Schriftstellers erkennbar. Anschließend wurde Kierkegaards Idee des religiösen Schriftstellers zu antiken und modernen Traditionen in Beziehung gesetzt. Rasmus Sevelsted parallelisierte das Verhältnis von Platon zu Sokrates mit dem von Kierkegaard zu seinen Pseudonymen, unter Hervorhebung der Notwendigkeit poetischer Veranschaulichung (dabei erläuterte er auch die Bedeutung der Atopie bei Platon). Wolfgang Spickermann nahm Kierkegaards positive Bezugnahmen auf Lukian zum Anlass, die Eigenschaften im Werk dieses historisch schwer fassbaren spätantiken Autors herauszustellen, die Kierkegaards Sympathie hervorgerufen haben müssen, insbesondere die ironisch- übermütige negative Dialektik im Zusammenhang von Philosophieund Religionskritik. Magnus Schlette untersuchte die Bedeutung der Autobiographie für den religiösen Schriftsteller Kierkegaard, vor allem anhand der wechselseitigen Beziehung von im engeren Sinne autobiographischen und pseudonymen Schriften und unter vergleichender Hinzuziehung der pietistischen Autobiographie, hier der Lebensgeschichte von August Hermann Francke; das Verhältnis von Werk und Existenz erfährt bei Kierkegaard demnach folgende Zuspitzung: Die literarische Imagination wird zu einem für die Selbstwerdung notwendigen Akt der Bewährung, das Werk wird zum notwendigen Medium des Christwerdens.

Eine Reihe von Vorträgen beschäftigte sich dann mit der literarischen Rezeption Kierkegaards und seiner Idee des religiösen Schriftstellers. In der von Christian Wiebe entworfenen Typologie der Rezeptionsformen in der Literatur um 1910 zeichnete sich eine Skala literarischer Umgangsweisen mit Kierkegaards Selbstverständnis ab: von der absichtlichen oder unabsichtlichen Vernachlässigung über die mehr oder weniger stark modifizierende Aneignung bis hin zur Verfälschung (wobei selbst die Proklamationen von Ludwig Derleth ihrer ästhetisch-politischen Zweideutigkeit wegen 
als Reflex auf Kierkegaards ähnlich zweideutige Schriften des Kirchenkampfs verstanden werden können). Das Thema wurde von Charles Cahill fortgeführt, der Kierkegaards Präsenz in der späten Weimarer Republik untersuchte; die Bezugnahme auf Kierkegaard bewirkte bisweilen überraschende Allianzen, wie die von Wilhelm Kütemeyer und Alfred Baeumler mit ihren Versuchen, den religiösen Schriftsteller gegen bzw. für den Nationalsozialismus zu mobilisieren; Kierkegaards Anziehungskraft beruht in solchen Zusammenhängen mit darauf, dass sich die zentrale Kategorie des Einzelnen für die Kritik an Institutionen eignet, der derart losgelöste Einzelne aber wieder beliebigen Zwecken untergeordnet werden kann. Jan Bürger führte das Thema schließlich mit Blick auf die Literatur des späteren zwanzigsten Jahrhunderts aus, indem er verschiedene Rezeptionsweisen vorstellte und dabei zugleich das Potential des Literaturarchivs demonstrierte, so dass bekannte Kierkegaard-Rezeptionen wie die von Max Frisch in neuem Licht erschienen und gänzlich neue Wirkungsgeschichten sichtbar wurden, so etwa ein Einfluss von Kierkegaards Wiederholung auf Paul Celans Todesfuge. In zwei weiteren Beiträgen wurden für die literarische Rezeption entscheidende Strukturen der Kierkegaardschen Texte behandelt. Angelika Jacobs zeigte, wie Kierkegaards Texte durch eine fundamentale Unruhe auf einen Schock hinwirken, der mit dem Konzept des Erhabenen verbunden werden kann und auf die Selbstaufhebung der Ästhetik und ein religiöses Selbstverhältnis des Lesers angelegt ist. Mit diesem ästhetisch induzierten Schock verwandt ist die Sprach- und Denkfigur des Paradoxen, der sich Mathias Mayer widmete: in einem geeigneten mentalitätsgeschichtlichen Kontext konnten die in Kierkegaards Texten entfalteten Paradoxien als Impuls $\mathrm{zu}$ einer so fundamentalen wie ungesicherten, ins Offene weisenden ethischen Reflexion der Moral wirken, zum Beispiel bei Broch und Kafka, doch lässt sich Kierkegaard auf diese Weise auch zum utopischen Potential der mystischen Paradoxie bei Musil in Beziehung setzen.

Mit einem Seitenblick wurde das Verhältnis der skandinavistischen Literaturwissenschaft zu Kierkegaard betrachtet. In seinem diesbezüglichen Überblick verdeutlichte Joachim Grage die Schwierigkeit eines genuin literaturwissenschaftlichen Umgangs mit Kierkegaard, wobei in den einschlägigen Arbeiten Kierkegaards Selbstverständnis als religiöser Schriftsteller entweder beiseitegelassen oder übernommen, kaum aber in seiner Problematik untersucht wird.

Abschließend wurde nach der Aktualität der Idee des religiösen Schriftstellers gefragt. Peter Tschuggnall erkannte in der Poesie grundsätzlich eine Möglichkeit religiöser Rede, die der seit der Jahrhundertwende artikulierten Sprachkrise Rechnung trägt; er vergegenwärtigte diese Theopoesie durch Werke aus den verschiedenen Künsten, insbesondere der Musik. George Pattison beantwortete die Frage, wie sich das Christ-Sein in einem post-christlichen Zeitalter literarisch zum Ausdruck bringen lasse, zunächst mit einer doppelten Verlusterklärung: Kierkegaards Zeitalter sei in religiöser Hinsicht durch das Ende des theistischen Konsenses gekennzeichnet, in ästhetischer Hinsicht durch das Ende der Kunst, deren Stelle das Ästhetische als Zeitgeist einnehme; daher stelle sich Kierkegaard die Aufgabe, die christliche Idee in der 
alltäglichen Existenz darzustellen, unter Verzicht auf metaphysische Absicherungen und in der Orientierung an der Lebensgeschichte Jesu, eine Aufgabe, der Kierkegaard mit all seinen schriftlichen Ausdrucksformen, mit den pseudonymen und erbaulichen Schriften wie mit den Journalen und Notizbüchern nachzukommen versuche. Schlussvortrag und Eröffnungsvortrag griffen so ineinander: Während der religiöse Schriftsteller eingangs anhand der Kierkegaardschen Konzepte der Existenzwissenschaft und christlichen Redekunst genau spezifiziert wurde, erschien er abschließend als die Idee, die das gesamte Werk Kierkegaards umfasst und zusammenhält.

Das Thema der Tagung, die so zentrale wie problematische Idee des religiösen Schriftstellers, und der entsprechend interdisziplinäre Ansatz erwiesen sich damit als sehr fruchtbar, zumal der 200. Geburtstag Kierkegaards so Anlass für eine kritische Auseinandersetzung mit seinem Werk war, wodurch die Problematik wie das utopische Potential von Kierkegaards Version der Sokratischen Atopie deutlich wurden. Neben den Referenten konnte eine große Zahl an Gästen auf der Tagung begrüßt werden, darunter von diplomatischer Seite Per Erik Veng, Botschafts-Rat an der Dänischen Botschaft in Berlin, und von journalistischer Seite Nikolaus Halmer (ORF) und Maximilian Krämer (F.A.Z.), die beide ausführlich über die Tagung berichteten. Eine Veröffentlichung der Tagungsbeiträge ist in Arbeit.

Wissenschaftliche Tagung der Kolleg-Forschergruppe ,Religiöse Individualisierung in historischer Perspektive' am Max-Weber-Kolleg in Verbindung mit der Akademie der Diözese Mainz und der Meister Eckhart-Gesellschaft vom 19. bis 21. April 2013 im Haus am Dom in Mainz: ,Sprachbilder und Bildersprache bei Meister Eckhart und in seiner Zeit. Strategien des Sprechens über das Unsagbare‘ (Dietmar Mieth)

In der Mystik begegnen uns Sprachbilder, ja eine ganze Bildersprache. Mystik bewegt sich an den Grenzen von sprachlicher Ausdrucksfähigkeit - und entfaltet gerade darin ihre Anziehungskraft. Das Interesse an Meister Eckhart, dessen sprachliche Faszination auch noch in den Übersetzungen in andere Sprachen erhalten bleibt, geht oft auf seine Sprachbilder zurück. Er setzt sie bewusst ein, um die scharfe Begrifflichkeit und die spekulative Kraft seines Denkens anschaulich umzusetzen und der Erfahrungswelt seiner Zuhörer und Zuhörerinnen anzupassen. So spricht er vom Siegeldruck des Wachses, vom Echo als Widerhall einer Stimme, die man nicht hört, vom Prozess des Sehens, der Holz und Auge zusammenschließt, von der Überblendung durch das Licht, von Bildern, die sich wechselseitig spiegeln, aber nicht fixiert sind. Sein Programm ist, wie es später Heinrich Seuse ausdrücken wird, Bilder mit Bildern zu überwinden und damit einen Bereich zu öffnen, in welchem unser Vorstellungsvermögen zugleich entfaltet und überschritten wird.

Diese Thematik ist bisher nur fallweise in den Forschungen, in deren Zentrum oft Eckharts philosophischtheologische Bildtheorie stand, behandelt worden. Die Tagung hat versucht, diesen Stand der wissenschaftlichen Bemühungen zu erweitern. 
Zugleich aber verfolgt sie die Absicht, solche Erkundungen mit den breiteren Interessen an den Sprachbildern in der europäischen Mystik zu verbinden und in diesem Sinne den Charakter einer reinen Fachtagung zu überschreiten.

Wolfgang Achtner, Gießen, hinterfragte das Tagungsthema kritisch, indem er die Bildkritik und das Motiv der Bildlosigkeit der ,Bildersprache“ Eckharts gegenüberstellte. Eckharts oft in Bildern ausgedrückte Bildkritik, d.h. seine Überzeugung, dass eine bildhaft vermittelte Erkenntnis für die Gotteserkenntnis nicht hinreichend ist, wurde vor den Hintergrund ihrer ideengeschichtlichen Voraussetzungen gestellt. Der Vortrag leuchtete die Bandbreite der verschiedenen Kontexte aus, in denen diese Bildkritik als Erkenntnismodus eingesetzt wird. Die scholastische Erkenntnistheorie, der aristotelische Vernunftbegriff und die apophatische Theologie wurden in ihrem Zusammenspiel und in ihrem Verhältnis zu Eckharts Theorie von der Gottesgeburt in der Seele vorgeführt. Mit Blick auf transkulturelle Analogien und einschlägige psychologische Mechanismen wurde die Frage erörtert, ob und wenn ja in welchem Sinne Eckhart überhaupt als Mystiker bezeichnet werden kann.

Martina Roesner, Wien, untersuchte ,Bilder der Eigenschaftslosigkeit. Die Verwendung relationaler Metaphorik in Meister Eckharts lateinischen Schriften'. Mit Blick auf Eckharts lateinische Schriften fällt auf, dass die Vergleiche, die er im Rahmen seiner theologisch-exegetischen Darlegungen verwendet, zwar häufig dem Bereich der Natur entstammen, aber nicht so sehr einzelne Naturdinge als vielmehr deren Grundstrukturen betreffen, wie etwa die Abfolge von Blüte, Zeugung und Frucht, die Beziehung des Herzens bzw. der Seele zum Organismus als Ganzem, das Verhältnis von Licht und Wärme zu ihrem Ausbreitungsmedium oder die Deutung der Schöpfung als ,Übersprudeln“ einer kochenden Flüssigkeit. In all diesen Fällen betrifft die bildhafte Analogie keine einzelne, dingliche Eigenschaft, sondern gilt der jeweils zum Tragen kommenden Verhältnisbestimmung zwischen gewissen Grundprinzipien wie Materie und Form, Ursache und Wirkung, Zentrum und Peripherie.

,Dô gedâhte ich ein glîchnisse [...] Vergleich und Gleichnis in den deutschen Predigten Meister Eckharts‘ lautete der Titel des Vortrags von Dagmar Gottschall, Salento. Der Beitrag stellte das Vergleichsrepertoire aus Eckharts deutschem Predigtwerk und mögliche Quellen vor: Es entstammt überwiegend dem Bereich der Naturphänomene, der Physik und der Optik. Ein Blick auf andere zeitgenössische Prediger zeigte die Auffälligkeit oder Unauffälligkeit Eckhartscher Vergleiche. Jeweils ist zu fragen: Inwieweit spielt das Publikum, inwieweit seine Selbstverständigung jeweils für einen Vergleich eine Rolle?

Stephan Grotz, Regensburg/Mainz, stellte ,Wie zerbricht man Gleichnisse? Bemerkungen zur Struktur von Meister Eckharts Bildersprache“ vor. Der Beitrag zeigte auf, dass Eckharts Bildersprache nicht so sehr darauf abzielt, das per se Unanschauliche doch noch etwas anschaulicher zu machen. Insofern hat Eckharts Bildersprache auch keinen vergleichenden Charakter in dem herkömmlichen Sinn. Eckharts Gleichnisse vergleichen nicht so sehr (also z.B. Gott mit irgendetwas); sie sprechen vielmehr 
von Gleichheit, und zwar vor allem von einer Gleichheit mit Gott. Der Vortrag entfaltete besonders Eckharts Umgang mit biblischen Vergleichen anhand der berühmten Predigt 9 ,Quasi (!) stella matutina‘. Hier ist das Wort ,quasi‘ gleichsam eine Leitfigur. In seinem Vortrag ,Meister Eckharts vünkelîn der sêle - Bild oder Begriff?‘ ging Alois Haas, Zürich, zunächst auf das Bild des Feuers und des Funkens in unterschiedlichen Kulturen und Religionen ein. Dabei ging es ihm vor allem historisch um die Bedeutung des Feuers in der Elementenlehre und deren Symbolfunktionen in der ,Achsenzeit'. Feuer und Funken stehen für Tiefe und positive Entfaltung aus einem Kern heraus. In der Zuspitzung auf Meister Eckharts Grundgedanke wurde von ihm eine Bündelung vieler vorhergehender begrifflicher und bildlicher Pointierungen beschrieben: in der Stoa, im Neuplatonismus, in der Lehre vom aufsteigenden Intellekt. Die Alternative von Begriff und Bild ist also falsch: Hinter allen Begriffen ist zugleich eine bildliche Fassung präsent, und alle Bilder sind mit begrifflichem Denken ausgestattet.

Markus Vinzent, London, stellte ,Eckharts Bildsprache in seinen lateinischen Predigten' vor. Er konnte mit Beispielen aufzeigen, wie Texte missverstanden und falsch übersetzt werden können, wenn man die Bildseite nicht korrekt darstellt und analysiert. Zudem konnte er zeigen, dass die Rhythmik in Eckharts lateinischem Sprach-Duktus verloren geht, wenn man übersieht, dass die Worte nur in einer bestimmten Abfolge eine besondere klangliche Struktur erzeugen. Insofern zeigte der Vortrag das rhythmische Sprechen in Eckharts lateinischen Sermones auf. Offensichtlich wurden hier nicht nur Texte als inhaltliche Vorlagen entwickelt, sondern zugleich enthielten sei für den Prediger Anleitungen dazu, wie etwas elegant vorzutragen war. Damit steht die lateinische Eckhart-Philologie vor neuen Aufgaben, die ihrerseits wiederum mit den systematischen Funktionen abzugleichen sind.

Die Reihe der Vorträge zu theologischen und mystischen Schriften aus dem Umkreis Eckharts eröffnete der Beitrag von Regina Schiewer, Eichstätt, zu den St. Georgener Predigten. An den von ihr präsentierten Beispieltexten konnte sie zeigen, wie weit die Reichhaltigkeit metaphorischer Sprache bereits im Anfang des 13. Jahrhunderts entwickelt war. René Wetzel, Genf, beschäftigte sich mit den Engelberger Predigten, die Johannes Tauler nahe stehen. Sie benutzen u.a. Gleichnisse der Natur (Sonnenablauf) für geistliche Vorgänge. Die Metaphern des Fließens und Zerfließens, des verborgenen Weins in der Traube, der Wüste und der Grundlosigkeit sind hier bereits als Routine fassbar. Eine ausführliche Untersuchung der Illuminationen von Seuse-Handschriften durch Ingrid Falque, Leiden, vermochte es, Verbindungen und auch Spannungen zwischen der bildhaften Sprache Seuses, die sich entscheidend von der Eckharts unterscheidet, und den Illustrationen aufzudecken. Die Illuminationen übernehmen eine Kommentarfunktion, die deutliche Rückschlüsse auf die Rezeption und die Gebrauchskontexte der Seuse-Texte erlauben. Ben Morgan, Oxford, und Cora Dietl, Gießen, beschäftigten sich in ihren jeweiligen Beiträgen mit Eckharts Bildersprache im Spiegel der zeitgenössischen Rezeption. 
Den Abschluss der Tagung bildete eine Erweiterung des Horizonts von Eckhart und seinem Umkreis auf die Mystik in der Ostkirche. ,Die Sprachkunst Eckharts und Gregorios’ Palamas - ein struktureller Vergleich“ war das Thema von Thomas Daiber, Gießen. Ähnlichkeiten zwischen Eckhart und Palamas (1296-1359) werden unter Hinweis auf eine gemeinsame Quelle, Ps. Dionys, ebenso bemerkt, wie offenkundige Unterschiede in ihrer Stellung und in der Haltung der jeweiligen Kirche zu ihnen. Palamas setzt sich in der orthodoxen Kirche weitgehend durch und wird zum anerkannten Bezug. Gott kann nach Eckhart nicht mit Eigenschaften (adjektivisch) bezeichnet werden, weil er die reine Substanz bezeichnet. Die für die Gottwerdung notwendige ,Eigenschaftslosigkeit‘ des Menschen wird hier begründet. Daiber spricht von einer ,linguistischen Gotteskonzeption“ bei Eckhart, in der Gott nicht ,kategorisierbar' sei. Palamas überbrückt das Problem der Unerkennbarkeit Gottes, indem der Mensch in die Energie Gottes hineingenommen wird und an ihr deshalb partizipiert. Vielleicht ergeben sich aber, so die Diskussion, hier mehr Möglichkeiten des Vergleichs, insofern Eckhart ja auch eine ,Einheit mit Gott im Wirken“ vorschwebt.

International conference of the research group 'Religious Individualization in Historical Perspective' at the Max-Weber-Center, May 6-8, 2013: 'The Agents of Isiac Cults. Identities, Functions and Modes of Representation' (Valentino Gasparini)

While the cultic networks established in the Egyptian, Greek and Roman worlds are familiar, as research-topics, to the historians of ancient religions, those relating to the Isiac deities have only recently aroused, somewhat limited, interest. Despite the works of experts such as Françoise Dunand, Sharon Kelly Heyob, Michel Malaise or Fabio Mora, the identities, functions and ways of representing the participants in those cults, whether priests, initiates, pilgrims or simple devotees, irrespective of their gender or status, are still largely unclear.

Our conference aimed to fill this gap by identifying the distinctive features of the actors of Isiac cults, both individually and as groups, without removing them from their context, one in which they interact with the actors of the other Graeco-Roman cults. For this purpose, a theoretical approach, specific to the history of religions of the ancient world, has been combined with a more empirical perspective, based on literary, epigraphic, archaeological and iconographic material.

The conference (financed by the German Research Foundation [DFG] and the Fonds de la Recherche Scientifique - FNRS de l'Université de Liège) has been organized by a scientific committee including Dr. Valentino Gasparini (Max-Weber-Center - Universität Erfurt) and Dr. Richard Veymiers (F.R.S.-FNRS - Université de Liège), with the cooperation of Prof. Jörg Rüpke (Max-Weber-Kolleg - Universität Erfurt), Prof. Françoise Van Haeperen (Université Catholique de Louvain), Dr. Thomas Morard (Université de Liège) and Prof. Vinciane Pirenne-Delforge (F.R.S.-FNRS - Université de Liège). 39 speakers have been invited from 8 different countries. 
The first part of the double meeting has been held at the University of Erfurt the 6th-8th of May 2013, building on the recent research on 'religious individualization in a historical perspective' at the Max-Weber-Center. The aim of this event was to reincorporate the Isiac cults in the historico-sociological discourse concerning religious pluralism. To what extent are we able to outline a sociology of the actors or Isiac cults? Who are the actors in these cults, where do they come from, what do they do and how do they interact with one another? These issues need to be tackled without preconceptions, taking due account of variations linked to geographic and chronological factors. The conference has begun with a discussion of the status quaestionis and with an introduction to the theoretical issues. The first section has been about the Isiac devotees and their attitude to religious choices. Specific issues to be discussed included: the significance of theophoric names, the degrees of exclusivity, the respect for the priestly or regional traditions and the different degrees of personal investment (pilgrimages, associations of devotees such as melanephoroi or hypostoloi, mysteryinitiation).

The second section dealt with the members of the Isiac priesthood: priests and priestesses, as well as oneirokritai, aretalogists and hierophonoi, neokoroi and zakoroi, stolistai and kleidouchoi, kannephoroi, lampterophoroi and pastophoroi. This led to an examination of their terminology and prosopography, and an attempt to specify their identities (origins, gender and status) and functions in different contexts, in order to decide the extent to which it is appropriate to speak of the 'Isiac priesthood'. The third and final section dealt with spaces and ritual activities. The aim here was to identify the different locations, public or private, in which the Isiac devotees performed their rituals, on a daily or occasional basis, especially during major festivals.

The second part of the conference has been held at the University of Liège the 23th-24th of September 2013. With regard to iconography, although the way of representing the divinities of the Isiac circle has been the subject of a great number of studies, the images of the Isiac community have not received the same degree of attention, with the exception of a few specific studies. The aim of the second episode in Liège was to examine to what extent it is possible to construct a panorama of the iconography of the actors of the Isiac cults. Following the same pattern as in Erfurt, after an introductory session on the status quaestionis and methodology, it has been possible to examine the appearance of the devotees based on particular media, such as funerary stelae, or on certain iconographic types, such as children with the 'Horus lock', before turning to the iconography of office-holders ('priests'). A third and final section dealt with the representations of Isiac ceremonies, such as processions, banquets, sacrifices and dances, showing these actors, namely devotees and priests, in full interaction with one another. Valentino Gasparini as well as oneirokritai, aretalogists and hierophonoi, neokoroi and zakoroi, stolistai and kleidouchoi, kannephoroi, lampterophoroi and pastophoroi. This led to an examination of their terminology and prosopography, and an attempt to specify their identities (origins, gender and status) and functions in different contexts, in order to decide the extent to which it is appropriate 
to speak of the 'Isiac priesthood'. The third and final section dealt with spaces and ritual activities. The aim here was to identify the different locations, public or private, in which the Isiac devotees performed their rituals, on a daily or occasional basis, especially during major festivals.

Tagung vom 24. bis 25. Mai 2013 am Max-Weber-Kolleg: „Pragmatismus und/oder Theorie sozialer Praktiken. Potentiale einer Theoriedifferenz“ (Andreas Pettenkofer)

Soziologische Erklärungen brauchen eine Sozialtheorie, die nicht nur den rationalen Akteur kennt, der - in souveräner Distanz zur jeweiligen Situation - kalkulierend seine Zwecke verfolgt. Einen wichtigen Beitrag, gerade was kultursoziologische Fraugen angeht, leistet hier die Diskussion über ,soziale Praktiken'. Sie rückt das Moment des nichtreflektierten Handelns in den Vordergrund; die Körperlichkeit des Handelns; sowie die Rolle der Dingwelt in Prozessen sozialer Ordnungsbildung. Damit zielt sie darauf, die handelnden ,Subjekte' ihrerseits als soziale Produkte zu begreifen. Mit dem Erfolg dieser Perspektive zeigen sich aber ihre Probleme: Wird die Entstehung personaler Identitäten und entsprechender Handlungsmuster hier nicht zu rasch auf Machtverhältnisse zurückgeführt? Führt die Idee, dass soziale Ordnung auf nichtreflektierten Routinen aufbaut, die durch die Körperlichkeit des Handelns und die Materialität der Situation gestützt werden, nicht zu übertriebenen Stabilitätsannahmen? Muss dieses Verständnis der Körperlichkeit des Handelns, wie auch das Verständnis der Rolle materieller Artefakte, nicht zumindest ergänzt werden? Hier scheint es lohnend, die pragmatistische Tradition aufzunehmen, die von einer ähnlichen Problemstellung ausgeht, aber andere Lösungen vorschlägt: ein Konzept nichtreflektierten Handelns, das auf das Wechselspiel von Routine und Reflexion achtet; ein anderes Verständnis der Körperlichkeit des Handelns und der basalen Sozialität des Subjekts; jeweils mit Konsequenzen für die Analyse sozialer Ordnungsbildung. $\mathrm{Zu}$ fragen wäre dann: Welche Potentiale und welche Grenzen der pragmatistischen Perspektive zeigen sich, wenn man sie mit der Debatte über ,soziale Praktiken` konfrontiert? Bieten diese Perspektiven Konzepte an, die einander ergänzen und sich verbinden lassen? Gibt es bereits Ansätze einer geglückten Verbindung? Wo handelt es sich um unvereinbare Theorieoptionen, deren Kenntnis aber zur Schärfung der Konzepte und zur Klärung der möglichen Theoriestrategien beiträgt?

Zur Diskussion solcher Fragen fand im Mai am Max-Weber-Kolleg eine Tagung statt, organisiert von Hella Dietz (Göttingen), Frithjof Nungesser (Graz) und Andreas Pettenkofer (MWK), mit Unterstützung der Sektion Kultursoziologie in der Deutschen Gesellschaft für Soziologie. Nach einem kurzen Einführungsvortrag (Hella Dietz, Frithjof Nungesser) argumentierte Andreas Pettenkofer (Erfurt) dafür, das Konzept ,Praktiken` - unter Nutzung von Elementen der durkheimianischen wie der pragmatistischen Tradition - nicht im Sinne eine Theorie über bestimmte (präreflexive etc.) 
Handlungsmuster zu verstehen, sondern im Sinne einer Theorie über einen bestimmten Situationstyp, nämlich über Beweissituationen. Gegen derartige Integrationsvorschläge betonte Jörg Potthast (Berlin), am Fall der techniksoziologischen Diskussion, den seines Erachtens voreiligen Charakter der im Kontext des ,Praktiken'-Konzepts stattfindenden Pragmatismusrezeption, die - scheinbar paradoxerweise - gerade dazu führe, dass das Bild eines unproblematischen, reflexions- und konfliktfreien Normalbetriebs des Sozialen aufrechterhalten werde. Jörg Strübing (Tübingen) und Frithjof Nungesser (Graz) unternahmen beide einen Vergleich der wesentlich an Bourdieu orientierten Varianten einer ,Theorie sozialer Praktiken' mit pragmatistischen Ansätzen, die an Mead anknüpften. Dabei betonte Strübing - unter dem Titel „Practice Theory: Where Is the Mead/t?“ - vor allem die Defizite dieses PraktikenKonzepts, indem er vorführte, dass die pragmatistische Tradition jene Phänomene von Routinehandeln, die das ,Praktikten'-Konzept ins Zentrum rückt, differenzierter beschreibt. Dagegen hob Nungesser, mit Verweis auf die ,Janusköpfigkeit der Sozialität“, eher die Komplementarität der beiden Herangehensweisen vor und unterstrich, dass gerade für die Erklärung von Konfliktphänomenen die vorliegenden pragmatistisch inspirierten Konzepte nicht ausreichten. Die letzten beiden Vorträge des ersten Tages zielten darauf, den Nutzen der diskutierten Konzepte anhand empirischer Fallstudien zu prüfen: Tanja Bogusz (Berlin) berichtete über ihre ethnographische Begleitung eines Biodiversitäts-Projekts in Papua Neuguinea; sie versuchte - mit Blick auf Durkheim und Dewey - herauszuarbeiten, wie die Konzepte, die diese unterschiedlichen Theorietraditionen anbieten, an je unterschiedlichen Punkten des Forschungsprozesses nützlich werden. Hella Dietz (Göttingen) berichtete über ein laufendes Projekt zur südamerikanischen Wahrheitskommission; ihr ging es darum zu zeigen, wie Überlegungen von Dewey und Boltanski helfen, über eine enge machttheoretische Beschreibung solcher Phänomene hinauszukommen - wobei die Diskussion dann unter anderem die Frage betraf, ob sich Deweys Perspektive auch eignet, solche Machtphänomene zu erfassen.

Der zweite Tag begann mit einem Vortrag von Henning Laux (Bremen), der dafür plädierte, dass auch die Soziologie sich stärker mit der Philosophie Richard Rortys auseinandersetzen sollte, die - mit ihrer Aufwertung der Kontingenz und ihrem Konzept eines ironischen Engagements - sogar einen gesellschaftstheoretischen Nutzen biete; eine solchermaßen informierte Theorieperspektive sei speziell für heutige, nicht mehr durch hohe Stabilität gekennzeichnete Gesellschaften angemessen. Hannes Krämer (Frankfurt/Oder) kontrastierte anhand des Problemfelds ,Kreativität‘ die pragmatistische mit der ethnomethodologischen Herangehensweise; ausgehend von einem kürzlich abgeschlossenen Projekt zur Marketingbranche zeigte er, wie die Ethnomethodologie an die Stelle der Frage, welche Handlungsprozesse tatsächlich kreativen Charakter haben, die Frage setzt, wie die Beteiligten bestimmte Handlungsweisen als kreativ markieren (,doing creativity'). Hilmar Schäfer (Frankfurt/Oder) widmete sich den theoretischen wie methodischen Konvergenzen von pragmatistischer Soziologie und ,ActorNetwork Theory` (Callon, Latour); er illustrierte das mit 
Überlegungen aus einem gerade begonnenen Projekt, das sich dem Problem des ,kulturellen Erbes' im Bereich der Architektur widmet. - Die letzten beiden Vorträge der Tagung konzentrierten sich auf die Frage, welche methodologischen Konsequenzen aus diesen sozialtheoretischen Überlegungen zu ziehen wären. Alexander Antony (Erlangen) berichtete über sein Dissertationsprojekt, das sich am Fall der Atemtherapie mit der Frage beschäftigt, wie Phänomene eines körpernahen ,impliziten Wissens ‘ in soziologischen Forschungen erfasst werden können; seine These lautete, dass man Deweys Analysen dieser Wissensform und der mit ihr verbundenen Handlungsweisen am besten mit einer ,autoethnographischen` Methode gerecht wird. Robert Schmidt (Erlangen) betonte zunächst nochmals - ausgehend von den Themen ,Körperlichkeit des Handelns', ,Materialität‘ und ,implizites Wissen' - die Komplementarität der auf der Tagung verhandelten Theorieströmungen und plädierte dann dafür, dass nur ein ethnographisches - oder jedenfalls: einem ethnographischen Erkenntnisstil folgendes - Vorgehen geeignet sei, diese theoretischen Einsichten umzusetzen. Da alle Beteiligten die Diskussionen sehr interessant fanden, endete die Tagung mit der Entscheidung, sich nächstes Jahr wieder zu treffen. Eine Buchveröffentlichung ist in Planung.

Tagung im Rahmen der Kolleg-Forschergruppe ,Religiöse Individualisierung in historischer Perspektive“ vom 20. bis 21. Juni 2013 am Max-Weber-Kolleg: ,Transplantation - Transmortalität - Transparenz' (Andrea M. Esser)

Das philosophische Verständnis des Todes und dessen praktische Bedeutungen sowie damit einhergehende ethische Konsequenzen sind zentrale Gegenstände der Forschung von Prof. Dr. Andrea M. Esser, mit denen sie sich als Fellow am Max-WeberKolleg und als Leiterin des philosophischen Teilprojekts des durch die VolkswagenStiftung geförderten interdisziplinären Forschungsprojekts ,Tod und toter Körper befasst. Dabei bezieht sich ihre Forschung nicht nur auf eine begrifflich-theoretische Reflexion über den Tod und den Hirntod, sondern auch auf deren praktische Implikationen und Konsequenzen für die Organspendepraxis, deren rechtliche Normierung und gesellschaftliche Verwirklichung praktische Probleme einer philosophischethischen Beurteilung darstellen.

Anlass für die Konzeption der Tagung war die im Sommer 2012 verabschiedete Neuregelung des Transplantationsgesetzes in Deutschland. Dieses Gesetz sieht vor, alle Bürgerinnen und Bürger umfassend über Ablauf und Organisation der Organspende zu informieren, und sie in regelmäßigen Abständen dazu aufzufordern, ihre Entscheidung für oder gegen eine Organspende zu dokumentieren. Welche Institutionen das Informationsmaterial für diese Aufklärungskampagnen erarbeiten und nach welchen Maßgaben sie die dafür vorgesehenen Materialien jeweils gestalten, war bislang kaum Gegenstand kritischer öffentlicher Diskussionen. Um eine solche 
Diskussion kritisch führen zu können, bedarf es zunächst der Erarbeitung empirischer Erkenntnisse darüber, welches Wissen über die Organspende gesellschaftlich vorherrscht, wie die rechtlich gebotene Aufklärung institutionell umgesetzt wird, welcher medialen Ästhetisierungsformen sich dabei bedient wird und wie die normativ wirksamen Inhalte darin zum Ausdruck kommen. An der Erarbeitung dieser Erkenntnisse besteht nach Auffassung der Mitglieder des Forschungsprojekts ,Tod und toter Körper' nicht nur ein wissenschaftliches, sondern auch ein öffentliches Interesse. Aus diesem Grund hat das philosophische Teilprojekt unter der Leitung von Andrea Esser am 20. und 21. Juni 2013 Expertinnen und Experten der Debatte in das Max-Weber-Kolleg eingeladen, um im Rahmen der Tagung die Frage zu diskutieren, was die in der öffentlichen Diskussion aufgestellten Schlagworte ,Transparenz , ,Information' und ,Aufklärung‘ im Kontext der Organspende überhaupt bedeuten können und welche Praxis als ,Aufklärung über die Organspende“ verstanden werden kann (und soll).

Den Auftakt der Tagung bildeten zwei öffentliche Abendvorträge. Der Philosoph Prof. Dr. Matthias Vogel (Gießen) leistete in seinem Vortrag eine erste Klärung eines der Grundbegriffe der Debatte. Aufklärung stellt, so Vogel, einen offenen und sozialen Lern- und Erfahrungsprozess dar, der darauf angelegt ist, praktische Bedingungen unserer Möglichkeiten des Verstehens zu entwickeln. Insofern sich unser Verstehen aber nicht nur im Medium der Sprache, sondern auch durch andere Medien vollziehe, seien Verstehensprozesse auch durch visuelle und andere ästhetische Darstellungsformen strukturiert. Diese medial vermittelten Inhalte, wie sie z.B. in Werbekampagnen zur Organspende zu beobachten seien, prägten wesentlich die Entwürfe unserer Selbst-Bilder, an denen wir uns normativ in Entscheidungen orientieren. Wie solche Entscheidungen als selbstbestimmte oder autonome gelten könnten, entwickelte Vogel durch die Explikation der normativen Bedingungen eines Aufklärungsprozesses. Der Anwalt und Journalist Dr. Oliver Tolmein (Hamburg) nahm das Stichwort der ,Selbstbestimmung' auf und führte in seinem Vortrag die These aus, dass Vorab-Erklärungen zur Organspende im Grunde den juristischen Status von Patientenverfügungen hätten. Damit sei aber eine zentrale Schwachstelle des Transplantationsgesetzes in der Novellierung nicht behoben, sondern in Teilen sogar verschärft worden. Solange sich diese Erklärung nämlich in einer bloßen Zustimmung zur Organspende erschöpfe, sei sie ungeeignet, medizinische Maßnahmen im Vorfeld der Organentnahme, in denen die Patientinnen und Patienten zwar bereits einwilligungsunfähig seien, aber nicht als tot gelten würden, hinreichend bestimmt zu normieren und regulieren. Darüber hinaus wies Tolmein darauf hin, dass allein schon die ,Bitte des Staates‘ an seine Bürgerinnen und Bürger, sich zu entscheiden, das Neutralitätsgebot des Staates unterlaufe, da dieses Ansinnen eine materiale Wertentscheidung für die Organspende impliziere.

Den als intensives Arbeitsgespräch konzipierten Workshop am darauf folgenden Tag eröffnete der Medienwissenschaftler Prof. Dr. Rainer Leschke (Siegen) mit einer medientheoretischen Reflexion auf wirkmächtige kulturelle Bilder, die u.a. eine stark 
negative Codierung leiblicher Fragmentierung aufweisen, so dass realistische visuelle Darstellung von Organspenden seiner Meinung nach zu einem Problem für die Bereitschaft zur Spende führen müssten.

Dass wir uns in unserem Urteilen und Handeln auch zu solchen realistischen Darstellungsformen und Bildern und deren negativer Codierung kritisch reflektierend ins Verhältnis setzen können und im Sinne einer angemessenen Aufklärungspraxis auch müssen, stellte Andrea Esser in ihrem Beitrag heraus. Auf der Basis eines pragmatistischen Verständnisses von Bedeutungsklärung diagnostizierte und kritisierte sie in den aktuellen Werbekampagnen das Vorherrschen von ,Individualismus', ,Moralischem Dogmatismus‘ und einem ,Magisch-mythischen Denken‘. Damit aber leisteten die Kampagnen einem ,abstrakten Denken' Vorschub, welches eine selbstbestimmte und kritische Entscheidung über die Zustimmung oder Ablehnung der Organspende schwerlich ermögliche.

In eine ähnliche Richtung argumentierte auch die Philosophin PD Dr. Theda Rehbock (Dresden/Marburg), die in ihrem Beitrag vernünftige Selbstbestimmung an Bedingungen einer kritischen Aufklärung band. Das bedeute konkret, die Bürgerinnen und Bürger über die besondere Situation des Hirntodes und die praktischen Implikationen der Organentnahme (aggressive Hirntoddiagnostik, lebendige Anmutung Hirntoter, erschwerte Abschiednahme usw.) umfassend und ohne moralisierenden Druck zu informieren, damit diese sich vor diesem Hintergrund ein Urteil bilden könnten, in dem nicht schon von vornherein entschieden ist, ob Organspende per se gut oder schlecht ist.

Die Leiterin des rechtswissenschaftlichen Teilprojekts Prof. Dr. Brigitte Tag (Zürich) informierte in ihrem Beitrag über die rechtlichen Rahmenbedingungen der Aufklärung über die Organspende in Deutschland und stellte klar, dass dem Staat zwar qua Gesetz ein Aufklärungsauftrag obliege, dies aber nicht bedeute, dass nicht auch andere Institutionen als die Krankenkassen und die Deutsche Stiftung Organspende (DSO) Kampagnen starten dürften.

Mit welchen medialen Mitteln und Informationsmaterialien z.B. die Techniker Krankenkasse oder die Werbekampagnen der BZgA arbeiten, wie sie dabei gezielt eine Pro-Einstellung zum Hirntodkonzept sowie zur Organspendepraxis herstellen und welche strukturellen und individuellen Interessen den Hintergrund dieser Kampagnen darstellen, war Untersuchungsgegenstand der Beiträge des Journalisten und Soziologen Dr. Ludger Fittkau (Darmstadt) sowie der medienanalytischen Untersuchung der dem Teilprojekt Soziologie angehörenden Forscherinnen Dr. Antje Kahl und Dr. Tina Weber (beide Berlin).

Zum Abschluss des Workshops nahm die Philosophin Prof. Dr. Barbara Merker (Frankfurt a. M.) noch einmal die Frage nach dem Hirntod auf und diagnostizierte ein folgenreiches ,Missverständnis‘, dem die Hirntoddebatte ihrem Urteil zufolge bis heute aufsäße. So sei die Grundfrage der Debatte, ob ein hirntoter Mensch wirklich tot sei, falsch gestellt, da sie unterstelle, dass es eine reale Grenze zwischen Leben und 
Tod in der Natur gäbe. Diese Auffassung beruhe aber, wie sie argumentativ herausstellte, auf einem begrifflichen Klassifikationsproblem. Da, so Merker, die Grenze nicht in der Natur gegeben ist, sondern die Natur und deren individuelle oder allgemeine Normen in einer zunächst kontingenten, dann aber sozial vorgeschriebenen oder noch zu bestimmenden normativen Relation stünden, gingen diese grundsätzlichen Überlegungen der erneuten Frage nach Definition, Kriterium und Feststellung des Hirntodes und den normativen Regulierungen unserer Praxis voraus.

Dass die gegenwärtig vorherrschenden medial vermittelten Bilder und Formen der Aufklärung über Organspende zumeist unzureichend sind, um einen Begriff von Aufklärung zu realisieren, der den entwickelten normativen Geltungsbedingungen genügt, kann als ein Resultat der Tagung gelten. Welche Bedingungen und Kriterien für ein kritisches Verständnis des Hirntods und einer angemessenen Aufklärung der Organspende gelten sollen, konnte in Grundzügen auf dieser Tagung entwickelt werden. Die weitere Entwicklung dieser Geltungsbedingungen und konkrete Empfehlungen zur Ausgestaltung öffentlicher, politischer und rechtlicher Praxen bleiben aber weiterhin gewichtige Aufgaben der wissenschaftlichen und öffentlichen Diskurse. Um hieran weiter zu wirken sei darauf verwiesen, dass Radiomitschnitte dieser Tagung Anfang 2014 in der Sendung ,Hörsaal‘ von DRadio Wissen zu hören sein sollen. Darüber hinaus ist für Mitte 2014 eine Publikation des Forschungsprojekts, Tod und toter Körper' mit dem Titel ,Die Krise der Organspende - Anspruch, Analyse und Kritik aktueller Aufklärungsbemühungen im Kontext der postmortalen Organspende، geplant. Hier sollen die Erträge der Tagung durch weitere empirische Analysen untermauert und mit ethischen Reflexionen verbunden werden.

\section{Meister Eckhart-Tage vom 4. bis 6. Juli 2013 in Erfurt (Dietmar Mieth)}

Die Zusammenarbeit an der Kolleg-Forschergruppe am Max-Weber-Kolleg (MWK) der Universität Erfurt ermöglicht Synergie-Effekte zwischen den Programmen und Projekten der Meister Eckhart Gesellschaft (MEG), des MWK sowie den Katholischen Akademien in Bayern und in Mainz.

In Erfurt fand sich 2012 zusätzlich ein Initiativkreis Meister Eckhart (www.meistereckhart-erfurt.de) zusammen, der damit begann, für 2013 Eckhart-Tage in Erfurt zu planen. Vertreten waren die Predigergemeinde, die MEG, die Universität Erfurt durch das MWK, die Evangelische Stadtakademie Meister Eckhart, das Katholische Forum, und eine Reihe von engagierten Einzelpersonen.

Begleitend zur Initiative für 2013 wurden Broschüren für eine Eckhart-Initiative im Bildungs-Tourismus bzw. spirituellen Tourismus erstellt. Die Broschüre Meister Eckharts Faszination heute liegt inzwischen nicht nur in Erfurt (Predigerkirche, Tourismusbüro) aus, sondern sie ist inzwischen auch auf Englisch erhältlich. Sie wird auch im englischsprachigen Raum verteilt. Eine zweite Broschüre, ebenfalls in beiden Sprachen, beschreibt Einen Weg der Erfahrung mit Meister Eckhart durch Erfurt 
(für die Broschüren: Autor: Mieth, Übersetzung: Vinzent, Fotograf: Schmidt). Das Datum der Eckhart-Tage 2013 erinnert auch an Eckharts Weg nach seiner zweiten Pariser Professur 2013 an den Rhein. Dem Thema ,1313-2013: Der Thüringer Meister Eckhart als Begründer der Rheinischen Mystik?' widmete sich ein zweitägiger wissenschaftlicher Workshop, veranstaltet vom MWK im Predigerkloster (s. dazu der eigene Bericht).

In Straßburg fand dann ebenfalls unter Leitung von Frau Prof. Vannier ein ähnlicher Workshop am 19. September 2013 statt. Auch dieser wurde von einer öffentlichen Veranstaltung mit Musik und Lektüre von Eckhart-Texten in der Krypta des Straßburger Münsters begleitet. Für die Erfurter Eckhart-Tage wurde die renommierte Schauspielerin Martina Gedeck zu einer Eckhart-Lesung in der Predigerkirche mit Hilfe der Herbstlese e.V. und zugleich als Schirmherrin des Programms eingeladen. Diese Lesung am Donnerstagabend, den 4. Juli 2013, in der Predigerkirche war ausverkauft und sehr eindrucksvoll. Frau Gedeck verstand es, in einer von innen getragenen Intensität die Gedanken Meister Eckharts, trotz ihres hohen philosophischen Anspruches, mit viel Einsicht und Einfühlung in einer direkt das Herz ansprechenden Unmittelbarkeit vorzutragen.

Zu den Eckhart-Tagen gehörte ein Einkehrtag am Samstag, den 6. Juli 2013, im Predigerkloster, den Frau Morawietz, Erfurter Theologin, vorbereitet und durchgeführt hat, mit der innerlichen und schweigenden Verarbeitung von Texten im Chorgestühl der Kirche (ca. 50 Teilnehmer/innen). Den Abschluss bildete ein festlicher, ökumenischer Gottesdienst, umrahmt von Liedern Mechthilds von Magdeburg, in der Predigerkirche am Samstag, den 6. Juli, mit Pfarrer Dr. Holger Kaffka, der evangelischen Landesbischöfin Ilse Junkermann, Weihbischof/Diözesanadministrator Dr. Reinhard Hauke und Kardinal Professor Dr. Walter Kasper aus Rom, der zu Eckharts Predigt zur Geschichte der Tempelreinigung Jesu im Neuen Testament (bei Eckhart die Predigt Nr. 1) predigte. Auch diese Veranstaltung fand eine vollbesetzte Kirche.

Die Meister Eckhart-Tage in Erfurt werden eine Fortsetzung finden, voraussichtlich 2016. Dazwischen sind weitere Veranstaltungen und Initiativen zu Meister Eckhart in Erfurt zu erwarten. Ein Büro für Eckhart-Initiativen wurde in der Predigerstr. 9 eröffnet. Den Abschluss für das Jahr 2013 wird die Einweihung eines Bodendenkmales vor dem Portal der Predigerkirche dienen mit in den Boden eingelassenen Zitaten Meister Eckharts. 
Tagung in Zusammenarbeit mit der Meister Eckhart-Gesellschaft und der Èquipe de Recherches sur les Mystics Rhénans (Université de Metz) vom 4. bis 5. Juli 2013 im Predigerkloster Erfurt: ,1313-2013: Der Thüringer Meister Eckhart als Begründer der Rheinischen Mystik?‘ (Dietmar Mieth)

Vom 4. bis 5. Juli fand im Rahmen der Eckhart Tage 2013, organisiert von Professor Dr. Dietmar Mieth, Präsident der Meister Eckhart-Gesellschaft, in Zusammenarbeit mit der Équipe de Recherches sur les Mystics Rhénans (Université de Metz) und der Kolleg-Forschergruppe ,Religiöse Individualisierung in historischer Perspektive' eine Tagung zum Thema ,1313-2013: Der Thüringer Meister Eckhart als Begründer der Rheinischen Mystik?‘ statt. Nach einer kurzen Begrüßung durch Prof. Wolfgang Spickermann, Leiter des Max-Weber-Kollegs, an dem die Kolleg-Forschergruppe angesiedelt ist, hielt Prof. Volker Leppin aus Tübingen den ersten Vortrag: ,Eckhart und Luther‘. In Bezug auf das Verhältnis von Eckhart zum Protestantismus galt er einerseits als Vorbereiter der Reformation, andererseits aber auch als (schlechter) Scholastiker der ,alten' Kirche.

Prof. Marie-Anne Vannier von der Universität Metz stellte Eckhart als Begründer der Rheinischen Mystik vor. ,Rheinische Mystik' wurde nach dem 2. Weltkrieg eine Begriffsprägung gegen die Vereinnahmung der ,Deutschen Mystik‘ durch den Nationalsozialismus. ,Mystik' betont hier gegen philosophische Reduktionen die religiöse Erfahrung. Die Mystik der drei Dominikaner, Eckhart, Tauler, Seuse, bildet den Kern der ,Rheinischen Mystik‘ als ,spekulative‘ Mystik.

Die beiden darauf folgenden Vorträge befassten sich mit der Rezeptionsgeschichte von Eckharts Gedanken. Dr. Maxime Mauriège, Universität Köln, Thomas Institut, untersuchte die ,compilatio mystica‘ als Fortsetzung der Anliegen Meister Eckharts. Die aus dem 15. Jahrhundert stammenden, aber erst im 17. Jahrhundert zusammengestellten Texte (Hamburger Codex 1614), auch ,Mosaiktraktate‘ wegen ihrer Disparatheit genannt, enthalten überwiegend Gedanken Eckharts oder der ,Eckhartisten“. Das ist am Inhalt und an der Sprache nachweisbar. Die Intention der Kompilation ist nicht klar, aber sie beweist, dass es eine kontinuierliche, wenn auch nicht genaue, Überlieferung der Gedanken Eckharts gegeben hat und dass diese weiter rezipiert wurden. PD Dr. Andrés Quero-Sánchez, Universität Regensburg und Max-Weber-Kolleg, untersuchte die Wirkung Eckharts im deutschen Idealismus in seinem Vortrag: ,Die neuzeitliche Wiederaufnahme der ,mystischen' Vernunft: Fichte, Schelling, Hegel'. Eckharts ,Warumlosigkeit', seine Betonung der ,Grundlosigkeit' und der 'Unmittelbarkeit', in welchen Ziel- und Wirkursachen ausgeschlossen werden, können in einer Dialektik von Modernität betrachtet werden: die ,konkrete‘ Moderne, die vom empirischen Einzelding ausgeht und Überhöhungen entlarvt (,aufklärt‘) und die idealistische Moderne, die sich gerade dagegen richtet, und die durch Eckhart bzw. seine Reprise im Idealismus vorbereitet ist.

Der Bibelwissenschaftler Prof. Christoph Bultmann, Universität Erfurt, stellte die Frage: ,Wie legt Eckhart die Bibel aus? Bezüge zur alttestamentlichen Weisheit‘. Mit 
den historischen Entstehungskontexten der Predigten Eckharts befasste sich Prof. Freimut Löser, Universität Augsburg, in seinem Vortrag: ,Thüringer Predigten Meister Eckharts - Vorschlag für eine Edition'. Wie ist der Bezug von Predigten zu Thüringen bzw. Erfurt zu klären? Zwei thüringische Predigten (in mitteldeutscher Sprache) finden sich in London: Pr. 32 (Elisabeth) und Pr. 95. Bei der Elisabeth-Predigt lässt sich der Thüringer Bezug besonders gut zeigen. Prof. Katharina Bracht, Universität Jena, untersuchte ein Gedicht, das Eckhart zugeschrieben wird: Das ,Granum Sinapis‘ und die Väter-Theologie. Das Gedicht ist in Thüringen entstanden. Von Ruh wird es Meister Eckhart zugeschrieben. Dr. Chris Wojtulewicz, King's College London, sprach zu: ,Leading the debates? Eckhart in the Context of Early Fourtheenth Century Paris‘. Dabei ging es darum zu zeigen, welche Prägungen, die aus Eckharts lateinisch verfassten Pariser Quaestionen (1311-1313) stammen, sich in die deutschen Predigten hinein verfolgen lassen. Das britische Forschungsprojekt, dass Eckharts Pariser Quaestiones und Disputationes neu erschließen will, verfolgt Spuren in die Predigten des ,späten` Eckharts am Rhein.

Dr. Saeed Zarrabi Zadeh, Universität Erfurt, ging in seinem Vortrag ,Practical Mysticism - Eckhart and Sufism' den Beziehungen zwischen Rheinischer Mystik und Sufismus nach. Zwischen Eckhart und dem islamischen Sufismus hat man gern unter dem leitenden Gesichtspunkt von Parallelen bzw. Ähnlichkeiten geforscht. Für Parallelen verwies man in der Struktur des spekulativen ,Systems' auf Ibn Arrabi (geb. 1240). Der Vergleich Eckhart-Rumi, den der Referent vorgenommen hat, beruht auf einer anderen Hermeneutik: Gerade die Unterschiedlichkeit zwischen einer poetischen und affektiven Mystik (Rumi) und einer intellektiven Mystik (Eckhart) erlaubt es, die praktischen Methoden des Nachvollzuges sich wechselseitig spiegeln zu lassen.

,Unmittelbarkeit und Vermittlungsstrukturen göttlicher Gegenwart in der mystischen Theologie Eckharts von Hochheim und Nikolaus' von Kues' war das Thema von Dr. Christian Ströbele, Universität Tübingen. Eckhart bekam Probleme, die in den theologischen Gutachten der Avignonenser Gutachten sichtbar sind, weil ihm eine vorbehaltlose Identifizierung von Mensch und Gott vorgehalten wurde. Bei der Relecture, die Cusanus den Texten angedeihen ließ, hat er die Intentionen Eckharts als Zielvorstellungen ,sub specie aeternitatis“ bewahrt, zugleich aber die bleibende irdische ,Alterität‘ zwischen göttlichem und menschlichen Erkennen, Sein und Leben hervorgehoben. Im Unterschied zu Eckhart baut er explizite Sicherungen gegen Missverständnisse ein, die von den Avignonenser Gutachern repräsentiert werden, welche Eckharts eigene Absicherungen - etwa die Lehre von der bleibenden Kontingenz oder seine deutliche Berufung auf die Worte der Schrift - vermutlich als Alibi verstanden haben. Auch für Prof. Dietmar Mieth, Universität Tübingen und Max-Weber-Kolleg, war das Thema Unmittelbarkeit bei Meister Eckart zentral für seinen Vortrag: ,Die individuelle Unmittelbarkeit der Mystik als Herausforderung der Religionen'. Die historischen Konflikte der individuellen Mystik, die man an den Beispielen Meister Eck- 
hart und deutlicher noch am Prozess gegen Marguerite Porete aufzeigen kann, verweisen auf wiederholbare Konstellationen. Im katholischen Bereich ist es eher die Ekklesiologie, in welcher die Kirche als Ursakrament die Heilsmittel allein bereit hält, im Protestantismus ist später eher der Konflikt zwischen Erfahrung und gläubiger Orthodoxie, die sich alles von ,extra nos' her sagen lässt. Während im Pietismus z.B. bis heute die Erfahrung höher eingeschätzt wird als das Sakrament, ist das in der Orthodoxie umgekehrt. Diese Konflikte sind im Islam als Spannung zwischen Sufismus und rechtstheologischer Regulierung von Praktiken ebenso zu beobachten wie im Judentum, wo man die Spannung an der zunächst sehr ambivalenten Behandlung des Moses Maimonides bis ins 14. Jahrhundert hinein ablesen kann. Das Problem verschärfte sich, als sich Mystik Anfang des 20. Jahrhunderts vom Monotheismus als Religion löste (vgl. die ,gottlose Mystik', die einflussreich von Fritz Mauthner thematisiert wurde) und neureligiöse Reprisen der Mystik diese noch eher gegen Institution und Dogma kehrten. Dies kommt auch in der Forderung des Eckhart-Preisträgers Ernst Tugendhat (2007) zum Ausdruck, Mystik aus humanistischen Gründen an die Stelle von Religion zu setzen.

Tagung vom 15. bis 17. Juli 2013 am Max-Weber-Kolleg: ,Forms of Religious Individualisation. Concepts and Processes‘ (Asaph Ben-Tov)

Seit 2009 hat die Kolleg-Forschergruppe ,Religiöse Individualisierung in historischer Perspektive، in kritischer Auseinandersetzung mit dem Bild von Individualisierung, das Modernisierungstheorien entwickelt haben, in unterschiedlichen historischen Kontexten religiöse Individualisierungsprozesse untersucht. Anlässlich des Abschlusses der ersten DFG-Förderphase veranstaltete die Kolleg-Forschergruppe eine Tagung zu ihrem Kernthema. Vor allem diente diese Tagung als Gelegenheit, über die bisherige Forschung jetziger und ehemaliger Kollegiaten zu reflektieren: durch eine Betrachtung der thematischen Vielfalt der Forschungsarbeiten in der Forschergruppe in den ersten vier Jahren und gleichzeitig durch eine vorsichtige Überlegung zu überspannenden Typologien.

Während der dreitägigen Tagung (15.-17. Juli 2013) wurden zahlreiche abgeschlossene wie laufende Arbeiten vorgestellt und diskutiert. Die Beiträge, die sich über eine große Bandbreite dehnten, befassten sich u.a. mit der methodologischen Herausforderung archäologischer Spuren religiöser Individualisierung in der griechischrömischen Antike, religiöser Kompetenz und individualisierten Praktiken in der Antike, der Mystik und religiöser Individualisierung und Heterodoxie im christlichen Mittelalter, Individualisierung und Gewissen in der Frühen Neuzeit sowie mit weiteren Fallstudien, die die Diskussion bis zum frühen 20. Jahrhundert führten. Die nicht-europäischen Schwerpunkte mehrerer Fellows und Kollegiaten fanden sich in Beiträgen zur religiösen Individualisierung im Hinduismus, im Jainismus und in der konfuzianischen Lehre. Die breit gefächerte Tagung diente zugleich als Zwischenfazit 
im Übergang von der ersten zur zweiten Förderphase sowie auch als ein reflektierter Impuls für die weitere Entwicklung der Forschergruppe.

Tagung in Kooperation mit der University of Chicago vom 3. bis 5. Juli 2013 am Max-Weber-Kolleg: ,Public and Private in Ancient Mediterranean Law and Religion“ (lörg Rüpke)

Diese Tagung im Rahmen der Kolleg-Forschergruppe ,Religiöse Individualisierung in historischer Perspektive، fand in Kooperation mit dem Classics Department der University of Chicago statt. Ausgangspunkt war die Rolle, die der Begriff ,privat‘ im modernen Denken über das Individuum spielt, im Vergleich mit der antiken Konzeptualisierung von ,privatus' und ,publicus'. Während Religion etwa im liberalen angloamerikanischen Diskurs vielfach als Privatangelegenheit begriffen wird, spricht Cicero in seinem Dialog Über die Gesetze allen Individuen gerade private und öffentliche religiöse Rollen zu (2,19). Um eine Engführung zu vermeiden, aber zugleich intensive kulturelle und soziale Konstellationen untersuchen zu können, konzentrierte sich die Tagung auf die Antike, war hier aber mit der Einbeziehung von rabbinischem Judentum und frühem Islam zeitlich breit und komparativ angelegt.

Fokus war in allen untersuchten Fallbeispielen die Frage nach der Leistung der Unterscheidung von ,öffentlich` und ,privat‘ und den Veränderungen, wie Clifford Ando und Jörg Rüpke in ihrer Einleitung erläuterten. Eine erste Gruppe von Diskussionen auf der Basis der vorab gelesenen Beiträge befasste sich mit rechtlichen Konstruktionen. Edward Harris (Manchester) fragte nach der Rollenabgrenzung von Familie und Staat im attischen Recht bei Mord, Judith Evans-Grubbs (Emory University) untersuchte den Übergang von Privatem in Öffentliches im Falle von illegitimer Nachkommenschaft und Inzest. Natalie Dohrmann aus Philadelphia thematisierte die Durchdringung von privater und öffentlicher Sphäre in rabbinischer Rechtskultur. Ahmed El-Shamsy (Chicago) lenkte den Blick auf dasselbe Problem im frühen islamischen Recht.

Eine zweite Gruppe von Fällen fragte nach der öffentlichen Thematisierung und Normierung von Religion im Medium des Rechts. Rubina Raja (Aarhus) stellte die Nutzung öffentlichen Raumes für private religiöse Ereignisse (und die daraus resultierende Problematisierung der Unterscheidung) für das syrische Palmyra vor, William van Andringa (Lille) legte den Fall privater Tempelstiftungen in römischen Kolonien vor. Dieses Beispiel konnte dann mit dem hauptstädtischen Rechtsdiskurs im Kampf Ciceros um sein den Göttern von Dritten geweihtes Eigentum (Elisabeth Begemann, Erfurt) abgeglichen warden. Salvatore Randazzo aus Catania führte den komplexen Fall religiöser Vereine und der diesbezüglichen Rechtsbildung vor.

Religiöse Vorstellungen und Diskurse bildeten den Gegenstand der dritten Gruppe, in der Claudia Bergmann (Erfurt) eschatologische Zuspitzungen von öffent- 
lich oder privat in Bankett-Vorstellungen, Catherine Hezser (SOAS, London) Überlegungen zu Funktionen einer neutralen Zone zwischen öffentlich und privat im rabbinischen Denken und Esther Eidinow (Manchester) Fragen nach der Zugänglichkeit des privaten Denkens bei Menschen und Göttern zur Diskussion stellte.

Die Notwendigkeit, die je unterschiedlichen begrifflichen und sozialen Strategien zu unterscheiden, fügte sich gut mit dem vergleichenden Befund ähnlicher Lösungen und Probleme zusammen: Ort und Stellenwert individueller Intention und Reflexionen sowie die Komplexitätssteigerung in städtischen Gesellschaften bildeten dabei die Pole der Diskussion und die wichtigsten Erträge der Tagung.

Workshop der Kolleg-Forschergruppe, Religiöse Individualisierung in historischer Perspektive' am Max-Weber-Kolleg und des Großprojektes ,Meister Eckhart und die Pariser Universität‘ am King's College London vom 14. bis 15. November 2013 in Erfurt, gefördert vom britischen AHRC, in Verbindung mit der Meister EckhartGesellschaft: ,Thomas von Erfurt und Meister Eckhart‘ (Markus Vinzent)

Thomas von Erfurt wurde bekannt als Verfasser einer an der Universität Paris vielgelesenen philosophisch-systematischen Grammatik (veröffentlicht um 1310). Er war aber mehr als nur Autor dieses systematischen Lehrbuches. Als Magister in Erfurt an St. Severus und vermutlich auch am Schottenkloster und an anderen Stiftsschulen, deren Rektor er zeitweise war, machte er sich als Zeitgenosse Meister Eckharts einen Namen, der damals in Erfurt als Provinzial der Dominikaner residierte. Trotz seiner Bedeutung blieb Thomas in seiner eigenen Wirkstätte Erfurt bislang weithin unbekannt, seine Beziehung zu Meister Eckhart ist noch ungeklärt, und innerhalb der philosophischen Forschung ist sein Werk in Europa unterbeleuchtet, während in den USA Thomas von Erfurt schon länger untersucht wird. Dass er gerade in seiner Heimat und in Europa wenig beachtet wird, ist umso erstaunlicher, als bekanntermaßen seine spekulative Grammatik (die bis ins 20. Jh. unter dem Namen des Duns Scotus bekannt war) eine wichtige Anregung für Ch. Pierce und seine Ausbildung der Semiotik bildete und dieses Werk (wenn auch noch vermeintlich als Schrift Duns Scotus') den Ausgangspunkt für die Habilitationsschrift Martin Heideggers darstellte. Thomas hat folglich Heidegger einen wesentlichen Anstoß für die Ausbildung seiner Philosophie gegeben.

Der Workshop beabsichtigte, in interdisziplinärer Kooperation auf Thomas von Erfurt aufmerksam zu machen und insbesondere die Diskursbeziehung zwischen Thomas und Eckhart und die Verbindung von Erfurt und Paris herauszustellen und inhaltlich die Verschränkung von Grammatik, Metaphysik und Bibelexegese in Erfahrung zu bringen.

Der Workshop fand im Max-Weber-Kolleg vom 14. bis 15. November 2013 statt, organisiert von Markus Vinzent und Dietmar Mieth. Die Eröffnung übernahm Christian Lehmann (Sprachwissenschaft, Erfurt) mit einem einführenden Einblick in die 
Grammatik des Thomas von Erfurt. Gefolgt wurde er von einer ersten Sektion, die die Bedeutung Thomas' in der philosophischen Rezeption beleuchtete: Andrés QueroSánchez (Philosoph, MWK) referierte über Thomas von Erfurt bei Martin Heidegger, Gesche Linde (Theologin, Darmstadt, Fellow MWK) über Thomas von Erfurt bei Charles Peirce und Stephan Grotz (Philosoph, Hamburg) über Spuren der modistischen Grammatik in der Metaphysik Eckharts. In einem Abendvortrag sprach Oliver Davies (King's College, London) zur Hermeneutik, Metaphysik und Mystik.

Am zweiten Tag wurde das Verhältnis zwischen Thomas von Erfurt und Meister Eckhart näher betrachtet. Claire Taylor Jones (Germanistik, Notre Dame, USA) wies auf Einflüsse des Thomas auf Eckhart, Dietmar Mieth (Theologe, Tübingen, Fellow MWK) sprach über den Einfluss der Modistik auf Meister Eckharts Bibelexegese und Markus Vinzent (Theologe und Historiker, Fellow MWK) über Thomas, Eckhart und Paris mit Blick auf die Bedeutung von Personalpronomen im Denken beider.

Tagung an der Katholischen Akademie in Bayern vom 28. bis 30. März 2014 in Zusammenarbeit mit der Meister Eckhart Gesellschaft und dem Max-Weber-Kolleg, gefördert durch die Deutsche Forschungsgemeinschaft: ,Meister Eckhart interreligiös‘ (Dietmar Mieth)

Die Unmittelbarkeit der individuellen religiösen Einsicht ist etwas, das alle Religionen prägt. Was ist dabei das Einzigartige, das Meister Eckhart heute zu einem religiösen Botschafter überall in der Welt macht? Der Name ,Meister Eckhart` ist wie ein Schlüssel, der die Tür zum Gespräch öffnet.

Die Tagung erörtert in verschiedenen fachlichen Zugängen die Grundlagen eines interreligiösen Diskurses. Eckhart ist ein Prüfstein dieses Gespräches, u.a. auch am Max-Weber-Kolleg. Das Einzigartige in der interreligiösen Aufmerksamkeit für Meister Eckhart könnte u.a. darin bestehen: Es ist Meister Eckharts Absicht, in der Menschwerdung Gottes das Menschentum jedes Menschen zu würdigen. Maßgebliche Grundzüge seines eigenen Denkens verdankt Meister Eckhart zudem nicht nur der christlichen Tradition, sondern dem jüdischen Religionsphilosophen Moses Maimonides und islamischen Philosophen.

Hinsichtlich der interreligiösen Wirkung Meister Eckharts wird oft nach dem Buddhismus gefragt. Daher hat Shizuteru Ueda, der 1965 über Meister Eckhart promoviert hat, der langjährige dritte Leiter des Zen-buddhistischen Instituts in Kyoto, den öffentlichen Abendvortrag gehalten.

Die Verbindung der indischen Religiosität in ihren unterschiedlichen Ausprägungen mit Meister Eckhart ist seit dem 19. Jahrhundert ein Thema, teilweise auch über die Theosophie vermittelt. Sowohl in Indien, z.B. im Bhakti, als auch im Islam, im Sufismus, ist die Liebe mit Selbsthingabe und Offenheit für das Göttliche verbunden. Islamische Wissenschaftler suchen etwa, Ibn Arrabi und Rumi mit Meister Eck- 
hart ins Gespräch zu bringen. Aber es gibt auch Differenzen, z.B. in der Wahrnehmung des Körpers in den Formen der mystischen Versenkung, im Verständnis des Göttlichen und in Bezug auf die Institutionen der Gesellschaft.

Meister Eckhart wird auch in einer literarischen ,Mystik` auf jeweils eigene Weise rezipiert, z.B. auch in der deutschen Literatur (genannt werden hier gern Rilke, Musil, Celan). ,Mystik statt Religion“ sehen manche als Weg in die Zukunft.

Die Zusammenarbeit der beteiligten Institutionen (Kolleg-Forschergruppe am Max-Weber-Kolleg, Meister Eckhart-Gesellschaft, Katholische Akademie in Bayern) war reibungslos und vorzüglich. Die Betreuung der Referent/inn/en, die Versorgung der Teilnehmer/innen und die Organisation des Programmablaufs wurden sehr gut aufgenommen. Vor allem das Niveau, zugleich die Bemühung um Verständlichkeit und die konstruktive Stimmung in den Debatten wurden sehr gelobt. Für alle Vorträge standen auch Kurztexte zur Verfügung. Die Diskussion war stets rege. Der Zuspruch von akademischen Teilnehmer/inn/en war darüber hinaus sehr groß, stets über 200, beim Abendvortrag Uedas 300 Personen.

Internationale Tagung vom 11. bis 13. Juni 2014 am Max-Weber-Kolleg, gefördert durch die Deutsche Forschungsgemeinschaft: ,Realizing Justice? Encountering Normative Justice and the Realities of (In)Justice in South Asia‘ (Antje Linkenbach-Fuchs)

Vom 11. bis 13. Juni 2014 fand in den Räumen des MaxWeber-Kollegs der Universität Erfurt die Tagung „Realizing Justice? Encountering Normative Justice and the Realities of (In)Justice in South Asia“ statt. An der interdisziplinären Tagung nahmen 25 Wissenschaftlerinnen und Wissenschaftler aus Deutschland, Indien, Neuseeland, Großbritannien und der Schweiz teil; das Spektrum der Disziplinen umfasste Philosophie, Rechtswissenschaft, Soziologie, Ethnologie, Religionswissenschaft und Indologie. Die einzelnen Sitzungen wurden von einer Reihe interessierter Kolleginnen und Kollegen sowie Doktoranden besucht. Insgesamt stieß die Tagung auf erhebliche Resonanz, was sich u.a. an der hohen Teilnahmebereitschaft der von den Organisatoren eingeladenen Personen zeigte, sowie an den intensiven und ergiebigen Diskussionen nach den Vorträgen und in der Abschlusssitzung. Die Veranstaltung zeichnete sich aus durch verschiedene Zugangsweisen zu der Tagungsthematik. Einige Beiträge stellten normativ-theoretische und konzeptionelle Überlegungen zu den Begriffen von Gerechtigkeit und Recht aus westlicher und indischer (textwissenschaftlicher) Perspektive in den Mittelpunkt; die überwiegende Zahl der Referenten und Referentinnen aber widmete sich der Frage nach Gerechtigkeit aus einer realitäts- und realisierungsorientierten Perspektive. Sie präsentierten Überlegungen, die auf eigener historischer bzw. gegenwartsbezogener empirischer Forschung zum Thema Gerechtigkeit in unterschiedlichen gesellschaftlichen Feldern sowie Regionen Indiens basierte. Stark thematisiert wurden die Pluralität von Gerechtigkeitsvorstellungen und 
Gerechtigkeitsakteuren, die vielfältigen institutionellen und nicht-institutionellen Versuche der Realisierung von Gerechtigkeit (staatliche, nicht-staatliche), sowie die verschiedenen Formen existierender Ungerechtigkeit und die Reaktionen darauf.

Mit einem systematisierenden Überblick über vier zentrale und jeweils in sich plurale Dimensionen von Gerechtigkeit eröffnete Gunnar Folke Schuppert (Rechtswissenschaft) die Tagung. Andreas Pettenkofer (Soziologie) plädierte für einen pragmatistisch-soziologischen Umgang mit der Gerechtigkeitsfrage und verlangte, neben einer Betrachtung der normativen Ordnungen verstärkt die interaktive Situation von Gesellschaftssubjekten (real world situations) in den Blick zu nehmen. Der vergleichende Beitrag von Winfried Hinsch (Philosophie) und Dorothea Schulz (Ethnologie) konzentrierte sich auf Probleme, die sich für universalistische Gerechtigkeitskonzeptionen in post-kolonialen Kontexten mit dem für sie spezifischen Pluralismus religiöser und weltanschaulicher Zugehörigkeiten ergeben. Mahendra Singh (Rechtswissenschaft) leitete mit seinem Beitrag zum Konzept der Gerechtigkeit in der indischen Verfassung zu normativen Ordnungen und Realitäten auf dem südasiatischen Subkontinent über. Er betonte vor allem, dass die Indian Constitution die Idee von Gerechtigkeit bereits in ihrer (verpflichtenden) Präambel aufgreift und sich dabei vor allem an marginalisierte Gruppen richtet.

Vier Beiträge befassten sich mit Normen und Realitäten von Gerechtigkeit in Indien aus textwissenschaftlicher und/oder historischer Sicht. Nach deutlicher Kritik an Amartya Sens Fokus auf niti und nyaya als zentrale Rechtsbegriffe im hinduistischen Indien präsentierte Patrick Olivelle (Indologie) dharma als das Konzept, welches es erlaube, Vorstellungen von Recht, Pflicht und Gerechtigkeit im hinduistischen Kontext auszudrücken. Auch Timothy Lubin (Religion Südasiens) rückte dhar$m a$ ins Zentrum seines Beitrags. Er konfrontierte spätmittelalterliche Inschriften zu Eigentumstransaktionen mit normativ-theoretischen Aussagen in der Sanskrit Dharmashastra Literatur. Bei den Beiträgen von Lindsey Harlan und Peter Gottschalk (beide Religionswissenschaft) standen lokale Geschichte(n), Heldenerzählungen und Erinnerungskultur im Mittelpunkt. Harlan konzentrierte sich auf die Repräsentation und Verehrung zweier Heldenfiguren im urbanen Rajasthan und diskutierte Gerechtigkeitsvorstellungen im Kontext von Gewalt. Gottschalk thematisierte die narrative bzw. mythische Rekonstruktion von Aspekten der Ungerechtigkeit in der sozialen Ordnung am Beispiel eines Dorfes in Bihar.

Die Situation der indischen Dalit lässt die Widersprüche zwischen normativ geforderter Gerechtigkeit und realen Verhältnissen der Marginalisierung und sogar Gewalt in Indien besonders deutlich erscheinen. Daniel Gold (Religionswissenschaft) stellte zwei Dalit-Gruppen vor, die auf ihre sozio-ökonomische Situation unterschiedlich reagieren und damit auf ein unterschiedliches Verständnis von Gerechtigkeit (partikular vs. universal) verweisen. Beatrice Renzi (Ethnologie) verdeutlichte die Intersektionalität der Diskriminierung und die daraus erwachsende Dynamik der Ungerechtigkeit. Julia Eckert (Ethnologie) griff erneut die Frage nach alternativen Norm- 
vorstellungen und Gerechtigkeitskonzeptionen auf. Sie konfrontierte unterschiedliche Begründungsstrategien und zeigte, dass die von einer Gruppe eingeforderten Rechte (auf Land, Menschenwürde, citizenship etc.) von anderen Teilen der Gesellschaft nicht notwendig akzeptiert werden müssen. Shalini Randeria (Ethnologie) versuchte in ihrem Beitrag eine Analyse institutionalisierter Agenten des Rechts und der Gerechtigkeit. Bezogen auf zwei Entwicklungsgroßprojekte in Indien im ländlichen und im urbanen Raum thematisierte sie die Dynamiken, die im Kontext von Neoliberalismus und Globalisierung zu einer fundamentalen Veränderung der Funktionen und Aufgaben von NGOs, Gerichten und Administration und damit auch zu einem Wandel im der Bedeutung von Recht und Gerechtigkeit geführt haben. Normative Ideen und praktische Formen der Gerechtigkeitsfindung existieren nicht nur im säkularen Kontext, sie sind auch für den religiösen Bereich prägend.

Zwei Beiträge der Konferenz haben sich mit dem Phänomen der göttlichen Gerechtigkeit in Kumaon (Zentralhimalaya) befasst. Monika Krengel (Ethnologie) verwies zunächst auf das Nebeneinander und die gleichzeitige Inanspruchnahme verschiedener Alternativen der Gerechtigkeitsfindung (staatliche Gerichte, customary law, Gottheiten). Eine Gottheit der Gerechtigkeit (nyay ka devta) mit Namen Goludev stand bei Aditya Malik (Religionswissenschaft) im Zentrum seines Beitrags. Goludevs Sensibilität für Ungerechtigkeit habe seine Quelle in der eigenen Unrechtserfahrung, eine Tatsache, die ihn auch für Niedrigkastige und Frauen attraktiv mache. Der letzte Beitrag von Antje Linkenbach-Fuchs (Ethnologie) widmete sich dem Thema der Umweltgerechtigkeit. Sie hinterfragte die dem Begriff implizite Annahme einer Vereinbarkeit von Sorge um die Umwelt und Wunsch nach sozialer Gerechtigkeit und spürte dem Verhältnis beider Forderungen am Beispiel zweier aktueller tribaler (international unterstützter) Umweltbewegungen in Indien nach. Das Zusammenspiel von Gerechtigkeitssuche und sustainability in diesen beiden Fällen rührt aus ihrer Sicht daher, dass beide Forderungen Teil sind von Ansprüchen auf höherer Ebene: dem Anspruch auf Anerkennung (von Differenz) und dem Ideal eines selbstbestimmten guten und würdevollen Lebens, das auf einem respektvollen Umgang mit der natürlichen Umwelt basiert.

Unter den Tagungsteilnehmern bestand Konsens, dass es sinnvoll und ergiebig war, den Blick auf die Formen gelebter, realisierter Gerechtigkeit bzw. Ungerechtigkeit in nicht-westlichen Ländern (hier: Südasien) zu lenken, ohne die normative Ebene aus den Augen zu verlieren. Als besonders positiv erschien es, dass Normen und Realitäten in historischer und regionaler Perspektive betrachtet, d.h. Begrifflichkeiten sowie Praktiken in ihrer jeweiligen zeitlich spezifischen Ausformung und Entwicklung, aber auch in ihrer regionalen Partikularität analysiert wurden. Durch diese Vorgehensweise konnten neue Erkenntnisse gewonnen und weiterführende Problemstellungen identifiziert werden. Die Tagungsergebnisse sollen in einer Publikation einer breiteren Öffentlichkeit zugänglich gemacht werden. 
Internationale Konferenz vom 24. bis 26. September 2014 an der Bergischen Universität Wuppertal in Kooperation mit dem Max-Weber-Kolleg, gefördert durch die DFG: „,... man könnte fast sagen: die Satire flucht und der Humor betet.' Humor und Religiosität in der Moderne“ (Markus Kleinert)

In der Einführung wurde zunächst in Anlehnung an Wittgenstein das Verhältnis von der gegenwärtig gewöhnlichen Verwendung des Humorbegriffs und jener emphatischen Bedeutung erörtert, die der Humor in der Kunst und Philosophie seit der Aufklärung erhalten hat und die primärer Anlass ist, den Humor auf dieser Tagung als Artikulation von Religiosität unter den Bedingungen der Moderne zu thematisieren. (Gerald Hartung, Wuppertal) Dann wurden zwei Aspekte des Tagungsthemas hervorgehoben: zum einen die Rekonstruktion, die Untersuchung kanonischer wie vernachlässigter Beiträge zum modernen Humor unter besonderer Berücksichtigung religiöser Implikationen; zum anderen die Gegenwartsrelevanz dieser Rekonstruktion, insofern sie zu einer Klärung anhält, was unter spezifisch moderner Religiosität zu verstehen ist; so kann die Beschäftigung mit dem Humor - in kritischer Reflexion der großen Narrative zur Moderne (Rationalisierung, Säkularisierung, Individualisierung) - zu einer Theorie der modernen Kultur beitragen (Markus Kleinert, Erfurt).

Um Humor und Religiosität als Habitus zueinander ins Verhältnis setzen zu können, ging Volkhard Krech (Bochum) von der Untersuchung des jeweiligen Wortfelds aus, wobei er gegenüber der Konzentration auf den vor allem in der Tradition Jean Pauls metaphysizierten ,Welt-Humor' für die Berücksichtigung auch bescheidenerer, banaler bzw. banalisierter Erscheinungsformen des Humors plädierte. Auf dieser Basis wurden dann verschiedene Verbindungen von humoristischem und religiösem Habitus dargestellt, von der einseitigen Integration (etwa der mystische Begriff von Gelassenheit als humoristisches Moment innerhalb einer religiösen Haltung) bis zum wechselseitigen Korrektiv (wenn Humor und Religiosität als eigenständige Formen des Umgangs mit Kontingenz der Verabsolutierung einer Form entgegenwirken). Zu dieser Darstellung bot der Vortrag von Gerhard Danzer (Berlin) insofern ein Gegenstück, als darin gerade der - mit Harald Höffdings Begriff - ,große Humor` behandelt wurde, und zwar in exemplarischer Abgrenzung von dem mit Freud gedeuteten Witz und dem mit Bergson gedeuteten Komischen. Die humoristische Weltanschauung äußert sich demnach nicht im Verlachen des an eine dreigliedrige Sozialstruktur gebundenen Witzes oder dem auf Wiedereinbeziehung des Gegenübers zielenden Lachen der Komik, sondern im Lächeln einer souveränen Persönlichkeit, die sich der gewöhnlichen Wirklichkeit bewusst und ihr zugleich spielerisch überlegen ist. Die Frage, ob dieses Lächeln als Sinnbild des Humors gelten kann und inwieweit es ggf. affirmative oder subversive Züge hat, sowie die Frage nach dem Verhältnis zwischen dem Humor als Weltanschauung und den alltäglichen Formen des Humors wurden im weiteren Verlauf der Tagung wiederholt diskutiert.

Nach den beiden systematisch überblickshaften Darstellungen beleuchtete eine Reihe von Vorträgen einzelne philosophische und künstlerische Beiträge zum Humor 
in der Moderne. Oliver Koch (Bochum) erläuterte Jean Pauls Humorkonzept, das sich durch den emphatischen Transzendenzbezug von der vorangehenden englischen Tradition abhebt und - in Übereinstimmung mit Jacobis Philosophie - in einer Doppelstellung gegen die bloße Differenz negativer Theologie und die bloße Identität des Pantheismus behauptet. Michael Scheffel (Wuppertal) deutete E.T.A. Hoffmanns Prinzessin Brambilla in einer detaillierten Textinterpretation als gelungene Umsetzung des frühromantischen Entwurfs einer Tranzendentalpoesie, insofern darin Reflexivität auf allen Erzählebenen verwirklicht und zugleich - unter den Stichworten Humor und Einbildungskraft - aus der Statik der Spiegelung in einen allumfassenden Prozess überführt wird, in den nicht zuletzt der Rezipient einbezogen ist. Lydia B. Amir (Rishon LeZion) untersuchte vor allem die epistemologische Funktion des $\mathrm{Hu}$ mors bei Shaftesbury, Hamann und Kierkegaard: vom ,test of ridicule “ über die Kritik eines verabsolutierten Verstandes bis zum Komikverständnis als Indikator der jeweiligen Existenzweise.

Einer vergleichsweise vernachlässigten Position der Philosophiegeschichte wandte sich Gerald Hartung zu, indem er die Humortheorie von Moritz Lazarus als Verhaltenslehre für den Menschen der säkularen Moderne deutete: an die Stelle einer Aufhebung tritt darin das humoristische Ausgleichen bestehenbleibender Gegensätze, metaphorisch: der Friedensschluss. Auf einen solchen Frieden zielt auch das Humorkonzept von Hermann Cohen, dessen Herausbildung Andrea Poma (Turin) nachzeichnete; der Humor verhindert demnach als übergeordnete temperierende Instanz die Verabsolutierung einzelner ästhetischer, ethischer oder religiöser Positionen. In schroffem Gegensatz zum befriedenden Humor bei Lazarus und Cohen steht Nietzsches radikal kritisches und selbstkritisches Lachen, wie Silvia Stoller (Wien) mit Bezug auf ,Die Fröhliche Wissenschaft‘ und ,Also sprach Zarathustra‘ ausführte (wobei die Gefährdung solcher Radikalität durch einen Verweis auf Canettis Blendung angedeutet wurde). Mittels begriffsgeschichtlicher Rekonstruktion arbeitete Markus Kleinert an Werken von Jean Paul, Peter Hille und Fontane heraus, welche religiösen Implikationen in der gängigen Rede von ,verklärendem Humor` und ,humoristischer Verklärung‘ enthalten sein können.

Klaus-Dieter Osthövener (Wuppertal) untersuchte das Verhältnis von Humor und Religion in der klassischen Moderne anhand von mythologischen und gleichnishaften Texten Kafkas, Musils Mann ohne Eigenschaften sowie Thomas Manns Doktor Faustus, wobei - neben verschiedenen Weisen der Wechselwirkung zwischen Kunst und Religion - auch die zur humoristischen Referenz auf Religion gegenläufige Tendenz zur Wiedergewinnung unbedingten Ernstes deutlich wurde. Ebenfalls dem Zeitraum der klassischen Moderne widmete sich Harald Tausch (Gießen), allerdings anhand einer Familiengeschichte: der des Kunsthistorikers Gustav Friedrich Hartlaub und seines Sohnes, des Schriftstellers und Künstlers Felix Hartlaub (sowie des persönlichen Umfelds, zu dem etwa der Kunsthistoriker Wilhelm Fraenger zählt); zu den in diesem Kreis verhandelten Themen gehört auch der Humor, letztlich ein Versuch, 
den Autonomieanspruch des Subjekts mit dessen geschichtlicher Bestimmtheit zusammenzubringen - und das mit praktischen Konsequenzen, wie an den sozialen Strukturen, Publikationswegen und Texten gezeigt wurde, die im Kreis der Hartlaubs während des Nationalsozialismus entstehen.

Eine wichtige Ergänzung zu diesen primär philosophisch und literarisch ausgerichteten Beiträgen bot Wolfgang Rathert (München), der - nach einem allgemeinen Überblick über das Verhältnis von Musik und Religion - anhand von Werken Robert Schumanns (z.B. der Humoreske op. 20 mit der unhörbaren „Inneren Stimme“) und Gustav Mahlers erörterte, in welchen Hinsichten sich die Kennzeichnungen humoristisch und religiös überhaupt auf musikalische Werke anwenden lassen. Will man die Referate und Diskussionen auf eine Formel bringen, so könnte man sagen: der Humor ist ein ebenso vertrautes wie strittiges Mittel zur Idealisierung der Realität - wobei Wesensbestimmungen, Erscheinungsformen und Bewertungen dieser Idealisierung thematisiert wurden. Eine besondere Attraktion bildete die Lesung von Brigitte Kronauer aus ihrem im Vorjahr erschienenen Roman ,Gewäsch und Gewimmel', die als öffentliche Veranstaltung im Von der Heydt-Museum Wuppertal stattfand. Der Journalist Nikolaus Halmer verfasste für den Österreichischen Rundfunk einen Bericht über die Tagung (http://science.orf.at/stories/1747532/). Gefördert wurde die Tagung durch die Deutsche Forschungsgemeinschaft (DFG), die Gesellschaft der Freunde der Bergischen Universität sowie von der Stadtsparkasse Wuppertal. Eine Veröffentlichung der Tagungsbeiträge ist geplant.

\begin{abstract}
,Meister Eckhart-Forschung und religiöse Individualisierung im Spätmittelalter‘, Workshop am 11. Dezember 2014 im Rahmen der KFG-Forschergruppe ,Religiöse Individualisierung in historischer Perspektive، (Dietmar Mieth)
\end{abstract}

Die Absicht dieses eintägigen Workshops war es, Forschungsstände miteinander ins Gespräch zu bringen. Zum einen ging es dabei in Ergänzung zur Meister Eckhart-Tagung in München 2012 darum, die Untersuchungen zur ,Religiösen Individualisierung“ im deutschen und lateinischen Werk Eckharts zu erweitern. Zum anderen sollten auch andere Spuren der religiösen Individualisierung im Mittelalter ergänzt und damit ins Gespräch gebracht werden. Dazu dienten die beiden Beiträge von Anneke Mulder-Bakker (Religionshistorikerin, Groningen, Fellow am Max-Weber-Kolleg) und Martina Roesner (Philosophin, Wien). Beide bezogen sich auf das Eucharistie-Verständnis. Frau Mulder-Bakker entfaltete anhand des Lebenswerkes der Begründerin der Fronleichnamsprozession (Juliana von Lüttich) deren Initiative zu einer volksnahen und öffentlichen Begegnung mit der leibhaft sichtbaren Eucharistie sowie die fördernde und zugleich einschränkende Behandlung dieser Initiative durch Papst Urban IV, der Erzdiakon in Lüttich gewesen war. Das Fest wurde 1264 eingeführt, die Liturgie aber - durch Thomas von Aquin - im Auftrag umgeschrieben. Frau Roesner zeichnete anhand der einschlägigen deutschen Werke Eckharts eine sehr spezielle 
Eucharistielehre nach, die von vorneherein als Entfaltung der naturalen Schöpfungsmacht Gottes betrachtet wird und den iterativen Vorgang der Gottesgeburt in einem wirkmächtigen Zeichen pointiert und exemplifiziert. Chris Wojtulewicz (London) machte mit den Reaktionen auf Eckhart und seine Pariser Quaestionen vertraut, indem er anhand verschiedener handschriftlicher Notizen in Kompilationen von Quaestionen nachwies, inwieweit Eckharts Themen aufgegriffen wurden. Jana Ilnicka (Rom, Saarbrücken) behandelte insbesondere den Begriff ,relatio‘ in der für Eckhart typischen Form der Beziehungslehre, die (nicht nur bei ihm) in Spannung zum Substanzbegriff steht, den Eckhart unter anderen Voraussetzungen beibehält. Hierbei behandelte sie insbesondere die erste der beiden Pariser Quaestionen (enthalten in den von Markus Vinzent wiederentdeckten Quaestionen Eckharts), die das Thema der ,relatio‘ behandeln. Andres Quero-Sánchez (Philosophie, Max-Weber-Kolleg) erarbeitete anhand der Texte zur ,Spekulativen Grammatik‘ (Boethius von Dacia, Thomas von Erfurt) deren Beziehungen und Spannungen zu Meister Eckhart, vor allem unter der Perspektive des Realismus und des Idealismus bzw. der ,mystischen Vernunft (bei Eckhart). Christian Ströbele (Fundamentaltheologie, Tübingen) verfolgte in Korrespondenz das Thema der Vernunft bei Anselm von Canterbury und Meister Eckhart als wechselseitige Implikation von Wahrheit, Rechtheit und Gerechtigkeit. Dabei beleuchtete er auch sprachgeschichtlich den Zusammenhang von ,gerade ausgerichtet" und ,gerecht'. Dietmar Mieth behandelte das Verhältnis von Interiorisierung (,Innerlichkeit') und Individualisierung am Beispiel der Unmittelbarkeit der spirituellen Erfahrung bei Eckhart aber auch bei den signifikanten Beginn, insbesondere Marguerite Porete. Mit dem Workshop wurde auch das Interesse an den religiösen Frauenbewegungen verstärkt. Dazu wurde der Arbeitskreis am Max-Weber-Kolleg (mit Sabine Schmolinsky), der sich mit diesem Thema beschäftigt, zur aktiven Teilnahme eingeladen.

Internationale Jahrestagung der Meister-Eckhart-Gesellschaft und der AlbertLudwigs-Universität Freiburg in Kooperation mit der Katholischen Akademie der Erzdiözese Freiburg in Freiburg i.Br. und dem Max-Weber-Kolleg vom 13. bis 15. März 2015: „Von ,Schwester Katrei“ bis zum ,Frankfurter‘ - Meister Eckharts Wirkung im 14. und 15. Jahrhundert“ (Dietmar Mieth)

Die Tagung war international hochgradig besetzt (London, Bern, Paris, Colmar, Lecce, Moskau). Sie zeigte insbesondere, welche Dynamik sich schon in der frühen Eckhart-Überlieferung erkennen lässt, wenn sich verschiedene Fächer (Germanistik, Philosophie, Geschichte, Theologie) interdisziplinär der Eckhart-Rezeption widmen. Das Eckhart-Bild der Moderne hat seine Vorläufer schon in den Redaktoren und Schreibern während und kurz nach Eckharts Lebenszeit. Dabei treffen Eckharts Texte auf individualisierte Konzepte ihrer Schreiber und anderer Rezeptoren. Besondere Aufmerksamkeit wurde daher auf der Tagung den Schreibstuben zuteil. Es ging um 
die Individualitäten der Schreiber, um die Ökonomie des Schreibens, um die Handschriften als „Wissensspeicher“, um die Selektion für bestimmte Zwecke, z.B. für die Moral im Kloster, insbesondere auch aufgrund der Volkssprache für Laienbrüder. Die Volkssprache avanciert dabei zur Formelsprache. Hier war bereits der Ansatzpunkt für das Eröffnungsreferat von Freimut Löser (Augsburg): „Unser Eckhart“, wie Schreiber „ihren“ deutschen Eckhart bezeichnen. Bereits im „Paradisus animae intelligentis“ (vor 1341), der 32 Eckhart-Predigten enthält, findet man seitens der Thüringer Dominikaner eine Akademisierung und Latinisierung als Konzeption vor. Eckharts Text über die „minne“ DW III, Pr. 6o, 22,3-7 kann geradezu als Widerspruch zu dieser thematischen Ausrichtung und Profilierung gelesen werden.

Die germanistische Forschung brachte weitere Erträge in die Tagung ein, die das lebendige Weiterwirken Eckharts im spirituellen Schriftgut aufzeigen. Regina Schiewers (Eichstätt) Beitrag über den „Seelenwinkel“ (eine Straßburger Hs. des 15. Jh.) verwies auf eine namentliche Zuordnung zu Eckhart in einer Spruchsammlung. Michael Hopf (Augsburg) untersuchte Eckhart-Legenden, also Textzeugen, die Eckhart als inszenierte literarische Figur narrativ behandeln. Echten Rezeptionen der Lehre Eckharts stehen Simplifizierungen in der Sache und in Bildern gegenüber. Eckhart dient als Figur einer „dramatisierten Theologie“. Lydia Wegner (Bern/Berlin) behandelte die sog. Mosaik-Traktate, insbesondere Pfeiffer Nr. XI und XIII. Im Vordergrund steht das Erlernen der Indifferenz und die gewagte Formel „den Tugenden Sterben“, die an Marguerite Porete erinnert. Dagmar Gottschall (Lecce) ging auf anonyme Traktate des 14. Jahrhunderts ein, z.B. das sog. „Geistbuch“. Teile stammen noch aus der Lebenszeit Meister Eckharts. Das gilt auch für Handschriften zu der Erzählung „Schwester Kathrei“ (ca. 1320). Die Exzerpte werden immer wieder verkürzt weiter gereicht. Laurentiu Gafiuc (Augsburg) zeigte auf, dass die Handschriften in weitaus überwiegender Zahl im Südwesten entstanden sind. Durch das Handschriften-Händlerwesen wurden sie dann oft erst im 19. Jahrhundert anders verteilt. Sie haben ihren „Sitz im Leben“ in Klöstern, insbesondere von Dominikanerinnen. Die ältesten verweisen auf 1350 in Straßburg oder Basel. Ihr jeweiliger spiritueller Zweck und Gebrauch hat Vorrang vor dem Autoren-Nachweis, den es jedoch an wenigen Stellen für Eckhart gibt. Balácz Nemes (Freiburg i.Br.) zeigte die Eckhart-Lektüre von Augustiner-Chorherren im Kloster Rebdorf im 15. Jahrhundert. Hier werden auch Kommentare geschrieben. Die Bewegung zur „devotio moderna“ ist spürbar. Eckharts Verabschiedung der „gratia creata“ stößt auf dogmatische Kritik.

Die Verzahnung des deutschen und des lateinischen Eckhart in der Rezeption behandelte Markus Vinzent (London/Erfurt) am Beispiel der neu zur Kenntnis genommenen und erstmals bearbeiteten Handschriften auf der Wartburg (1. Drittel 14. Jahrhundert). Dort findet sich ein ähnlicher Fall wie Eckharts lat. Vaterunser-Kommentar, der auch noch zu untersuchende Parallelen in deutschen Vaterunser-Kommentaren in handschriftlicher Eckhartumgebung aufweist. In der Wartburghandschrift finden sich Verweise auf Thomas von Aquin und Pariser Diskurse sowie auf die Eckhart- 
schen Bibelkommentare (In Gen., In Sap.). Vinzent verweist auch auf die eigenständigen und dem Vortrag angepassten Bibelübersetzungen Eckharts aus dem Lateinischen. Dabei werde der biblische Text zugespitzt und existentiell gesteigert. KlausBernwart Springer (Erfurt/Köln) behandelte Eckharts Wirkungen im Dominikanerorden im 14. und 15. Jahrhundert. Er listete vielfältige Zeugnisse auf, die z.T. noch in Eckharts Lebenszeit gehören. Der (Buch-)Historiker Gilbert Fournier (Colmar/Paris) lieferte neue und überraschende Erkenntnisse zur Eckhart-Rezeption bei Nikolaus Cusanus. Er hat die Handschrift Bernkastel-Kues, St. Nikolaus Hospital 21 genauer untersucht. Diese zeigt den lateinischen Eckhart in einem neuen Licht und eröffnet den Zugang zu einer widersprüchlichen Rezeption der Bulle „In agro dominico“, die auch im 15. Jahrhundert übersetzt wurde. Mikhail Korkhov (Moskau) beschrieb die lateinischen Übersetzungen deutscher Schriften von Meister Eckhart. Bei Johannes Wenck im 15. Jahrhundert finden sich Zitate z.B. aus dem Buch der göttlichen Tröstung und aus der Predigt DW 2. Eine Koblenzer Handschrift enthält die Übersetzungen ins Lateinische: Pr. 2, 6 und 52 (geistl. Armut), von der Geburt (Pfeiffer 475-478), ferner die Legende von Meister Eckharts „Wirtschaft“. Wenck sieht 1430 in Heidelberg den verurteilten Eckhart in einer Linie mit Wyclif, Hus und den Begarden. Abschließende aktualisierende Bemerkungen (Dietmar Mieth, Tübingen/Erfurt): Die vielfältige Rezeption Meister Eckharts ist oft über geflügelte Worte bekannt. So z.B. in Bezug auf die Gottesgeburt. Gern wird Angelus Silesius zitiert: „Und wäre Christus tausendmal geboren und nicht in dir, du wärest doch verloren." Was bei Meister Eckhart eine Ansage für die Gemeinschaft des Menschen mit Gott ist, wird hier zu einer Drohung ausgedeutet. Daran kann man erkennen, wie sehr Rezeptionen verändern können, indem sie scheinbar ein Motiv erhalten. Die Erkenntnis, dass Rezeptionen ambivalent sind, zog sich wie ein roter Faden durch die Tagung.

,Die Stimme des Autors. Religiöse Innovation in hellenistisch-römischer Zeit‘, internationale Tagung vom 20. bis 22. Mai 2015 im Rahmen der Kolleg-Forschergruppe ,Religiöse Individualisierung in historischer Perspektive“ im Augustinerkloster in Erfurt mit Unterstützung der DFG, der Fritz-Thyssen-Stiftung und in Zusammenarbeit mit ,Homines novi‘, Aarhus/AUFF (Eve-Marie Becker, Jörg Rüpke)

Eminente Texte der antiken literarischen kanones sind durch ihre Verfasser nicht nur - historisch und literarisch - ,autorisiert', sondern das jeweilige Konzept von Autorschaft wirkt auf die Produktion und Rezeption eines Textes direkt ein. Die Autorkonzeption ist damit - ähnlich dem literarischen genre - eine Art template, das literarische Texte generiert. Autorkonzeptionen erweisen sich dabei aber nicht als starre Formate, sondern sind in ihrer Rückbindung an Autoren-Personen immer auch dem Wandel und der Veränderung unterworfen. Insofern machen Autorkonzepte ein erhebliches literarisches Potential in der (antiken) Literatur aus. Das gilt, wie die Ta- 
gung zeigen konnte, besonders für den Bereich der religiösen Literatur. Für die Religionsgeschichte der Kaiserzeit mit ihrer enormen religiösen Produktivität, die sich ebenso in einer intensivierten religiösen Kommunikation wie in zahllosen, oft kurzlebigen, aber eben auch langfristig erfolgreichen Gruppenbildungen niederschlug, ist die Frage der literarischen Autorschaft von besonderer, auch sozio-politischer Bedeutung: Autoren waren hier nämlich vielfach auch religiöse, (Klein-) Unternehmer‘. Die Tagung ging der Frage nach, wie bestimmte Autoren, die wir als ,reale Autoren“ bezeichnen können, sich selbst als ,Autoren` zu erkennen und dabei ein religiöses und literarisches Profil geben. Leitenden Fragestellungen waren: Welche Elemente der literarischen Profilgebung begegnen uns? Welche ,Autorenkonzepte‘ und Erzählerfiguren und -positionen werden dadurch im Bereich von religiöser Literatur geschaffen? Welcher literarischen genres bedienen sich die jeweiligen Autoren? Stehen Autorkonzeption und genre in einem inneren Zusammenhang? Findet die Autor-Profilierung innerhalb und/oder außerhalb (auto-)biographischer Texte bzw. Textteile statt? Welche erkennbaren oder verschleierten Intentionen verfolgen die Autoren mit ihrer (literarischen) Profilgebung? Geben sie selbst Hinweise auf intendierte Rezeptionsprozesse (Rezeptionsanweisungen) - gibt es ggf. selbst-kanonisierende literarische Elemente? Woran machen Zeitgenossen religiöse Innovation oder Devianz fest? Tragen Autorenprofile und deren mögliche Imitierung zur ,religiösen Individualisierung bei? Welche Rollenmodelle, welche Autoritätsrelationen bieten sie an? Welche Rezeptionsformen und -institutionalisierungen legen sie nahe?

Die Tagung griff diese Fragen in einer religionsgeschichtlichen Breite auf, die zeitlich bei dem ersten frühjüdischen ,Autor` (Ben Sira) einsetzt und bis zum Ende des zweiten Jahrhunderts n.Chr. reichte und sich räumlich auf das Imperium Romanum richtete. Sie konzentrierte sich auf jene Sprachen und Sprachtraditionen (Griechisch, Latein, mit Seitenblicken auf das Hebräische und Syrische), die in großem Umfang den Austausch von literarischen Modellen, Institutionen literarischer Kommunikation und schließlich auch - durch Zweisprachigkeit, vor allem aber zahllose Übersetzungen - den Austausch von Textinhalten ermöglichten. Dabei wurden grundlegende Fragestellungen zum kultur- und ideengeschichtlichen Kontext der antiken Autoren mit konkreten Textinterpretationen verbunden. Als Ergebnis lässt sich festhalten: Die Frage nach Autoren in religiösen Texten zielt auf Formen und Veränderung von Autorenkonzepten in religiösen Texten des antiken Mittelmeerraums. Vorstellungen von individueller Produktion von und Verantwortung für Texte und die Orthonymie, die Angabe eines Verfassers bzw. einer Verfasserin mit Namen spielen hier eine große Rolle - eine erstaunlich große Rolle sogar, wenn man die vielen Alternativen von anonymer oder geteilter Textproduktion oder die Modifikation von Texten während des immer wieder notwendigen Abschreibens von Texten oder während der Performanz solcher Texte bedenkt.

Religiöse Texte verkomplizieren diese Situation, indem sie neben der oder dem menschlichen Textproduzenten gerade transzendenten Stimmen Platz einräumen. Gottheiten, Engel oder Gestalten der Unterwelt können als ,eigentliche‘ Autoren so 
hinzutreten. Wenn solche Texte in einem rituellen Kontext zu Gehör gebracht werden, tritt eine weitere Rolle hinzu: die von rituellen Akteuren, seien das religiöse Spezialistinnen oder Schauspieler. Dabei mag es sich um Rezitationen in großen Auditorien vor offenem Publikum oder um das Verlesen und Interpretieren von Texten in geschlossenen kleinen Zirkeln handeln. In dieser Situation wird das explizite oder implizite Bild, das der Text oder der oder die textimmanente Erzählerin vom Autoren entwerfen, selbst zu einer Strategie, dem Text Autorität und einen bestimmten Status $\mathrm{zu}$ verleihen. Im engeren Sinne haben der oder die Verfasserin - dass die GenderKomponente bei diesen Prozessen eine große Rolle spielt, steht außer Frage - damit eine große Bedeutung für die Wahrheitsansprüche oder die Relevanzansprüche des Textes. Im weiteren Sinne wird er oder sie damit zu einem zentralen Akteur in der gesellschaftlichen Wirklichkeit. Ob als religiöser Spezialist oder gar ,religious entrepreneur' (mit Interessen an Gefolgschaft und Lebensunterhalt) betreten sie so das weite Feld von religiösen Diskursen und religiösen Praktiken.

'Creating Religion(s) by Historiography', international conference of the research group 'Religious Individualization in Historical Perspective' at the Augustinerkloster in Erfurt, June 10-12, 2015 (Jörg Rüpke)

The conference, organized by Martin Mulsow and Jörg Rüpke, was part of the research of the Kolleg-Forschergruppe 'Religious Individualisation in Historical Perspective' and financed by the German Science Foundation (DFG). To narrate one's past is one of the most important tools to define one's identity. This holds true for individuals in genealogies or conversion narratives as well as for groups and nations, bolstering their coherence and claims by national histories. Religious groups use similar tools as recent research has stressed. Given the lack or rudimentary state of religious organization, the lack of membership concepts, the contested character of orthodoxy and heresy, phenomena of 'civil religion' or widely shared practices and beliefs in many regions and epochs, the definition of the subject of a history is of paramount importance. It is by the very narrating of origins, conflicts, exclusions and alliances that the identity of the narratives' subjects, their characteristics and boundaries are defined. This is as crucial in separating believers and non-believers as in dressing the balance between religion as a collective enterprise ('religions') and religion as an individual practice ('spirituality'). If this seems typical of emic historical narratives, a closer look betrays that etic, scientific historiography usually follow these frameworks and divisions.

The conference addressed questions like: How instrumental is historiography of religion - emic and etic - in creating religions and the concept of a plural of religions as accountable social units with a history of its own? What are the terminological tools (religions, confessions, schools, sects)? What are the narrative tools (stories of oaths and treaties, of deviance, of contenders...)? What are compositional decisions 
to that purpose (ingroup-outgroup changes of perspectives, comparison, successions as organizing principle, definition and treatment of epochs)? Are individual or institutional historiographers reacting to or shaping processes of group formation? Are they empowering or censuring individuals? These questions were applied to the historiographical rise traditions like 'Judaism', ‘Christianity', 'Buddhism' and 'GelugpaBuddhism' in particular, but also on founding figures like 'Moses' or 'Zoroaster'. A crucial result was the insight that such inventions were not unique but were part of ancient, medieval or modern and contemporary situations and interests, interests in genealogies or 'pureness' as well as interests of particular groups and professional agents. Such situations are responsible for very different epistemological conditions for narrating 'religion' as ‘history'.

„Geschichtsschreibung (Storiografia)“, Workshop vom 18. bis 19. Juni 2015 in Zusammenarbeit mit Fondazione Collegio San Carlo di Modena und École Pratique des Hautes Études Paris in Modena (Veit Rosenberger)

An der Fondazione San Carlo in Modena, mit der das Max-Weber-Kolleg seit einigen Jahren eine Kooperation verbindet, fand am 18. und 19. Juni 2015 eine Tagung unter dem Titel „Storiografia. Ricerca storica e scrittura del passato“ statt. Vortragende kamen aus dem Umfeld der Fondazione San Carlo und aus der École Pratique des Hautes Études (Paris); aus Erfurt waren Dominik Fugger, Maik Patzelt und Veit Rosenberger mit von der Partie. Die Fondazione San Carlo, 1954 eingerichtet, befindet sich in den altehrwürdigen Räumen ihrer Vorgängerinstitution, dem im 17. Jahrhundert installierten „Collegio dei Nobili di San Carlo“, aus dem Bischöfe und Kardinäle hervorgegangen sind. Heute ist die Fondazione San Carlo eine geisteswissenschaftlich ausgerichtete Institution, unabhängig von der Universität und deren Politik. Ferner verfügt die Fondazione San Carlo nicht nur über eine herausragende Bibliothek, barocke Prunkräume und endlose Gänge, in denen die herausragenden Absolventen vergangener Jahrhunderte in Öl portraitiert sind, sondern auch über einen weiteren streng gehüteten Schatz. Im Speicher reifen einige Liter des berühmten aceto balsamico di Modena. Der Essig ruht je ein Jahr in sieben Fässern aus verschiedenen Holzarten. Angesichts der Dauer und angesichts des Verdunstungsverlustes über sieben Jahre hinweg wird der hohe Preis für den traditionell hergestellten Balsamico-Essig verständlich. In den Vorträgen wurden zwei Themenfelder behandelt: Zum einen die Möglichkeiten einer Geschichtsschreibung der Antike, zum anderen Ansätze in der Historiographie von Ferdinand Gregorovius über Michel Foucault und Michel de Certeau bis Isaiah Berlin. Carlo Altini, Direttore scientifico der Fondazione, skizzierte in seinem Grußwort die Situation der Geisteswissenschaften, die sich allerorten in der Defensive befinden. Wenn man bedenkt, dass zu Lebzeiten Max Webers die Geschichte als Leitwissenschaft fungierte, so ist die Fallhöhe beträchtlich. 
'XXI. World Congress of the International Association for the History of Religions' at the University of Erfurt, August 23-29, 2015 (Elisabeth Begemann)

From August 23 to 29, the XXI. Quinquennial World Congress of the International Association for the History of Religions (IAHR) was hosted at the University of Erfurt. More than 1300 scholars of religions were scheduled to present their research in almost 400 parallel panels and sessions over a period of four days. The topic of the congress, 'Dynamics of Religions: Past and Present', was outlined and presented by eighteen keynotes of leading scholars in the field of religious studies. In four daily parallel keynotes, they discussed the changes and continuities of religions and religious studies in their various fields, reflecting the four thematic areas of the congress, 'Religious Communities in Society: Adaptation and Transformation', 'Practices and Discourses: Innovation and Tradition', 'The Individual: Religiosity, Spiritualities and Individualization' and 'Methodology: Representations and Interpretations'. Keynote speakers were:

Peter Beyer (Ottawa): 'Forms of Religious Communities in Global Society: Tradition, Invention, and Transformation'

Vasudha Dalmia (Berkeley): 'Homogenizing Hinduism: A Watershed'

Cristiana Facchini (Bologna): 'Representing Judaism: Narrating, Visualizing, Performing, and Feeling a Religion'

Ingvild Saelid Gilhus (Bergen): 'Bodies, Texts and Otherness - Religious Change in Antiquity and Today'

Wouter Hanegraaff (Amsterdam): 'Fantastic Religion: Esoteric Fictionality and the Invention of Tradition'

Jeppe Sinding Jensen (Aarhus): 'No Human is an Island: Natures, Norms and Narratives'

Kim Knott (Lancaster): 'Inside Out? The (In)visibility of Religious Communities in Contemporary Societies'

Karénina Kollmar-Paulenz (Bern): 'Of Yellow Teaching and Black Faith: Entangled Knowledge Cultures and the Creation of Religious Traditions'

Suzanne Marchand (Louisiana State): 'Herodotus, Historian of World Religions: How the Reception-History of the Father of Lies Can Help Move the Conversation beyond 'Orientalism”,

Sylvia Marcos (Cuernavaca): 'Transformation and Revitalization: Mesoamerican Religious Traditions'

Martin Mulsow (Erfurt/Gotha): 'Global Intellectual History and the Dynamics of Religion'

Kalpana Ram (Macquarie): 'Religion, Human Agency and Change: The Importance of Intermediary Experiences'

Hubert Seiwert (Leipzig): 'Dynamics of Religion and Cultural Evolution' 
Susumu Shimazono (Tokio): 'Religion and Public Space in Contemporary Japan: The Reactivation of State Shinto and Buddhism as Public Religion'

Dianne Marie Stewart (Emory): 'From Syncretism to Social Belonging: Retheorizing Tradition and Innovation in African Heritage Religious Cultures of the Caribbean and the Americas'

Abdulkader Tayob (Kapstadt): 'The Biographical Trajectories of Political Islam' Gerald West (Kwazulu Natal): 'Religion Intersecting De-nationalisation and Re-nationalisation in Post-Apartheid South Africa'

Xiaoyun Zheng (Peking): 'On the Management Mode of Chinese Theravada Buddhism'

The findings have been compiled in a publication, to which the abstracts of the panels and papers are added in an electronic open access version to serve as the congress proceedings (https://www.degruyter.com/view/title/516446).

The congress was preceded by two pre-conferences, of the SAMR and AESToR Net, which met on Saturday and Sunday at the Max-Weber-Kolleg Erfurt. Approximate sixty participants (invited speakers and guests) attended these conferences. The congress proper was opened Sunday, August 23, by the formal opening and keynote lecture at the Theater Erfurt. Among the guests were the Thuringian Minister President Ramelow and various honorary consuls to honor the occasion. The keynote 'Dynamics of Religion and Cultural Evolution' by Hubert Seiwert (Leipzig) was sponsored by a generous contribution by the family of the late Gary Lease and appeared in the program as Opening Keynote and Gary Lease Memorial Lecture, followed by a reception.

Congress participants came from all over the world to attend the Erfurt meeting. An approximate 50 per cent were Europeans, with the second largest percentage from Asia, followed by the Americas, Africa and c. $3 \%$ from Australia and New Zealand. With a grant by the German Research Foundation (DFG) and by the Ernst Abbe Stiftung, Jena, organizers were able to keep the participation fee to a relatively low $€ 150,00$ (early registration), even with a green fee added to offset some of the carbon dioxide produced during travel to and from the Congress. A total of more than thirty travel grants were awarded to allow scholars from less affluent regions and universities from all over the globe to attend the congress and present their research.

The organizers were also committed to reduce waste material and therefore to forego printed products, including a printed program, session guide or abstract book. These were only available in online versions for download from the IAHR Congress website, to which was added the congress app, sponsored by the publishing house de Gruyter. As most participants were equipped with notebooks, tablets and smart phones and because the congress provided free WiFi, this was an easy and widely accepted way of finding sessions, speakers and venues. 
The academic program was supplemented by a number of receptions in the evening hours that were hosted by national associations of religious studies and publishing houses. These receptions are and were a welcome opportunity to meet colleagues and friends in a more informal atmosphere. The congress barbecue on Wednesday evening - after the traditional tour day, which gave our guests the opportunity to discover Erfurt and Thuringia - was the largest of these events, with more than 800 participants enjoying the food, drink and music.

The program of the IAHR Congress was made up of proposed panels and individually submitted papers. All papers submitted to the congress underwent anonymous peer review in order to ensure a high academic standard. The local organizing team, headed by congress directors Christoph Bochinger, Bayreuth, and Jörg Rüpke, Erfurt, approached sixteen leading scholars to act as program committee, reviewing more than 1600 proposals, most of which could, fortunately, be accepted. This policy produced a varied, stimulating and diverse program, the high quality of which many of our participants commented on.

The more than one hundred helpers from German and international universities ensured a smooth running of the congress, not only in the sessions, but in helping participants find their way around campus and helping and advising in numerous larger and smaller matters.

The congress ended Saturday, August 29, with the closing keynote 'Gilhus: Bodies, Texts and Otherness - Religious Change in Antiquity and Today' by Ingvild Gilhus, Bergen, and the General Assembly at the Altes Heizkraftwerk, Erfurt, which was generously made available for our use by the Achava-Festival.

Though a new executive committee of the IAHR was elected during the congress and the previous executive committee concluded their term of office, the host of the next IAHR Congress has not yet been decided on.

Tagung vom 8. bis 10. September 2015 in Manchester: 'Experiences of Sanctuaries, Experiences of Empire' (Anna-Katharina Rieger)

A joint research meeting of the Curere Network ("Cultural Responses to the Roman Empire") (resp. Katell Berthelot) and the "Sanctuary Project” (resp. Greg Woolf, financed by the Humboldt Foundation) was organized by Peter Oakes, a member of the network at Manchester. In a very convenient and concentrated atmosphere, about 25 participants discussed the religious dimension of the Roman Empire embracing Judaism, Christianity and Roman Eastern Mediterranean traditions. In particular, sanctuaries as places of 'condensed' religious and political activity and the reflections of such activities in texts were the focus of the contributions. The papers covered topics from the Jerusalem temple and its architectural language (S. Rocca) as well as its religio-political operationalisation in Graeco-Roman texts, mainly Flavius Josephus, and Midrashic texts (M. B. Shahar, V. Noam, M. Morgenstern) to traces of Christian 
communities in archaeological and epigraphical evidence at Philippi/Greece (P. Oakes). The Graeco-Roman religion was represented by papers on social networks and agents in two Dacian sanctuaries of Iupiter Dolichenus (C. Szabó), the role of literary production and collection in the functioning of Asklepieia in Asia Minor (G. Petridou) and the evidence in architecture but not in ritual practices of the emperors' worship in Southern Syria (A.-K. Rieger). A contribution on the Augusteum at a Pan sanctuary, built by king Herodes, discussed the ways of how Graeco-Roman traditions could merge with Jewish ones (R. Deines). The worship of gods modelled along the salutatio of the Roman elite and creating intimate experiences stimulated thoughts about the intertwined social and religious realms in the society of the urbs Roma (M. Patzelt). Some recurring issues were the value and end of architectural analogies, the definition of worship in Roman and Jewish contexts, as well as the aim and function of Midrashic texts, while aspects of economic entanglements of sanctuaries as well as a differentiation of templum in the sense of jurdical and spiritual templa were not covered by the papers. A highlight was the afternoon in the John Rylands Library, where Philip Alexander, expert in Jewish Literature, together with a curator explained an amazing selection of objects and manuscripts ranging from an Assyrian clay tablet to a Coptic papyrus, to coloured Bible and Tora manuscripts, and to a 19th century collection of Jewish amulets. The day ended with a tour through the reading rooms of the neo-Gothic library.

“Interrelational Selves and Individualization”, Winter School Max-Weber-Kolleg, 5-9 January 2016 (Martin Fuchs)

What do we mean when we talk of "the Self"? What do terms like self-realization, selfawareness, self-transformation, self-esteem, self-determination, self-surrender or self-transcendence refer to? What do images of an unfolding self, or of the cultivation of a self, connote? The Winter School examined philosophical debates on notions of self-hood against the backdrop of historical and comparative research about cultural concepts of selves. This includes processes of (religious) individualization. Instead of discussing authoritative conceptualizations of the self and selves, we focused on the difficulties, and on the debates involved, in exploring (or constructing) notions of self-hood. Thus we took up and discussed suggestions of a minimal self in relation or opposition to propositions of narrative, dialogical, relational or experiential selves. One assumption underlying the discussion was that the formation and/or exploration of (notions of) selves has to be seen within an interactionist frame, i.e. interactional relationships with other selves, as well as with the "world", including dimensions and selves that transcend what is directly accessible. (In this wide sense, the self can be understood as social.)

The questions arising from these considerations included the processuality (versus stability) of selves, the question of the non-self, as well as denials of the reality of 
selfhood, the relationship between concepts of self and concepts of identity (as well as non-identity), personhood and subjectivity (including self-responsibility), the role of, and relationship to, the body (one's own and the bodies of others), and the ownership of self. Thus, we investigated the modalities of selfhood. These reach from mutuality and respect, including identification with one's other, to somewhat antagonistic delineations of selves, to constellations characterized by the lack and need for recognition of selfhood and the power of self-determination of social beings. Aspects of passivity were included - the self as recipient of the activities of others - , as they encompass the dynamics of self-perception and perception by others. The winter school was organized by Martin Fuchs, Max-Weber-Kolleg, and Magnus Schlette, FEST, Heidelberg (Philosophy) with the participation of Thomas Fuchs, University of Heidelberg (Psychiatry, Philosophy), Jonardon Ganeri, New York University (Philosophy), Karen Joisten, University of Kassel (Philosophy), Angelika Malinar, University of Zürich (Indology, Philosophy), Chakravarthi Ram-Prasad (Lancester, Philosophy) and Dan Zahavi, University of Copenhagen (Philosophy).

\section{„Zum Verhältnis von Erfahrung und Normativität. Interdisziplinäre Perspektiven“, Workshop anlässlich des 75. Geburtstags von Prof. Dr. Dietmar Mieth vom 21. bis 22. Januar 2016 am Max-Weber-Kolleg (Antje Linkenbach)}

Mit der Frage nach dem Verhältnis von Normativität und Erfahrung griff der Workshop ein Thema auf, das für den Theologen und Sozialethiker Dietmar Mieth, langjähriger Fellow des Max-Weber-Kollegs, eine zentrale Herausforderung darstellt. Das Phänomen Erfahrung wurde im Kontext des Workshops in einem lebensweltlich-alltäglichen Sinn einerseits und in einem außeralltäglichen signifikanten Sinn andererseits thematisiert (und nicht in seiner Relevanz für die positivistischen Wissenschaften). Die Veranstaltung hatte einen explorativen Charakter; sie näherte sich dem Thema aus interdisziplinärer Perspektive und war auch interessiert, die empirische Relevanz theoretischer Überlegungen zu berücksichtigen. Mit Theologie, Philosophie, Soziologie, Anthropologie, Ökonomie und Religionswissenschaft repräsentierten die teilnehmenden Wissenschaftlerinnen und Wissenschaftler ein breites disziplinäres Spektrum. Der Workshop versuchte eine Verständigung über den hier relevanten Normenbegriff, der im Kern moralisch gedeutet wurde (Dietmar Mieth, MaxWeber-Kolleg). Weiterhin wurde der Erfahrungsbegriff in seinen Formen, Dimensionen, Hierarchien, Intensitäten und Dramatisierungen vor allem aus pragmatistischer Sicht und damit als Resultat von Situation und Kontingenz diskutiert (Matthias Jung, Universität Koblenz; Andreas Pettenkofer, Max-Weber-Kolleg). Die Frage nach der Handlungs- und Gestaltungskraft von Erfahrung schlug die Brücke zu der Ebene der Normen und reflektierte ihre Fähigkeit zu Begründung, Erhalt, aber auch zu Kritik und Transformation normativer Ordnungen (Ludwig Siep, Universität Münster; Andrea Esser, Universität Jena; Bettina Hollstein, Max-Weber-Kolleg). Eher skeptische 
Sichtweisen auf den Erfahrungsbegriff kamen aus dem Kontext der protestantischen Erfahrungs- und Erlebniskritik und der Max-Weber-Forschung (Gesche Linde, Universität Rostock; Johannes Weiß, Universität Kassel; Carsten Hermann-Pillath, MaxWeber-Kolleg). Für die Bestimmung des Verhältnisses von Normativität und Erfahrung besitzt das Phänomen der Kontrasterfahrung als Wurzel von Gesellschaftskritik besondere Relevanz (Christoph Henning, Max-Weber-Kolleg). Diese These konnte anhand von Exklusions- und Missachtungserfahrungen marginalisierter Gruppen in Indien vertieft und konkretisiert werden (Martin Fuchs, Antje Linkenbach, beide MaxWeber-Kolleg). Die Tagung ging mit einer abschließenden Gesprächsrunde zum Thema „Normativität und Gesellschaftskritik“ zu Ende, in der die Erkenntnisse des Workshops im Lichte zukünftiger Projektplanung am Max-Weber-Kolleg ausgewertet wurden.

„Religiösen Zweifel denken“, Tagung im Rahmen der Kolleg-Forschergruppe „Religiöse Individualisierung in historischer Perspektive“ vom 11. bis 12. Februar 2016 am Max-Weber-Kolleg (Veronika Hoffmann)

Traditionell galt religiöser Zweifel im Christentum in aller Regel als eine Bedrohung des Glaubens. Diese Sicht wird jedoch in jüngerer Zeit zunehmend in Frage gestellt und der Zweifel demgegenüber z.B. als Sicherungsmechanismus gegen fundamentalistisch-intolerante Engführungen oder als kritischer Begleiter einer intellektuell redlichen religiösen Überzeugung verstanden. In der theologischen Reflexion ist diese Frage bisher nur begrenzt aufgegriffen worden. Unter den Bedingungen aktueller religiöser Pluralisierung und Individualisierung und eines aggressiv auftretenden atheistischen Naturalismus muss sie jedoch als ein wesentlicher Aspekt wissenschaftlicher Reflexion auf Religion betrachtet werden. Dazu wollte die Tagung „Religiösen Zweifel denken“ einen Beitrag leisten, die am 11./12. Februar 2016 am Max-WeberKolleg stattfand.

Das Augenmerk richtete sich dabei zum einen auf die Vielfalt der möglichen Perspektiven und Zugänge, die sich aus der Mehrdeutigkeit des Begriffs „Zweifel“ ergeben: So kann Zweifel aus erkenntnistheoretischer Sicht in seiner Anfrage an bestehende Vorstellungen und Grundannahmen neue Räume der Interpretation öffnen. Er kann sich aber auch in stärker existenzieller Hinsicht äußern: als verunsichernde Infragestellung von etwas, das zentrale Bedeutsamkeit besitzt, oder als Vertrauenskrise. Zum anderen lassen sich mehrere mögliche Deutungshorizonte unterscheiden, die unter Umständen miteinander in Spannung treten. Deutungen aus einer religiösen Innensicht heraus, die beispielsweise auf der Linie der reformatorischen Konzeption der „Anfechtung“ Zweifel als Glaubensprüfung verstehen, versuchen in der Regel, dem Zweifel einen Ort im Raum des Glaubens zu geben. Solche Innendeutungen lassen sich aber heute nicht mehr von den zugleich möglichen Außendeutungen ei- 
ner kritischen Anfrage an den Glauben abschotten. Dementsprechend sind auch theologische Gewissheitskonzepte unter Bedingungen verschärften Pluralitäts- und Kontingenzbewusstseins nicht mehr in traditioneller Weise zugänglich. Eine Neukonzeption des religiösen Gewissheitsbegriffes - möglicherweise in Fortführung von Überlegungen zur „kontingenten Gewissheit“ (Joas) oder der „zweiten Naivität“ (Ricœur) - ist, so zeigten die Diskussionen der Tagung, ein theologisches Desiderat.

In den Blick rückte außerdem das Verhältnis religiösen Zweifels zu einem Verständnis individueller „Authentizität“. Das Ideal einer Treue zu sich selbst verbietet das Festhalten an einem Glauben, der einem zutiefst zweifelhaft geworden ist. Aber wie genau wären hier Elemente des Willentlichen und des Widerfahrenden im Blick auf Glaube und Zweifel zueinander ins Verhältnis zu setzen? Und in welcher Weise wäre die theologische Dimension der Gnade einzutragen, die Gott auch dem Zweifelnden oder den Glauben Verlierenden nicht entzieht?

Die Tagung ging diesen Fragen aus unterschiedlichen konfessionellen, theologischen und religionsphilosophischen Perspektiven nach. Veronika Hoffmann (Erfurt/ Siegen) skizzierte einleitend „veränderte Bedingungen des Zweifels“ unter der Perspektive der von Charles Taylor analysierten „,veränderten Bedingungen des Glaubens“. Jürgen Werbick (Münster) lotete traditionelle Umgangsweisen mit dem Zweifel in der lutherischen Anfechtung und der Mystik auf ihr Anregungs-, aber auch Irritationspotenzial für den aktuellen Zweifelsdiskurs aus. Im Blick auf aktuelle soziologische „Dekonversions“-Studien widmete sich Karsten Lehmkühler (Straßburg) dem Thema eines von der Wahrhaftigkeit gegenüber sich selbst geforderten Glaubensverlustes und seinen theologischen Deutungen, während Andreas Koritensky (Paderborn) Ansätze einer virtue epistemology im Blick auf mögliche Fehlformen religiöser Urteilsbildung vorstellte. In einer „Theorie imaginativer Rationalität“, wie sie Gregor Maria Hoff (Salzburg) skizzierte, lässt sich der Zweifel epistemologisch als Erweiterung von Interpretations- und Handlungsmöglichkeiten lesen. Maureen JunkerKenny (Dublin) zeigte kritisch insbesondere an Habermas' Verständnis von Religion, wie dieses von Gewissheitsunterstellung ausgeht, und stellte ihm differenzierende Zugänge Paul Ricœurs in der Figur der „Bezeugung“ (attestation) und einer „zweiten Naivität“ nach dem Durchgang durch die „Wüste der Kritik“ entgegen. Abschließend entwarf Michael Bongardt (Berlin) eine dreifache Phänomenologie des Zweifels: an der Kirche, am Glauben, an Gott, und akzentuierte gegenüber einem Zweifel an Glaubensvorstellungen die dem religiösen Glauben eigentümlichen Dimensionen der Beziehung und des Vertrauens, die möglicherweise das Zerbrechen bestimmter religiöser Konzepte sogar voraussetzten. 
„Eine Lichtung des deutschen Waldes - Mystik, Idealismus und Romantik“, Tagung der Meister Eckhart-Forschungsstelle vom 19. bis 21. Mai 2016 am Max-Weber-Kolleg (Andrés Quero-Sánchez)

Die Tagung fand im Rahmen des von der Deutschen Forschungsgemeinschaft finanzierten Forschungsprojekts: „Der ewige Begriff des Individuums“: Eine historischphilologisch-systematische Untersuchung der ,mystischen Vernunft“ und deren Rezeption im Werk Schellings (QU 258/3-1) sowie in Zusammenarbeit mit der KollegForschergruppe „Religiöse Individualisierung in historischer Perspektive“ (KFOR 1013) im Erfurter Predigerkloster und IBZ statt. Die Internationale Tagung hat die interdisziplinäre Diskussion zwischen Historikern, Germanisten, Theologen und Philosophen aus verschiedenen Ländern (Deutschland, Österreich, Spanien, Frankreich, Großbritannien; USA und der Schweiz) ermöglicht sowie die folgenden Themenkomplexe untersucht:

(1) Kann man Eckharts ,Mystik‘ als eine idealistische Form des Denkens auffassen? Wenn ja, inwieweit (Dietmar Mieth [Erfurt]: Bild und Begriff bei Meister Eckhart; Marie-Anne Vannier [Metz]: Eckhart und der Idealismus)?

(2) Die Frage nach den konkreten Editionen der Schriften Meister Eckharts, die dessen Rezeption im 18./19. Jahrhundert ermöglicht haben (Janina Franzke [Augsburg]: Der Baseler Taulerdruck; Rudolf Weigand [Eichstätt]: Speners Tauler-Ausgabe).

(3) Die nationalsozialistische Rezeption Meister Eckharts (Henning Dörr [Köln]: Meister Eckhart in Rosenbergs ,Mythos des 20. Jahrhunderts‘; Martina Roesner [Wien]: Vom ,deutschen Geist‘ zum ,deutschen Willen'; Christoph Henning [Erfurt]: Meister Eckhart und Hermann Schwarz; Maxime Mauriège [Köln]: Die Frage nach der nationalsozialistischen ,Rechtgläubigkeit‘ Eckharts in den 30er Jahren).

(4) Der Zusammenhang zwischen Mystik und Romantik (Peter Nickl [Regensburg]: Brentano und die Mystik; Bärbel Frischmann [Erfurt]: Friedrich Schlegel und die Mystik; Alexandra Besson [Université de Lorraine]: Novalis und die negative Theologie).

(5) Der Zusammenhang zwischen Platonismus, Idealismus und Mystik (Theo Kobusch [Bonn]: Der Begriff ,Selbstentäußerung‘; Andrés Quero-Sánchez [Erfurt]: Der Begriff ,Korruption‘; Jens Halfwassen [Heidelberg]: Die Anfänge des Deutschen Idealismus im Tübinger Stift).

(6) Die Rolle der Mystik in Fichte (Ives Radrizzani [München]: Fichtes Kritik am Mystischen; Christoph Asmuth [Berlin]: Meister Eckhart und Fichte).

(7) Die Rolle der Mystik im Werk Schellings (Markus Enders [Freiburg]: Die Freiheit Gottes bei Eckhart und Schelling; Ben Morgan [Oxford]: Eckhart, Schelling und Heidegger; Lore Hühn [Freiburg]: Der Begriff ,Gelassenheit‘ in Schellings Spätwerk; Harald Schwaetzer [Bernkastel-Kues: Franz von Baader; Christian Jung [London]: Emanuel Swedenborg; Christian Danz [Wien]: Schellings ,Stuttgarter Privatvorlesungen').

(8) Die Rolle der Mystik in Hegel (Glenn Magee [New York]: Hegel und Böhme).

(9) Die Rolle der Mystik in Hölderlin (Markus Vinzent [London/Erfurt]: Eckhart und Hölderlin). 
Der Tagungsband wird von A. Quero-Sánchez herausgegeben, er erscheint im Jahre 2017 bei Brill (Leiden/Boston) (Reihe: Studies on Mysticism, Idealism and Phenomenology/Studien zu Mystik, Idealismus und Phänomenologie).

„Storiografia II“, Tagung mit FSC Modena und EPHE Paris vom 16. bis 17. Juni 2016 in Modena (Jörg Rüpke)

Unter dem Titel „Storiografia: Ricerca storica e scrittura del passato II“ wurden am 16. und 17. Juni 2016 an der Fondazione San Calo in Modena die Zusammenarbeit von FSC, Ecole Pratique des Hautes Etudes, Paris, und dem Max-Weber-Kolleg Erfurt mit einer weiteren gemeinsamen Tagung der Doktorandenprogramme fortgesetzt. Zwei Tage lang wurden klassische Werke der Historiographie und Probleme der Geschichtsschreibung in Vorträgen und Diskussionen beleuchtet. Dabei ging es etwa um Philosophiegeschichtsschreibung seit der Antike (etwa bei Plotin und Simplicius), um Geschichtsbilder bei Nietzsche und eschatologische Motive in der zeitgenössischen französischen Philosophie. Für die historiographische Tradition Italiens wurde nach der faschistischen Nutzung der Anthropologie des 19. Jahrhunderts wie der Memorialkultur des 20. gefragt, für Ungarn nach den internationalen Netzwerken der eigenen Nationalgeschichtsschreibung. Beiträge aus Erfurt betrafen die These, dass „Christentum“ ein Konstrukt der Historiographie des 2. Jahrhunderts sei (J. Rüpke), die Umdeutungen der Geschichte des Samaritaners (D. Mieth) und jüngere methodische Reflexionen zur Verflechtungsgeschichte in Deutschland (R. Suitner). Für 2017 wurde das Thema „Tradition und Traditionskritik“ ins Auge gefasst. Geplant ist die Tagung für den 22. und 23. Juni 2017.

\section{„Bhakti and Self“, Tagung vom 21. bis 24. Juni 2016 am Max-Weber-Kolleg (Martin Fuchs)}

Insofar as one can generalize about bhakti, one aspect that seems to stand out is the element of creativity and innovation characteristic of this religious strand. Over long stretches of Indian history, bhakti was recurrently renewed, exemplifying new forms of experience and inventing new modes of articulation. Observed from a certain angle, bhakti exhibits potentials for religious individualization that many (though not all) forms of bhakti have tapped into and that differ from the forms of individualization represented by the figure of the renouncer elaborately discussed elsewhere (notwithstanding cases in which both modes of religious individualization can be combined). A particularly characteristic of bhakti is the emphasis put on the relational aspects of human experience manifested in (imageries of) continual interactions with the divine, or the divine's representative, as well as in continual interactions with 
other bhaktas. It is this kind of inner social dynamics that lends itself to an exploration of the inter-relational dimensions of self/selves, and of individual identity and personhood as they have been or still are articulated by different formats of bhakti. As lived religion(s), this perspective on bhakti provides an angle different from largely philosophical or theological debates over concepts of selfhood, soul, or atman. While research on bhakti has been burgeoning over the last two or three decades, particularly in India and North America, the aspect of relationality of selves has so far not received the attention it deserves.

The conference on "Bhakti and Self", held at the Max-Weber-Kolleg Erfurt, in the context of the research group "Religious Individualization in Historical Perspective" (KFG) and organized by Martin Fuchs together with Rahul Parson, discussed notions of selfhood, individualization and inter-subjectivity articulated in bhakti contexts covering different periods and regions of South Asian history. In his introductory presentation, Martin Fuchs (Max-Weber-Kolleg Erfurt) focused on the dimensions and implications of the triangular relationship between a bhakti devotee (bhakta), the divine and other bhaktas, and its resonances with certain modes of sociological thinking. Karen Pechilis (Drew University) discussed the relationship between ordinary and extraordinary people and the possibility of an ordinary, everyday individualism taking up a comparison within Tamil religious intertextuality between the 6thcentury female bhakti poet Kāraikkāl Ammaiyār's poetry and the authoritative 12thcentury biography of her authored by Cēkkilār. Anne Feldhaus (Arizona State University) engaged with 13th-century Marathi literature of the Mahānubhāvs and their views of the selfhood of divine incarnations focussing on devotees' views of the subjectivity of the group's two principal divine incarnations: Cakradhar, the founder of the group, and Gundam Rāül, his guru. Again with respect to Maharashtra, in this case Jnandev and his work known as the Jnaneshwari, a commentary on the Bhagavad Gita (c. 1290 CE); Christian Novetzke (University of Washington) discussed the work's soteriological critique of inequality and the conceptual field where unequivocal demands for social equality meet the complications of social distinction endemic to everyday life. Like Novetzke, Purushottam Agrawal (Delhi) started from questioning the idea that concepts of freedom attached to notions of the individual is the sole purview of the modern West. Focussing on Kabir who is known for his unique poetic power and his outright and sarcastically expressed rejection of the varnashrama hierarchy, he depicted his idea of 'Self' as the most articulate expression of the philosophical notion of the individual in the early modern north India. Vasudha Dalmia (University of California, Berkeley) discussed the Vallabha Sampradaya 16th-century compendium, the Do sau Bavan Vaishnavan ki Varta, emphasizing the tension between community belonging and the depiction of the model devotees as different from the ordinary people, between reciprocity and excess. With respect to the transregional lyrical networks of bhakti saint-poets of the 16th and 17th century, John Stratton Hawley (Barnard College) discussed the ways in which the saliency of self- 
hood was both affirmed and denied. In her presentation on Tulsidas, Vasudha Paramasivan (University of California, Berkeley) raised the question whether it is possible to speak about the fashioning of a "poetic self". Jon Keune (Michigan State University) highlighted how bhakti theology shaped the ways that Marathi authors represented the selves and voices of Untouchables, referring in particular to Eknath and Chokhamela. On the background of changing narratives of the Bavari panth, Till Luge (Orient Institute, Istanbul) discussed the relationship between the construction of both social distinctions and spiritual practice. Heidi Pauwel's (University of Washington) presentation on the 18th-century autobiographical pilgrimage report of the Krishna bhakta Nagaridas (Savant Singh) discussed his depiction of his self-transformation. Taking the case of the autobiography of Piro, a Muslim prostitute who joined the Gulabdasi dera (19th century), Anshu Malhotra (Delhi University) followed up on how Piro deployed and expanded on bhakti's repository of stories and legends as a resource that allowed her to "imagine herself otherwise", envisage a soteriological path for herself and take her place next to her guru as an ostensible consort in the dera. Turning to the 20th century and somewhat reversing the perspective, Denis Matringe (École des Hautes Études en Sciences Sociales, Paris) discussed the bhakti of a French 20th-century Indologist, Lilian Silburn who became a follower of a Hindu Sufi (Naqshbandi) guru in Kanpur, Radha Mohan Lal Adhauliya. Rinku Lamba (Jawaharlal Nehru University, New Delhi) undertook a comparison of the approach to self in (sant) bhakti with the kind of subject/self envisioned in the writings of Gandhi, Tagore, and Ambedkar on the question of religion. In the final paper, Kumkum Sangari (University of Wisconsin) deliberated on the contingency and instability of the self as mode of continuation; she emphasized that bhaktas did not express a given self but sought producing a self. The final discussion addressed the diversity and potientialities and the wide range of explorations of the relationality of self in the field of bhakti, a field that calls for further explorations. The intention is to publish the papers.

„Towards a Global History of Ideas“, Tagung der Kolleg-Forschergruppe „Religiöse Individualisierung in historischer Perspektive“, in Kooperation mit dem Forschungszentrum Gotha vom 7. bis 9. Juli 2016 im Augustinerkloster in Erfurt (Martin Mulsow)

In den vergangenen Jahren war zu beobachten, wie eine ganze Reihe wissensgeschichtlicher Disziplinen sich „globalifizieren“ (Jürgen Osterhammel), d.h. auf die Globalisierung mit einer Ausweitung ihrer Agenda reagieren. Man spricht von einer „Global History of Science“, von „World Antiquarianism“, „World Philology“, „Global Art History“ und neuerdings auch von einer „Global Intellectual History“, angeregt nicht zuletzt von Christopher Bayly. Der Tagung ging es darum zu konkretisieren, 
was denn eine solche globale Ideengeschichte sein könne, wie sie sich von den anderen Globalgeschichten abgrenzt und welche Kategorien sie benötigt. Sie konzentrierte sich auf drei Aspekte: (1) Erfahrungen mit der Globalifizierung von Wissensund Ideengeschichte, Probleme, institutionelle Konsequenzen. (2) Spezifische Probleme, wenn es um eine Globalifizierung der Forschung zur Vormoderne geht, also vor der Zeit der akuten Globalisierung des 19. und 20. Jahrhunderts. Wie sind die „entanglements“ dieser frühen Phasen weltweiter Interdependenz, insbesondere in der Frühen Neuzeit, zu analysieren? (3) Wechselwirkungen zwischen den diversen Bereichen globalifizierter Wissensgeschichte. Eingeladen waren zahlreiche prominente Forscher der internationalen Diskussion.

Nachdem Martin Mulsow (Erfurt/Gotha) den Entwurf einer Referenztheorie der Globalisierung vorgestellt hatte, gab Sebastian Conrad (Berlin) am Beispiel der Rezeption von Zolas Nana einen Eindruck von den vielfältigen globalen Aneignungen kultureller Stoffe im 19. Jahrhundert. Jürgen Renn (Berlin) stellte die komplexe Kategorien-Matrix vor, mit der am MPI für Wissenschaftsgeschichte in Berlin Globalisierung des Wissens erforscht wird, und Hans Medick (Göttingen) zeigte anhand von chinesischen Erfahrungen die globalen Potentiale von Mikrohistorie auf. Als Abendvortrag sprach Jan Assmann (Konstanz) von Offenbarung als globalem Phänomen. Am nächsten Tag begannen Iris Schröder (Erfurt) und Benjamin Steiner (Erfurt) mit Vorträgen über Afrika: Schröder erörterte die Problematik von kartographischen Grenzziehungen am Fall von Äthiopien, Steiner die Schwierigkeiten, eine intellectual history von oralen und kolonial durchwirkten Kulturen zu erstellen. Dominic Sachsenmaier (Göttingen) nahm sich danach der paradoxen Ungleichheit an, mit der Globalgeschichtsschreibung heute praktiziert wird: an angloamerikanischer Forschung wird alles rezipiert, doch Forschungen aus exotischen Ländern oder Ostasien werden nicht wahrgenommen. Stefan Hanß (Cambridge) stellte ein Skizzenbuch aus dem Istanbul des 16. Jahrhunderts vor, das als wahres islamisch-europäisches Hybridprodukt in diplomatischen Zirkeln entstanden war, dessen Bilder aber in diverse westeuropäische Türkentraktate Eingang fanden. Auch Carlo Ginzburg (Pisa) ging es um Hybridphänomene. Er zeigte am Beispiel des Inka-Historiographen Garcilaso de la Vega, welche intrikaten Fragen linguistischen Transfers sich in Fällen stellen, in denen Ideen zwischen den Kulturen ausgetauscht werden, so dass es einer „Ethnophilologie“ bedürfe, die sich ihrer annimmt. Kapil Raj (Paris) untersuchte die Vielfalt der Akteure, die sich in der Kartenproduktion insbesondere in Indien zusammengefunden hat. Anna Akasoy lenkte schließlich die Aufmerksamkeit auf die islamische Welt: Ist das intellektuelle „Erbe“ des Islams aus Sicht der Europäer vorgeprägt durch deren Wahrnehmungsraster?

Am letzten Tag erwies Knud Haakonssen (Erfurt/St. Andrews) dem großen Ideenhistoriker John G.A. Pocock die Ehre, indem er den Neuseeländer als „Insel-Theoretiker" beschrieb, der als solcher eine besondere Sensibilität für Globalgeschichte und Transmissionen entwickelt habe. Paola Molino (München) stellte ihr Projekt einer 
vergleichenden Geschichte der Bibliotheks-Katalogisierungen vor und verstärkte damit das Moment der Praktiken, auf das heutige Ideengeschichte immer zurückkommt, um sich vor unangebrachten „Höhenflügen“ und Gipfelgeschichten zu schützen. Abschließend kam dann Gerhard Wolf (Florenz) mit einhundert Bildern von asiatischeuropäischen Mischformen und Transferphänomenen aus Kunst und materieller Kultur auf die visuellen Aspekte zurück, die schon zuvor thematisch waren. Er schlug vor, an Panofskys Idea und an Warburg anzuknüpfen, wenn man den ideengeschichtlichen Aspekt von visueller Kultur fassen wolle. Insgesamt eröffnete die Konferenz damit einen bunten Strauß von Fragen und Forschungsansätzen, die alle noch weiter diskutiert werden müssen. Es wurde deutlich, dass hier noch keine Disziplin vorliegt, sondern ein neues und undefiniertes Feld, auf das Beiträge von verschiedensten Richtungen getragen werden. So aber war die Tagung auch gemeint gewesen: als ein erstes Vermessen eines künftigen Faches, das noch seine Kontur sucht. Einige der Beiträge werden als erstes Heft der neuen Zeitschrift Global Intellectual History veröffentlicht werden.

„Wolveramus dicitur. Neue Überlegungen zu Entstehungskontexten und Funktionen der ältesten lebensgroßen Bronzestatue des deutschen Mittelalters“, Tagung am 25. August 2016 am Max-Weber-Kolleg (Matthias Engmann)

Unter der Leitung von Jörg Rüpke, Dietmar Mieth und Julie Casteigt haben sich am 25. August 2016 im Internationalen Begegnungszentrum der Universität Erfurt (IBZ) dreizehn Wissenschaftler aus den Gebieten der Kunsthistorie, Werkstoffwissenschaft, Theologie, Philosophie, antiker und mittelalterlicher Geschichte zusammengefunden, um die Entstehung und Verwendung des Kandelabers „Wolfram“ im Mariendom zu Erfurt zu erörtern und anhand von neuen Daten zu diskutieren.

In der ersten Sektion der Tagung - Das Objekt - hebt zunächst Norbert Schmidt die stilistischen Merkmale des Wolfram hervor. An ausgewählten Beispielen zeigt er, dass man sowohl aus der Physiognomie, der Haar- und Bartgestaltung als auch aus der dargestellten Bekleidung und dem speziellen Faltenwurf, die so oder ähnlich auch woanders in der Kunstgeschichte zu finden sind, kaum ein bestimmtes Jahrzehnt und sogar nur mit Vorsicht ein bestimmtes Jahrhundert der Entstehungszeit ablesen lässt. Darüber hinaus könne man versucht sein, dem Künstler/Stifter/Auftraggeber zu unterstellen, dass (abgesehen von dem kleinen Futteral) sämtliche zur Identifikation und Interpretation der Figur nötigen Attribute bewusst weggelassen worden sind, um tatsächlich ein anthropomorphes Gerät (Leuchter) ohne persönliche Zuschreibung zu schaffen. Hiltrud Westermann-Angerhausen vergleicht den Wolfram mit anderen Bronzen aus dem gleichen Zeitraum und stellt unter anderem die Hypothese auf, dass es einzig den Überlieferungsumständen (Kriege, Wiederverwendung von Bronze) zugeschrieben werden muss, dass nur ein einziger mittelalterlicher, freistehender Personenleuchter überliefert ist. Außerdem stelle er lediglich eine 
Anthropomorphisierung dar und keine Personifizierung, was für die Memorialkultur normal war und auf keine weitere Funktion schließen lassen muss als die, dass er ein Kandelaber ist. Schließlich zeigt Bernhard Mai anhand seiner metallurgischen Untersuchungsergebnisse, dass Kopf und Hände des Wolfram separat und dass die Inschrift zusammen mit dem Torso gegossen wurde (und nicht im Nachhinein eingestanzt worden sei).

In der zweiten Sektion der Tagung - Die Inschrift - stellt zunächst Franz Jäger im Vergleich mit anderen Bronze-Inschriften heraus, dass die Buchstabenform des Wolfram romanische Merkmale aufweist und nicht nach dem 12. Jh. hergestellt worden sei. Michael Matscha erwähnt, dass Wolfram und Hildeburg die Namen der Stifter sind (wobei die einnamige Nennung seit dem 12. Jh. üblich ist). Durch philologische Untersuchung und Kontextualisierung der Inschrift, die in Teilen sogar bis auf das 10. Jh. zurückverfolgt werden kann, wird diese zwischen das 12. Jh. und (nicht später als) Mitte des 14. Jh. datiert. Dietmar Mieth plädiert sodann auf die Hermeneutik der Untersuchung: Was bedeutet der Wolfram? Dabei wird Wolfram in den liturgischen Kontext des Stundengebets und Responsoriums gestellt, wobei zwischen einem okkasionellen und rituellen Gebrauch des Wolfram unterschieden wird. Und er plädiert anhand einer historisch-liturgischen Deutung der Inschrift darauf, dass diese um das 14. Jh. entstanden ist. In der anschließenden Diskussion wird mehrfach darauf hingewiesen, dass der Wolfram zwar erst 1425 genannt wird, aber schon davor in Gebrauch gewesen sein muss, und zwar an verschiedensten Orten/Kirchen Erfurts.

In der dritten Sektion der Tagung - Leuchter, Licht - präsentiert Frank Joachim Stehwig, die vorhergehende Diskussion aufgreifend, zunächst seine Ergebnisse zur Recherche der Statuten der juristischen Fakultät. In deren Beschreibung der Feierlichkeiten für das Patronatsfest der Fakultät am Tag des hl. Ivo (am 19. Mai im Chor der Erfurter Stiftskirche St. Marien, heute Dom) wird der Wolfram-Leuchter erstmals erwähnt. Diese Quelle wird sodann mit den 1270/1280 entstandenen Statuten der Stiftskirche abgeglichen. Dort ist im Zusammenhang mit einem Statut ein großer Leuchter erwähnt, der in der Nähe des Hochaltars im Chor der Kirche an exponierter Stelle stand und dem eine wichtige liturgische Funktion zukam. Vera Henkelmann erörtert sodann die symbolisch-funktionale Bedeutung der Beleuchtung im kirchlichen Kontext und verortet den Erfurter Leuchter in der Tradition der mittelalterlichen Sakralleuchter. Der sogenannte Wolfram erweist sich hierbei als Memorialleuchter, der jedoch nicht zwingend an einem Grab gestanden haben muss. Johannes Tripps unterstreicht schließlich die Zugehörigkeit des Wolfram-Leuchters zu den sogenannten „stummen Gehilfen“ (anthropomorphe Altargeräte), die zwischen 1150 und 1250 entstanden sind und im Laufe des 13. Jh. durch angelomorphe Altargeräte abgelöst werden. Im Gegensatz zu allen anderen Beispielen der „stummen Gehilfen“ trägt der Wolfram z.B. kein liturgisches Gewand, das rein stilistisch unter dem „Druck“ der Konstruktion steht (der Faltenwurf ist aus Gründen der Stabilität so gestaltet). In der vierten Sektion der Tagung - Rituale/Judeneid - interpretiert Jörg Rüpke die an den Erfurter Judeneid geknüpften Rituale als solche zwischen öffentlichem und privatem 
Raum. In diese Spannung verortet er den Wolfram als zwischen Kontexten und Orten changierenden Funktionsträger von öffentlichen Ritualen. Er vertritt die Thesen, dass Wolfram, neben seiner Funktion als Kandelaber auch die Funktion einer vor der Kirche stehenden Torarollenhalters innehatte, wie auch, dass Wolfram (teils prozessionsartig) die religiösen Räume wechselte und deshalb mobil sein musste (und deshalb nicht am Sockel festgemacht sein durfte). Letztlich laufe diese Betrachtungsweise auf eine Methodik hinaus, die materiale Befunde mit zeitgenössischen Praktiken zusammendenken will. In der fünften Sektion der Tagung - Bilderwelt - unterstreicht Naomi Feuchtwanger-Sarig, dass zunächst das Problem besteht, dass es keine Vergleichsobjekte zum Wolfram gibt, betont aber ihre Überzeugung, dass er nur in einem christlichen Kontext denkbar ist und nicht als Torarollenhalter fungiert haben kann, was - neben einer detaillierten Analyse der Attribute des Wolfram - auf ihr Hauptargument zurück geht, dass die Tora das Heiligste ist, das weder berührt werden darf noch (öffentlich) ausgerollt wird. Markus Vinzent unternimmt sodann (ebenso wie der darauffolgenden Vortrag von Julie Casteigt) einen Wechsel zu einer allgemeineren Perspektive. Er insistiert auf eine methodologische Fokussierung der hermeneutisch-kontextualisierenden Entschlüsselung der Wolframfigur. Während Vinzent anhand von Meister Eckharts Umgang mit Bibelexegese und Schriftpraxen eine hermeneutische Bewegung betont, die zwischen jüdischem und christlichem Denken changiert, hebt Casteigt - anhand von Albert dem Großen - eine Bewegung heraus, die vom jüdischen auf das christliche Denken hingeht. Hierbei wird letztlich keine synthetische, sondern eine „kondensative“ Betrachtungsperspektive verfolgt (Casteigt), also eine, die Möglichkeiten eröffnet, bereitstellt und ernstnimmt und dabei auch von dem Grundsatz geleitet ist, dass es sowohl im hochkulturellen wie auch sozialem Bereich mittelalterlichen Lebens keine Trennung zwischen christlicher und jüdischer Kultur (in Erfurt) gab (Vinzent). Am Schluss einigten sich die Experten und Teilnehmer auf das Ergebnis, dass der Wolfram nicht jüdischen, sondern definitiv christlichen Ursprungs ist und aus dem 12. Jh. stammt. Über die Frage, ob der Wolfram-Leuchter als „reiner“ Kandelaber genutzt wurde oder nicht, gab die Tagung wichtige Anregungen und zeigte den weiteren Forschungs- und Diskussionsbedarf.

Tagung in Zusammenarbeit mit SOAS der University of London vom 8. bis 10. September 2016 in London: 'Max Weber's Hinduism and Buddhism. Reflections on a Sociological Classic 100 Years on' (Martin Fuchs)

Max Weber's study of Hinduism and Buddhism, published as the second volume of his Gesammelte Aufsätze zur Religionssoziologie (Collected Essays on the Sociology of Religion) and touching upon, besides religion, social structure, political and economic history, and scientific achievements of the Indian civilizational region, while outdated and controversial in several respects, has not received the attention it deserves, neither among scholars of South Asia, who often do not understand the place of the 
study within Weber's œuvre, nor among sociologists who have engaged with Weber's theories and agendas but usually lack knowledge and an understanding of the religious and the general history of the Indian subcontinent and its social structures. The conference on the occasion of the 100th anniversary of Weber's "India study" brought together scholars from both these backgrounds who, to a lesser or greater degree, have been involved in attempts to overcome this lacuna. Scholars from South Asian countries, however, remained underrepresented, the reason being that, other than his general sociology, Weber's comparative sociology of religion and his work on India have never attained much interest in South Asian scholarship.

The keynote, at least, was given by one of the most renowned Indian scholars, the historian Romila Thapar (Jawaharlal Nehru University, New Delhi), who made a fresh attempt to come to terms with Weber's India and demanded an empirically and historically much more refined and sensitive approach to the study of South Asia. Several contributors took up concepts of Weber or engaged with his depiction of specific dimensions of Indian civilizational history. Stephan Kalberg (Boston) reconstructed Weber's depiction of the different life orders in the Indian context. Wolfgang Schluchter (Heidelberg) discussed Weber's multiple intra- and trans-civilizational comparisons. Andreas Buss (Ottawa) and Hans Kippenberg (Bremen) took up core concepts of Weber, Eigengesetzlichkeit and Entzauberung (often translated as disenchantment). Peter Flügel critically discussed Weber's rendering of Jainism against the background of modern scholarship. Sam Whimster (London) reconstructed the transition to capitalism with regard to Weber's views and with a special focus on the agrarian sector. Helwig Schmidt-Glintzer (Lichtenberg-Kolleg Göttingen) discussed Weber's understanding of the role of the literati in Hinduism and Buddhism borrowing from his knowledge of the Chinese case. Laura Ford (New York) reconstructed Weber's distinction between formal and substantive rationality and read Weber's inadequate understanding of the Indian legal tradition against his understanding of European natural law traditions. Hermann Kulke (Kiel) made a strong argument for the relevance of Weber's notion of legitimization for an understanding of state formation processes in Indian history. In a similar vein, David Gellner (Oxford) took issue with Sheldon Pollock and his critique of Weber's legitimation concept.

Other contributions went beyond Weber. Richard Gombrich (Oxford) applied Weberian ideas to an analysis of three Buddhist movements in modern Taiwan. Susantha Goonatilake (Colombo) attacked the Orientalism and Euro-centrism of Western scholars. Meghnad Jagdishchandra discussed Indian modernity from an economic angle. At the end, taking Weber's difficulties of doing justice to bhakti as a case in point, Martin Fuchs (MaxWeber-Kolleg Erfurt) discussed the potentialities and limitations of Weber's approach to intercultural comparison and the study of world religions and suggested a new conceptualization of Indian religious dynamics. Revisiting Weber's concept of "world" and of attitudes and relations to the world, he discussed possibilities of connecting certain dimension of Weber's conceptualization with the concept of world relations and articulations of the world of the likes of Maurice Merleau- 
Ponty, Johann Arnason, and Hartmut Rosa. The contributions of the conference will be published.

Sixth International Conference of the Society for the Study of Western Esotericism vom 1. bis 3. Juni 2017 (Bernd-Christian Otto)

Die sechste internationale Tagung der Society for the Study of Western Esotericism fand vom 1. bis 3. Juni im Augustinerkloster in Erfurt statt. Insgesamt nahmen etwa 160 Wissenschaftler aus aller Welt an der Tagung teil. Das Tagungsprogramm umfasste drei volle Tage, insgesamt etwa hundert Einzelvorträge, die gestaffelt in vier parallelen Panels stattfanden. Ferner gab es an jedem der drei Tage eine Keynote Session, in der jeweils drei etablierte Wissenschaftler kürzere, ineinander verzahnte Vorträge hielten, die in der zweiten Stunde mittels einer strukturierten Plenardiskussion besprochen wurden. Am zweiten Tag wurden zudem ein Workshop zu Kompetenzen von Nachwuchswissenschaftlern sowie zwei kürzere Führungen (eine Kloster- und eine Stadtführung) angeboten. Am ersten Abend gab es einen von der Foundation of the Chair of Hermetic Philosophy and Related Currents finanzierten Empfang im Renaissancehof des Augustinerklosters.

Die Tagung war nicht nur aufgrund der insgesamt geglückten Organisation, des tollen Ambientes, des guten Wetters und der großen nationalen wie internationalen Resonanz und Teilnehmerzahl ein großer Erfolg. Es war insbesondere das Konferenzthema - „Western Esotericism and Deviance“ -, das offenbar einen Nerv der gegenwärtigen Debatte getroffen hatte und zu fundierten wie fruchtbaren Diskussionen führte. Zum einen wurde das Meisternarrativ einer prinzipiellen kulturellen Ausgegrenztheit und Marginalität westlicher Esoterik (Stichwort „Rejected Knowledge“) neu aufgerollt und aufgebrochen; zum anderen wurden zahlreiche Fallstudien vorgestellt, die vor dem Hintergrund des Tagungsthemas viel nuanciertere Befunde boten, die nicht nur unterschiedliche Grade, sondern auch zeit- und ortsabhängige Progressions- und Dekadenzdynamiken hinsichtlich der kulturellen Akzeptanz oder Ausgegrenztheit esoterischer Strömungen anzeigten.

Namentlich zu nennen sind nicht nur die inspirierenden Beiträge der Keynote Speaker, etwa von Olav Hammer, Jay Johnston, Richard Gordon, Claire Fanger, Marion Gibson oder Martin Mulsow. Auch die Panels über „The Cultic Milieu Reconsidered“ (Egil Asprem, Kevin Whitesides), „Deviance and Orthodoxy in Islamic Esotericism“ (Mark Sedgwick, Alexandre Toumarkine) oder „Esotericists Embracing Deviance“ (Allison P. Coudert) konnten wichtige Denkanstöße zur Thematik liefern.

Der große Erfolg der Tagung zeigte sich zudem in der Presseresonanz (u.a. Radiound Fernsehinterviews für den MDR) sowie zahlreichen positiven Rückmeldungen von Teilnehmern im Nachgang des Kongresses. Eine Veröffentlichung der wichtigsten (etwa 25) Beiträge ist bereits in Vorbereitung und wird von mir und Marco Pasi (Amsterdam) in der Aries Book Series des Brill-Verlags herausgegeben werden. 
Tradizione. La costruzione dell'identità in prospettiva storica, Tagung vom 22. bis 23. Juni 2017 in Modena (Jörg Rüpke)

Vom 22. bis 23. Juni 2017 fand an der Fondazione San Carlo in Modena und auf Einladung von Professor Carlo Altini die nun schon fünfte gemeinsame Tagung des dortigen Doktoranden- und Postdoktorandenkollegs mit der Section sciences religieuses der École Pratique des Hautes Études Paris und dem Max-Weber-Kolleg statt. In Vorträgen und dreisprachigen Diskussionen wurden von Angehörigen dieser Institutionen Fallstudien und Reflexionen über zentrale Begriffe vorgestellt. Die Beiträge reichten von der Antike bis zur französischen Kant-Rezeption und Traditionen französischer Laicité. Von den Erfurter Teilnehmer/inne/n stellte Sarah Al-Taher Überlegungen zur menschlichen Identität als defizitäre Wesen in der Anthropologie von Platons Mythen vor, Tilo Wesche beschäftigte sich mit Aristoteles' Eigentumskonzept, und Maik Patzelt sprach über spätantike Witwenbilder und die ihnen zugeschriebenen Praktiken. Roberto Alciati, COFUND-Fellow am Max-Weber-Kolleg, stellte westliche Mönchstraditionen und -genealogien vor. Erneut boten die historischen Räume im Stadtzentrum von Modena einen guten Rahmen, über Alters- und Sprachgrenzen hinweg ins Gespräch zu kommen und gemeinsame Begriffsarbeit zu betreiben.

Religious Individualization in Historical Perspective: Types and Concepts, KFG-Abschlusstagung vom 27. bis 30. Juni 2017 (Jörg Rüpke)

Als Auftakt der letzten Arbeitsphase und mit dem Ziel, die unterschiedlichen individuellen Teilprojekte der Kolleg-Forschergruppe zu bündeln, fand zum Semesterende eine dreieinhalbtägige Tagung mit über vierzig Mitgliedern statt. Das gewählte Format war ungewöhnlich: Im stetigen Wechsel von Plenartreffen und Sitzungen unterschiedlicher Arbeitsgruppen wurden die letzten, noch nicht in den wöchentlichen Kolloquien diskutierten Texte für Kapitel eines gemeinsamen, mehrere ,Bände umfassenden Buches zu Dimensionen, Formen und Folgen religiöser Individualisierung diskutiert. Wichtiger noch war die Verklammerung dieser Beiträge durch gemeinsame Reflexionstexte von jeweils drei bis vier Autor/inn/en, deren Kapitel so durch eine gemeinsam verfasste Abschlussreflexion zusammengebunden und selbst noch einmal geschärft wurden. Bandweise trafen sich dann wiederum mehrere dieser Kleingruppen, um über Struktur und Titel ihrer Kapitelsammlung zu diskutieren. Nicht mit neuen Aufgaben von der Tagung zurückzukehren, sondern im Gefühl, eine Aufgabe erledigt zu haben, war die Zielsetzung.

Zuerst mit Skepsis betrachtet, war die Befriedigung doch groß, in wenigen Tagen diese neuen „Nachworte“ verfasst und damit die Reflexion des Gesamtvorhabens deutlich vorangebracht $\mathrm{zu}$ haben. Dass Restaufgaben noch zu erledigen waren, soll nicht verschwiegen werden. Das Gesamtergebnis soll zur Jahresmitte 2018 in Druck und parallel im Open-access-Modus online gehen. 
Tagung vom 4. bis 6. Juli 2017: ,Dalit and Religion“ (Martin Fuchs)

An interdisciplinary group of researchers from India, Mexico, the United States, Canada, Sweden and Germany met in the premises of the Augustinerkloster in Erfurt between 4th and 6th of July 2017 to discuss the topic Dalit and Religion.

Dalits (a modern self-designation for "Untouchables") and other disadvantaged people had to negotiate modes of religiosity and religious power structures continuously. Dalits had to face the denial of inclusion, and encountered severe problems when trying to establish spaces for themselves. At the same time Dalits invented ideas, practices and agendas of their own. Throughout Indian history the socio-religious hierarchy and the dominant, even hegemonic religious strands and traditions have been accompanied by counter-imaginaries, which represent universalistic concepts, but have never become dominant.

This conference had set itself the task to approach the field of religion in India from the perspective of discriminated, although differently positioned groups of people, and, therefore, from an angle that differs from the perspectives enshrined in the dominant religious discourses. It also put forward the ways religious practices and ideas are being articulated and appropriated by the various actors as well as on the ways new experiences and imaginaries are being formulated and expressed both historically and contemporaneously.

The religious traditions and strands covered included forms of Hinduism and forms of bhakti, forms of Islam, forms of Christianity and the new or Navayana Buddhism. Martin Fuchs (Max-Weber-Kolleg) gave an introduction into the topic. G. Aloysius (Puducherry) focused on the dilemmas facing excluded social groups in India and the ways their sense of religiosity changes. Saurabh Dube (Mexico) insisted that the question of religiosity for Dalits does not admit singular solutions.

Prithvi Datta Chandra Shobhi (Karnataka) discussed the relationship between Virashaiva bhakti and Untouchability in the twelfth century; he followed this up by discussing how Untouchables themselves in a later period, since the sixteenth century, produced critical epics. Ishita Banerjee-Dube (Mexico) foregrounded the ambivalences of (graded) inclusion, taking the case of Mahima Dharma (Odisha). She asked to what extent a change of faith could guarantee dignity and an erasure of negative discrimination. Beatrice Renzi (Max-Weber-Kolleg) explored Dalit counter-discourses and their relation to Brahmanical Hinduism in Madhya Pradesh and highlighted the critical importance of re-appropriating the divine to reclaim rights and dignity. Sanjay Jothe (Mumbai) focused on the contradiction among followers of the Kabirpanth between notions of a "mystic" Kabir and a "social revolutionary" Kabir. In contrast, Valerian Rodrigues (Mangalore) elaborated on the presence of Kabir as the "absent guru" in the life and work of B.R. Ambedkar.

Milind Wakankar (New Delhi) took up the instance of the seventeenth-century poet of the Qadiri Sufi sect, Sheikh Muhammad, who wrote Varkari (i.e., bhakti) po- 
etry in Marathi, focusing on interiority and negativity. Joel Lee (Massachusetts), taking the case of the Halalkhor, Dalit Muslims in Eastern Uttar Pradesh, discussed the ambivalence of dissent and resistance, swaying between intimate untouchability and intimate touchability. Ajay Bhardwaj (Vancouver) presented both a documentary and a paper in which he highlighted a case of close association of Dalits with Sufi shrines in Punjab.

Joseph M.T. (Mumbai) covered the variants of positions among Dalit Buddhists in Aurangabad (Maharashtra). Jon Keune (Michigan) discussed the relationship of Dalit Buddhism with transnational Buddhist activity in Nagpur (Maharashtra). P. Sanal Mohan (Kerala) discussed the case of autonomous Dalit churches in Kerala, new forms of prayer and a new concept of the body, reviving pre-Christian traditions. Heinz Werner Wessler (Uppsala) presented various positions regarding the question of conversion among North-Indian Dalits who resist the call to Buddhism as part of the Dalit awareness movement.

A thorough study of Dalit experiences with the different modes of religiosity is important beyond India and South Asia. Within the field of religious studies it will realign the focus on inter-subjectivity and the quality of human relationships, paying particular attention to the significance that dimensions which transcend the world of materiality and immediacy have for the people concerned.

Conference, 8-10 November 2017: 'Urban Religion in Late Antiquity’ (Emiliano Urciuoli)

Organized through the collaboration between the MaxWeber-Kolleg and the Centre for Urban Network Evolutions at Aarhus University, the international conference "Urban Religion in Late Antiquity" (Augustinerkloster, Erfurt) invited scholars from different disciplinary backgrounds (classics, Roman and early modern history, early Christian studies, Byzantine studies, religious studies, archeology and sociology of religion) to explore late antique Mediterranean city spaces in order to address such questions as: How is religion used by different agents to appropriate and "craft" urban space over time? How do religious practices and imaginaries produce a transcending global that is different from other projections of the trans-urban? How does the urban context change different or even competing practices of religious communication and the ensuing forms of sacralization?

Within the framework of a larger comparative approach, the conference focused on these processes in the historical context of the advanced imperial and late antique Mediterranean space ( $2 \mathrm{nd}$ - 8 th century CE). This is a period of sustained change and ever new appropriation of urban spaces by ever different agents within clearly articulated and monumentalized built environments. Interested in the individuals' making of urban space and in the processes of grouping following on, or directed against, such built environments, the papers looked for archeological evidence not only of 
new structures but also of rebuilding, ignoring or actively avoiding spaces, as well as of creating urban spaces by patterns of movements or marking in religious terms. Textual evidence for such strategies, as well as for imaginations of urban spaces, ritual practices, religious narratives or norms of reinterpreting and transcending them, were also specifically sought after. Without assuming an easy evolutionary path, the papers assumed and showcased high variability in the mutually productive relationship between the developments of urban-based religious practices and the developments of cities confronted with, and building on, agents who used religious practices in different phases of the history of religion. Both the mutual constitution and the mutual critique of the urban and the religious have emerged from the city-to-city investigations; they were further emphasized within the round-table and the final general discussions. The publication of the conference proceedings in the series "Religionsgeschichtliche Versuche und Vorarbeiten” (de Gruyter) is forthcoming.

\section{Meister Eckhart in Köln, Internationale Jahrestagung der Meister Eckhart-Gesell-} schaft vom 15. bis 18. März 2018 in Köln (Markus Vinzent)

Die Meister-Eckhart-Gesellschaft zusammen mit dem Thomas-Institut der Universität zu Köln organisierte ihre Internationale Jahrestagung 2018 zum Thema „Meister Eckhart in Köln“. Die wissenschaftliche Leitung und Organisation lag bei Andreas Speer, Direktor des ThomasInstituts der Universität zu Köln, Maxime Mauriège, Beauftragter für das Meister-Eckhart-Archiv am ThomasInstitut, und Freimut Löser, Professor für Deutsche Sprache und Literatur des Mittelalters, Universität Augsburg. Meister Eckharts Kölner Jahre stehen zumeist im Schlagschatten des Prozesses, der in dieser Stadt gegen ihn angestrengt wurde. Sein Wirken als Lektor am dominikanischen Generalstudium in Köln findet über das bloße Faktum hinaus kaum Beachtung, während seine dortige Predigttätigkeit häufig im Lichte des Prozesses wahrgenommen wird. Hierzu bieten die Prozessdokumente reichen Anlass und ebenso Eckharts Verteidigungsschriften. Nicht zuletzt hat die von Joseph Quint gewählte Editionsstrategie zu einem Bild des Kölner Eckhart beigetragen, das in wesentlichen Teilen von den Häresievorwürfen gegen den Meister geprägt ist.

Diese Leserichtung vom Ende her ist - ungeachtet ihrer Verdienste für die philologische Evidenz - nicht zuletzt deshalb problematisch, da die auf diese Weise intendierte oder gar erzeugte Teleologie nicht zwangsläufig mit den Intentionen und Fakten übereinstimmen muss, die Eckharts letztes großes Wirkungsfeld in Köln bis zum Beginn des Prozesses charakterisieren. In mehreren Vorträgen behandelte die Tagung die Frage, wodurch diese Jahre geprägt sind. Auffällig ist etwa, dass Eckhart seine Kölner Predigttätigkeit offenbar systematisch angelegt hat. Hiervon zeugen die zahlreichen Bezugnahmen auf Themen, Orte und Anlässe. Gibt es einen Kölner Predigtzyklus, wie ist dieser im Kirchenjahr einzuordnen und wie steht es um die Datierung? Auffällig sind auch die vielfältigen Bezüge auf Paris. Offensichtlich setzt sich 
Eckhart noch intensiv mit den scholastischen Debatten an der Sorbonne auseinander. Wer sind seine potentiellen Gesprächspartner? Lassen sich hier Unterschiede zu seiner Pariser Zeit als Student, Lektor und Magister feststellen? Gibt es besondere theologische Themen in den Kölner Predigten? Gibt es darin Anzeichen für Diskontinuitäten mit seinen früheren Lehren? Wie steht es um die relative, wie um die absolute Chronologie der Texte? Kann man von einer Entwicklung Eckharts oder gar von einem Spätwerk sprechen? Wie spricht Eckhart konkret in Köln? Welche Hinweise gibt es auf den Zusammenhang zwischen Schreibsprache und Oralität sowie auf den Dialekt? Wer liest wann in welcher Form und in welcher Zusammenstellung die Kölner Texte? Hier stellt sich die Frage von Rezeption und Redaktion. Was lässt sich über die Wirkung der Kölner Texte sagen? Wie weitreichend sind sie? Fungiert Köln als Schaltstelle einer Verbindung zu den Niederlanden?

Eckharts eigene Übersetzungen zentraler Passagen seiner Kölner Predigten ins Lateinische im Rahmen seiner Verteidigung bieten einen Zugang zur Terminologie und zum Zusammenhang von lateinischem und deutschem Werk. Schließlich stellt sich die Frage nach dem historischen Kontext von Eckharts Kölner Zeit: die Situation und Form der Seelsorge, das dominikanische Generalstudium und die deutsche Dominikanerschule, der Einfluss Alberts des Großen, die Stellung der Dominikaner in der Stadt und im Verhältnis zu den anderen Orden sowie zum Erzbischof von Köln. Was ergibt der Vergleich mit anderen volkssprachigen Texten aus Köln (etwa den „Kölner Klosterpredigten“)? Darf man ein „Eckhart-Publikum“ in Köln annehmen? Lassen sich Spuren von Eckharts Tätigkeit auch außerhalb der Predigten und Prozessmaterialien (etwa in Texten wie „Meister Eckharts Wirtschaft“) finden? Lassen sich Schüler Eckharts (z.B. Tauler, der im Kölner Dominikanerinnenkloster St. Gertrud gepredigt hat) oder Kölner ,Eckhartisten', d.h. Anhänger des Meisters identifizieren und somit Hinweise auf eine mittelbare Überlieferung finden? Wie steht es mit Kölner häretischen Kreisen und speziellen Seelsorgestrategien? Ziel der Tagung war es, eine differenzierte Sicht auf Meister Eckharts Kölner Zeit und eine sorgfältige Spurensuche in den historischen, philosophisch-theologischen und institutionellen Milieus zu bieten.

Tagung vom 16. bis 17. Mai 2018 in Metz: 'Maître Eckhart: Lecteur des Pères de l’Église' (Sarah Al-Taher, Markus Vinzent)

Im März 2018 wurde das DFG-ANR-Kooperationsprojekt „Lehren und Predigen mit patristischen auctoritates. Meister Eckhart, Brückenbildner zwischen Frankreich und Deutschland, Vergangenheit und Gegenwart“ unter der Leitung von Markus Vinzent (Max-Weber-Kolleg Erfurt) und Marie-Anne Vannier (Université de Lorraine) aufgenommen. In dieser Kooperation sollen Fragen nach Prozessen von Rezeption bzw. Appropriation, der Verschiebung von Autoritäten und Nutzung von Referenzen und 
der kreativen Dynamik von Lektüre und Relektüre untersucht werden. Neben Monographien und gesammelten Studien wird unter anderem ein kritischer Index der patristischen Quellen Eckharts erarbeitet. Anlässlich dieser Kooperation, innerhalb deren das deutsche und französische Team gemeinsam die Quellen Meister Eckharts erforschen und der Wissenschaft zur Verfügung stellen wird, fand die erste gemeinsame Tagung zum Thema „Maître Eckhart: Lecteur des Pères de l'Église“ in Metz statt. Vertreten wurde das Max-Weber-Kolleg durch Markus Vinzent, Julie Casteigt, Jana Ilnicka, Dietmar Mieth und Sarah Al-Taher.

In französischer und deutscher Sprache wurden zahlreiche Vorträge rund um das Thema „Eckhart und die Kirchenväter“ gehalten - besonderer Schwerpunkt war die Bedeutung und Vielseitigkeit der verschiedenen Quellen Eckharts. Neben einem historischen Erkenntnisgewinn ermöglicht die Erforschung der bislang vernachlässigten Quellen ein tieferes und vielseitigeres Verständnis der Nomenklatur zur Erfassung der verschiedenen Prozesse in der Literaturaneignung eines mittelalterlichen Autors wie Eckhart.

Julie Casteigt sprach zum Beispiel über den Einfluss der Kirchenväter in Eckharts Denken; Jana Ilnicka hielt einen Vortrag zum Thema „Boethius als Gewährsdenker für die Trinität“; Dietmar Mieth stellte die Nutzung patristischer Quellen Eckharts in den Bezug zur Gegenwart; Markus Vinzent nutzte das Beispiel der Referenz auf die Bekenntnisse des Augustinus bei Eckhart zur Frage nach Reziklat und Zitat. Zusammen mit den Beiträgen der französischen Kolleg/innen aus den historischen, sprachlichen und literaturwissenschaftlichen Disziplinen vor allem zu einzelnen patristischen Autoren (Hieronymus, Isidor von Sevilla etc.) wurde deutlich, dass zunächst Grundfragen etwa zu den Themen Zitat, Verweis, Referat etc. geklärt werden müssen, bevor zielgerichtet nach Eckharts möglichen Verwendungen von auctoritates gefragt werden kann. Durch diese erste, erfolgreiche gemeinsame Tagung in Metz konnte eine Plattform für eine produktive und anhaltende Zusammenarbeit geschaffen werden, die demnächst auch digital unterstützt wird. Das Auftakttreffen in Metz bot darüber hinaus einen guten Rahmen, um auch persönlich miteinander ins Gespräch zu kommen und sich gegenseitig zu bereichern. Im Rahmen des Kooperationsprojekts werden in Zukunft weitere gemeinsame Veranstaltungen stattfinden.

Conference, 4-6 July 2018: 'Religion of Quarters: Practicing Religion on a Neighborhood Scale in the Hellenistic and Imperial Periods' (Emiliano Urciuoli)

The International Conference "Religion of Quarters: Practicing Religion on a Neighborhood Scale in the Hellenistic and Imperial Periods" posited that the assumption that basic units of dwelling, working and gathering in densely populated quarters of the cities of the empire form a privileged focus of investigation for the study of ancient Mediterranean religions. Often devoid of monumental complexes, the kind of religion 
taking place on this scale of the urban fabric is traditionally grouped under the questionable rubric of "private religion". Questioning conventional dichotomies for the classification and spatialization of phenomena deemed religious (such as "public / private", "polis religion / cults"), the conference gathered together scholars from different fields in order to discuss how inner-city spaces affected the shape of religious representations, conducts and experiences during the Hellenistic and Roman Periods ("Urban Religion").

The topic of the conference comprised a rich variety of urban settlements: (a) multi-story crowded tenements with several rental apartments functioning as space for a variety of religious practices; (b) grand houses organized into portions whose physical setting could occasionally accommodate non-resident and extra-familial worshippers; (c) different non-residential locales (shops, halls, clubhouses etc.) belonging to the same city block and run by family members, leased to private individuals and / or used as meeting places for associations; (d) privately owned but publicly used facilities (neighborhood baths, cookshops and bars) functioning as neighborhood highlights and landmarks and forming the focus of the local communal life; (e) side-streets and crossroads with their relatively small-scaled religious material environments.

The program raised a number of questions: How and to what extent did the varying spatial features of domestic units and street networks affect the imagination and practice of religion? Which was the interplay between urban layout, locational aspect and occupancy patterns of buildings, and the construction of neighborhood-based religious networks? What forms of rivalry among religious specialists did such locations prompt? What codes of religious conduct became necessary and persuasive in such settings? Although the participants agreed that several critical problems still need to be solved and questions reassessed on both a theoretical and empirical level (e.g., What boundaries do neighborhoods delineate? How does localism and "locative religion" map onto "neighborhood religion"? Which are the most suitable comparative models for the study of neighborhood religion at a crosscultural level?), the conference has eventually probed and gauged the potentiality of a neighborhood-scale analysis of religious communication in ancient Mediterranean cities. The publication of the conference proceedings is planned for the second half of 2019. 


\title{
8.2 ERC Advanced Grant "Lived Ancient Religion"
}

\author{
Koordinatorin: Dr. Anna-Katharina Rieger
}

Internationale wissenschaftliche Tagung des ,Lived Ancient Religion'-Projekts vom 4. bis 7. November 2012 am Deutschen Archäologischen Institut und der British School in Rom: „Archäologie gelebter Religion in der Antike“ (Jörg Rüpke)

Religionsarchäologie hat sich in den vergangenen Jahren mit Hilfe neuer Methoden in der Archäologie zu einem wichtigen Arbeitsfeld entwickelt. Materielle Überreste werden als Spuren von Ritualen oder Ausdrucksformen religiöser Erfahrungen gedeutet. Die innovativste Forschung wird zweifelsohne in sehr konkreten Bereichen wie in der Archäologie des (Opfer-)Rituals und des Todes betrieben. Der Lived-Ancient-Religion-Ansatz lenkt die Aufmerksamkeit auf Praktiken und Alltagsreligion. In Form einer internationalen Tagung an zwei wichtigen Standorten archäologisch-altertumswissenschaftlicher Forschung und in Kooperation mit dem Istituto Svizzera wie der Universitet Aarhus (Henner von Hesberg, Rubina Raja, Christoph Riedweg, Jörg Rüpke, Christopher Smith) wurden auf der Basis vorab ausgetauschter Texte grundsätzliche methodische Probleme der Religionsarchäologie wie die neuen Perspektiven und die für sie notwendige Datengrundlage diskutiert, die die Frage nach gelebter Religion bietet und sich von einer ,archaeology of belief“ oder kognitionswissenschaftlichen Ansätzen (T. Insoll, H. Whitehouse) grundsätzlich unterscheidet.

Ein erster Blick galt der Perspektive des „Embodiment“, konkretisiert durch Laura Gawlinski (Loyola) an Bekleidung, Gideon Bohak (Jerusalem) an Amuletten und durch Thierry Luginbühl (Lausanne) an Prozessionsritualen im gallorömischen und indischen Bereich. Frederick G. Naerebout (Leiden) ergänzte das mit dem Blick auf Tanz, Robin Jensen (Vanderbilt) in ihrer Analyse von Bauten für Initiationsrituale, insbesondere die Taufe. Ein zweiter Blick galt den Formen religiöser Erfahrung, so des gemeinsamen Mahls (Marleen Martens, Brüssel) und Formen temporärer Deprivation (Richard Gordon, Erfurt), ein dritter Austauschprozessen und Modifikationen in Randzonen oder außerhalb des römischen Reiches, in Britannien, Nordafrika und Ägypten (Greg Woolf, St. Andrews; Valentino Gasparini und Lara Weiss, Erfurt).

Den räumlichen und materialen Bedingungen religiöser Erfahrung wurden expressive Formen gegenübergestellt: Alexandra Busch (Rom) untersuchte Altäre, Günther Schörner (Wien) Votive, die Körperteile darstellen, Wolfgang Spickermann (Erfurt, jetzt Graz) monumentale Inschriften. Marlis Arnhold (Erfurt, jetzt Bonn) schuf mit dem Blick auf die Kultanlagen, die von kleineren religiösen Vereinen errichtet wurden, einen Übergang zur folgenden Gruppe von Beiträgen. Hier fragten nach Räumen religiöser Erfahrungen Richard Neudecker (Rom), der antike Gärten vorstellte, wie Joannis Mylonopoulos (New York), der Formen der Erstellung sakraler Landschaften vorführte. Miguel John Versluys und Eva Mol (Leiden) ergänzten das mit einem Blick auf ,imagined communities“, Christopher Smith (Rom/St. Andrews) mit 
der Frage nach der Schaffung von Erinnerungsräumen in Städten wie Rom. Die klassischen Formen sakraler Räume bildeten den Abschluss dieser Sektion: Tempel (Henner von Hesberg, Rom), komplexe Heiligtumsanlagen, besonders in den nordwestlichen Provinzen (William van Andringa, Rennes), und offene Heiligtümer (Rubina Raja, Aarhus). Inge Nielsen (Hamburg) und Susanne Gödde (München) ergänzten die Befunde um Gebäude religiöser Gruppen und Theater.

Abschließend standen übergreifende analytische Probleme im Vordergrund. Die verschiedenen Etappen der religionsarchäologischen Gender-Forschung stellte Zsuzsa Varhelyi (Boston) vor, Steven Fine (New York) erläuterte exemplarisch das Problem des häufig faktischen Verlusts und der auf Graustufen fixierten Theoriebildung, Eric Rebillard (Ithaca) behandelte die Probleme, religiöse Identitäten aus archäologischen Befunden zu erhellen. Jörg Rüpke (Erfurt) vertiefte das Problem von kollektiv oder individualisierend orientierten analytischen Perspektiven. Zum Abschluss der Tagung behandelte John North (London) in der ersten „Roma/London Lecture“ das Thema „Göttinnen und Sibyllen“.

Die Ergebnisse der Diskussionen sollen in einen gemeinsamen und durch weitere Beiträge ergänzten „Companion to the Archaeology of Religion in the Ancient World“ einfließen, der sich inzwischen in der Schlussphase redaktioneller Bearbeitung befindet.

Opening conference for the ERC research project "Lived Ancient Religion: Questioning 'Cults' and 'Polis Religion'”, 11th -14th June 2013, at the Max-Weber-Center: "Sharpening the Knife: Making Religion Effective in Everyday Life" (Marlis Arnhold)

With this conference, the project funded by the European Union within the 7th Framework Programme which is located at the Max Weber Center of the University of Erfurt and directed by Prof. Dr. Jörg Rüpke (Erfurt, Germany) and Prof. Dr. Rubina Raja (Aarhus, Denmark) was publicly opened. Thus a series of consultations of experts was started. The conference pursued a twofold aim which focused both on the introduction to the project and its various aspects as well as the methodological issues raised by it. In order to "sharpen the knife" in regard to methodology, scholars from three continents, representing a wide range of subjects such as Archaeology, Ancient History, Philology, Religious Studies, and Theology, came together to contribute presentations from the perspective of their specific fields and to discuss their methodological approaches.

The conference started on 11 June with the ceremonial opening at the Thueringen State Chancellery which was attended by approximately 70 participants. They were welcomed by the patron of the conference, Marion Walsmann, Thueringen Minister for European Affairs and Head of the State Chancellery. Jörg Rüpke introduced the issues of the project before Rubina Raja concluded with a first insight into the scope of the project in her public lecture titled "Look at me! My Father was Famous: Priestly 
Self-Representations in the Roman Near East as Media Creating Meaning in Situations".

During the following days the conference continued at the Augustinerkloster, Erfurt. The first session on Wednesday, 12 June, brought the aspect of "The Role of Objects" to attention which was first addressed by Lucinda Dirven (Amsterdam). In her presentation "Imagining Religion in Mithraic Cults. The Case of Dura-Europos" she particularly stressed the issue of cult attendents staging rituals and myths and thus shed new light on the diversity of a cult that is generally perceived as rather uniform. The objects of this presentation can be found depicted on the walls of the Dura Europos-mithraeum itself. Lara Weiss, herself member of the ERC-project at Erfurt, spoke about "Conceptualizing the Creation of the Sacred: Mass Production vs. Handmade Figurines”. Showing examples from her investigations at Karanis in Egypt she discussed what different kinds of meaning the same object could have for different persons in different situations. A toy from the perspective of a child could very well have been a figurine for religious purposes from the standpoint of its parents. The session continued with the contribution of Michael Satlow (Providence, RI). Speaking about "Searching for Jewish Votive Objects in Roman Palestine", Michael Satlow dealt with the question under which conditions objects received a sacred meaning and were perceived as sacred by the authors of various Jewish texts. Particularly interesting was the temporal shift from referring to an object as "sacred" to "put into higher service" which Michael Satlow noted. The papers of this session thus discussed new methods illustrated in case studies and pinpointed the variety of experiences and memories stimulated.

The second session was dedicated to the issue "Group Styles" and likewise comprised three presentations. Markus Vinzent (London) contributed a critical view of the topic from the perspective of his studies on Marcion, titled "Practical and Cognitive Dissonance: Jewish Liturgical Traditions, Innovations and Counter-Rites in Marcion's Roman Community”. Then, Marlis Arnhold (Erfurt) raised the questions of the lack of visibility and limited visual accesses as well as the consequences of these for the understanding of cult-groups. For this, she analysed the archaeological, epigraphic and literary evidence of the Bona Dea cult at Ostia for her presentation "The Last One Shuts the Door: Cult-Groups Communicating Through (In)Visibility”. Finally the topic of the session was addressed by John North (London) in his investigation on the "Funeral Rituals and the Significance of the Nenia" which focused on the ritual lamentation at the end of Roman funerals and the views of various authors on it. The contributions to this session thus all shed a critical view on the term group and underlined the temporally limited, situational visibility and construction of the collective identities that defined them. This session raised the most controversial opinions during the final discussion. The topic is highly important as the modern notion of the term "group" still persists in scholarship and the questions, what makes a group actually a group, when, and how often, do require much discussion. 
Session III comprised four presentations on the topic "Meaning in Situations" and started with Anton Bierl (Basel) and his contribution on "Lived Religion and Construction of Meaning in Greek Literary Texts and Contexts". He focused on the situational construction of new meanings by various Greek authors using among others mythical stories problematising the notion of literary texts as "sources". Eric Rebillard (Ithaca, NY) spoke about "Everyday Christianity in Third-Century Carthage”. In reference to "everyday nationhood" he proposed a theoretical framework that could be used to analyze sites "where Christianness might, but need not, be at work". In the third contribution to the session, Vered Noam (Tel Aviv) addressed the Jewish views of what was perceived as impure ritual in various situations - and what not in others - in her presentation "Ritual Impurity and Human Intention". And finally, Christopher Smith (Rome) raised the question of what role prayers and other ritualised speech acts played in Roman religion drawing attention to the ideas of Eduard Norden's Euvre „Aus altrömischen Priesterbüchern“. The title of this book also served as title of his contribution. The session's contributions hence explored "meaning” in situational constructs and examined the effectiveness of religious instruments as employed in order to create, change, and enhance meanings.

It was followed by a poster session of altogether ten doctoral and postdoctoral researchers who had been invited to attend the conference.

The afternoon continued with the fourth session on "Appropriation" which drew attention on the individuals behind the actions that led to the construction of rituals and buildings as well as the production of meanings in difference to established traditions. Karen King (Harvard) started with her contribution "Religion(s) of the Book"/“Textual Communities" asking which of the lived practices actually had the potential to make it into 'book religion' and what authority the written word had in light of illiteracy. Michal Bar-Asher Siegal (Beer Sheva) continued with a presentation on "The Transmission and Collections of Traditions in Anthologies" which revealed her passion for the issue how traditions from anthologies were later on loaded with authority by religious communities. Under the title "Just Like the Emperor and his Family: Appropriating the Emperors' Religion in the Roman Empire” Zsuzsa Varhelyi (Boston) then drew attention of what can be termed "(implicit) religious trend-setting” through the emperors and their families. Independent of their specific topic, all of the contributions from this session explore the processual character of religious practice and underline that actually every agent is provider and acquisant at the same time which shows how complex religious change in fact is. This also accounts for the last presentation of this session, given by Angela Standhartinger (Marburg) on "The Beginning of the Eucharist or Constructing the Lord's Supper”. It centered on the "words of institution", 1 Cor 11:22-25/Mk 14,22-24 par., and their meaning and function in the context of the Eucharist, proposing an origin in the context of ritual lamentation at funerals.

The last session held on the morning of Friday, 14 June, dealt with „Learning and Memory" from the perspective of lived religion. The contributions here addressed the 
questions how individual religious practice depended upon the intellectual as well as the embodied availability and the situational salience of "traditions", that is, complex belief systems or simple sequences of ritual action. The terms "learning" and "memory" here refered to processes of acquireing knowledge by formal training or constant repetition and to instances of recalling emotions, complex patterns, cognitive or bodily knowledge. Asking for "The Implicit Reader of Antiquarian Literature: Questions in Ovid's Libri fastorum” Jörg Rüpke (Erfurt) shed new light on an extensively studied literary text from the time of Augustus. Katharina Waldner (Erfurt) analysed the rituals described and explained in the text of the Derveni Papyrus. Under the title "Reading, Knowledge and Religious Practice: The Derveni Papyrus and its Context” she discussed the contents of the texts in regard of its find context, that is burials which reveal a highly individualized burial practice, as well as in relation to presocratic philosophy.

The conference thus brought many aspects, methodological issues, and perspectives related to "Lived Ancient Religion" up, which provide a fruitful base both for further investigations by the various participants as well as the general approach of the overall ERC-project. With the knife thus sharpened connection points between the topics of the single sessions and with them, the complexity of the issue under investigation, have become much more visible.

„The Role of Objects - Creating Meaning in Situations“, internationale Tagung im Rahmen des ERC-Projekts „Lived Ancient Religion: Questioning, Cults“ and ,Polis Religion“, vom 9. bis 11. Oktober 2013 im Haus Hainstein/Wartburg in Eisenach (Lara Weiss)

Im Rahmen des von Jörg Rüpke initiierten Projekts Lived Ancient Religion (LAR) zur religionswissenschaftlichen Grundlagenforschung fand vom 9. bis 11. Oktober in der Eisenacher Tagungsstätte Haus Hainstein die von Rubina Raja und Lara Weiss organisierte internationale Tagung „The role of objects-creating meaning in situations“ statt. Sie war Richard Gordon zum 70. Geburtstag gewidmet.

Hintergrund für die Tagung war die Beobachtung, dass religiöse Objekte in der Antike einen gegenständlichen und visuellen Rahmen für gelebte Religion bildeten. Je nach Situation und Person konnten z.B. dieselben Dinge unterschiedliche Rollen spielen oder auch selbst zu bestimmenden Faktoren von religiösen Handlungen werden. Das Spektrum der Vorträge der Tagung des Max-Weber-Kollegs der Universität Erfurt umfasste jedoch nicht nur die mitteleuropäische Antike, sondern auch den vorderen Orient, Indien und Mesoamerika. Genauso international waren die geladenen Sprecher, die aus zehn Ländern (USA, Frankreich, Niederlande, Schweiz, Spanien, Bulgarien, Großbritannien, Italien, Dänemark und Israel) angereist waren und in regen Diskussionen der Frage auf den Grund gingen, wie genau verschiedene Dinge je 
nach Gebrauchskontext Sinn stifteten und wie sie bestehende Bedeutungen veränderten oder auch verstärkten.

In vier thematischen Folgen wurden jeweils verschiedene Themenkomplexe abgearbeitet. Die erste Session „Identifying Objects in Contemporary Discourse“ konzentrierte sich auf den Diskurs verschiedener Objekte. Während Patricia McAnany (Chapel Hill) die unterschiedlichen Bedeutungen von Knochenresten in verschiedenen Grabtypen diskutierte, zeigte Ioanna Patera (Paris) die Undefinierbarkeit von Opfergaben bzw. eben gerade nicht deren Ersatz auf. Die zweite Session „Transferable Meanings in Space and Time“ zeigte den Imperator Augustus als religiöses Objekt (Frank Daubner/Stuttgart) sowie Keramikware, aber auch -scherben als sichtbare Erinnerung an die im Tempel vollzogenen Opfer (Anna-Katharina Rieger/Erfurt). In der dritten Session „Objects, Spaces and Time“ diskutierte Richard Gordon (Erfurt) die Rolle von Fluchtafeln und Drew Wilburn (Oberlin) die Bedeutung von Straußeneiern als religiöse Objekte. In „Multiple Meanings“ konnte gezeigt werden, in welchen Situationen und unter welchen Bedingungen Objekte auch verschiedene Bedeutungen annehmen können. U.a. gelten solche vielfachen Bedeutungen für Opfergaben im Sanktuar der Magna Mater in Ostia (Alison Cooley/Warwick), die Gürtelschnalle römischer Soldaten (Stephanie Hoss/ Sheffield), beim Abendmahl ausgeteiltes Brot/Eucharistie (Volker Menze/Budapest), Textilfigürchen aus Ägypten (Karen Johnson/ Ann Arbor), Terrakottas aus Beit Nattif (Achim Lichtenberger/Bochum), die sogenannten Bankett-tesserae aus Palmyra (Rubina Raja/Aarhus) sowie die Amtstracht der jüdischen Hohepriester (Gideon Bohak/Tel Aviv). Die Session „Mobility and Immobility as Change Factors“ schließlich, ging der Frage nach, ob (Im)mobilität einen konzeptuellen Unterschied im Gebrauch von Objekten macht, was anhand von goldenen Glasmedallions im Grab- bzw. Hauskontext (Hallie Meredith/Dartmouth), der Ikonographie der Göttin Tyche auf phönizischen Münzen (Andreas Kropp/Nottingham), dem Banner von Indra im altvedischen Ritual (Angelika Malinar/Zürich) sowie für feste und bewegliche Hausaltare im römischen Ägypten (Lara Weiss/Erfurt) gezeigt werden konnte. Den Festvortrag hielt Francisco Marco Simon (Zaragoza) zu Objekten, die Freundschaftsverträge zwischen Städten religiös symbolisierten.

Die Tagung darf als voller Erfolg gelten. Es gab nicht nur zahlreiche Anknüpfungspunkte zwischen den einzelnen Beiträgen und Gesichtspunkten, sondern es kam auch schon gleich zu Beginn eine wunderbare Stimmung und Dynamik zwischen den Teilnehmern auf, die sicherlich nicht zuletzt auf die mitten im Wald gelegene Tagungsstätte mit einem malerischen Blick auf die Wartburg zurückzuführen ist. Nicht zuletzt durch die verschiedenen methodischen Ansätze konnte z.T. bekanntes Material neu definiert und verstanden werden. Es wurden aber auch einige Fragen für die weitere Forschung aufgeworfen, z.B. inwieweit man Objekte als Konzept jenseits ihrer Dinglichkeit verstehen könne. Als wichtigstes Ergebnis der Konferenz darf genannt werden, dass die Bedeutung religiöser Objekte keineswegs statisch ist. Im Gegenteil: Die Bedeutungen von Objekten unterscheiden sich nicht nur zwischen den jeweiligen Religionen, sondern können auch innerhalb bestimmter Kulturräume je 
nach Kontext verschieden sein, da die Objekte von den jeweiligen Akteuren in jeder Situation neu angeeignet werden und sich ihre Bedeutung dabei verändern kann. Damit inspirierte die Konferenz nicht nur alle Teilnehmer, sondern auch die laufende Forschung der Lived Ancient Religion-Mitarbeiter auf allen Ebenen, d.h. sowohl die eher archäologisch ausgerichteten als auch die eher historisch und philologisch ausgerichteten Forschungsprojekte.

Internationale Konferenz im Rahmen des ERC-Projekts „Lived Ancient Religion“ vom 29. bis 31. Januar 2014 auf Schloss Ettersburg bei Weimar: „Stories told Memories uttered“ (Christopher Degelmann)

Zwischen dem 29. und 31. Januar 2014 traf sich in Schloss Ettersburg bei Weimar eine internationale und interdisziplinäre Gruppe im Rahmen des vom European Research Council geförderten Projekts Lived Ancient Religion: Questioning ,cults ' and ,polis religion‘. Die inzwischen dritte Tagung der Erfurter Forschergruppe mit dem Titel „Stories told - Memories uttered“, organisiert von Christopher Degelmann und Jörg Rüpke, befasste sich mit der Bedeutung von Narrativen für die Erfahrung von Ritualen im griechisch-römischen Altertum und den Nachbarkulturen. Anhand von vornehmlich textlichen Quellen fragte sie nach der Art und Weise, wie Erzählungen von der eigenen, aber auch über fremde Religion das religiöse Individuum beeinflussen konnten oder zur Konstruktion einer kollektiven religiösen Identität beitrugen. Besonderes Augenmerk lag neben den zeitlichen und räumlichen Aspekten vor allem auf den damit einhergehenden sozialen, historischen und kognitiven Auswirkungen von religiösen Narrativen: Wie lang waren einzelne Geschichten, Fabeln und Sagen in Gebrauch? Wie weit verbreiteten sie sich? Welche Faktoren trugen zu ihrer Lang- oder Kurzlebigkeit bei? Wem dienten sie wozu und welche Machtverhältnisse wurden dadurch konfiguriert? Dabei bildeten nicht zuletzt die Struktur von Narrativen und die Suche nach den Konsequenzen der Beschaffenheit von Texten und Erzählungen einen zentralen Untersuchungsgegenstand.

Diese Fragen wurden entlang von Fallstudien überprüft. So untersuchte man Biographien, Pilgerberichte, Briefwechsel, Ritualtexte und Inschriften sowie viele andere Formen des verschriftlichen Wortes auf ihren Wert für die Bildung von kleineren und größeren Narrativen. Deutlich wurde ein Unterschied zwischen den griechischrömischen Traditionen und den älteren Kulturen des antiken Nahen Ostens, für den identitätsbildende Erzählungen aufgrund einer vor allem archäologisch, weniger textlich fundierten Quellenbasis kaum festzustellen sind. Aber auch christliche Zeugnisse bewegen sich zwischen eigener, auf Abgrenzung und Polemik bedachter Traditionsbildung und der Aneignung zahlreicher paganer Motive, die den Anhängern ein Gefühl der Vertrautheit in einer als religiös zumindest als feindlich konstruierten Umwelt vermitteln sollten. Allgemein deutet dieses Phänomen in eine Richtung, die auch 
für andere religiöse Gruppen beansprucht werden kann: Sie wurden sowohl von außen als auch von innen mit einem Label versehen, das sich in den Erzählungen von und über die jeweilige Religionsgemeinschaft niederschlug und narrativ kodiert war.

Außerdem kam mehrfach zur Sprache, wie limitiert unser Blick auf Narrative vor dem Hintergrund des gesprochenen Wortes ist. Zahlreiche, wirkmächtige - im eigentlichen Sinn des Wortes - Erzählungen können wir nicht mehr fassen, da man sie nicht verschriftlichte. Dazu zählten nicht nur langlebige Motive, die über Rhapsoden und dergleichen vermittelt wurden, sondern auch humorvolle Geschichten und Witze, die man etwa über siegreiche Feldherren zum Besten gab. Sie spiegelten häufig die persönlichen Erfahrungen der kleinen Leute wider, wie man sie auch in dem für die Antike nur marginal beleuchteten Phänomen des Gerüchts greifen kann. Die Untersuchung von entsprechenden Graffiti und Dipinti mag eine Alternative sein zu einer textwissenschaftlichen Annäherung an das Problem des ,gesprochenen Narratives“ und seiner Auswirkung wie Ausbreitung in verschiedene Textgruppen; doch sie ist nicht in der Lage, den narrativen Kontext einzubinden oder gar zu rekonstruieren. So wurde konstatiert, dass diese Erscheinung eine der zentralen Herausforderungen kommender Auseinandersetzung mit der Rolle religiöser Narrative in den Kulturen des antiken Mittelmeerraums darstellt.

International conference of the ERC project 'Lived Ancient Religion', 2nd to 4th June, 2014 at the Royal Academy of Sciences and Letters, Copenhagen: 'Grouping together in Lived Ancient Religion' (Anna-Katharina Rieger)

How do groups come into being? How do the members interact, internally and externally? What is the role of groups in changing societal and political situations? These were the main questions posed by the 4th LAR-conference "Grouping together in lived ancient religion", a conference, which offered new insights into the nature and dynamics of groups in religious contexts.

Focusing on situational communication in and of groups, the conference drew on the concept of "culture in interaction", implying the shaping of "group styles" for understanding formation, unity or diversity of religious groups (Lichterman - Eliasoph 2003). These concepts allow for theorising situational differences in creating and reproducing religious representations, knowledge and practices - away from public norms. Speech and text, selection of objects, dress and gesture, as well as choice of time and place might be significant in order to establish groups at least on a temporary basis. The six sessions of the conference were dedicated to the different situations and strategies by which people unify and specialize in, establish authority by or enunciate religious groups. Classicists, archaeologists, sociologists as well as scholars from Theology, Judaic studies and Ancient History gathered at the Royal Academy of Science and Letters of Denmark to discuss these issues. 
Paul Lichterman (Los Angeles) opened the first session by providing a rich discussion of the "sociological perspective on groups in religions contexts". He broadened his and N. Eliasoph's concept of group style (embracing group boundaries, group ties and speech norms) by group scenes that form the collective (religious) practice and can be appropriated depending on the individual situation. Many of the following contributions referred to his concepts and explored in how far they might bear on religiously defined groups in antiquity. Emiliano Urciuoli (Modena) utilized the fieldtheory of Pierre Bourdieu and looked at how Christians behaved as members of the political elite of pre-Constantinian Rome. The in principle contradictory fields of "power" and "Christian religion" were merged in the political and economic interest of these individuals, who belonged simultaneously to different "social universes". The contribution of Urciuoli raised the general issue of identities determined by the belonging to a group: Our terminological distinction of "Christ" and "Roman" was an entity in personam.

The second session - "Encounters in travelling" - focused on how groups may form and on how existing groups may (inter)act in the special situation of being on the move. Philippe Bornet (Lausanne) showed how Rabbis established their authority and fostered the spread of ideas or rules by travelling around. Changing places and coming into contact with different groups helped to build up a network where they were active as guests, teachers and arbitrators. Katharina Rieger (Erfurt) analysed Late Hellenistic and Roman sacred places along the routes of the Arab Desert that are both adapted to and formed by travelling individuals and groups. Through religious practices as dedications and graffiti these travellers communicated to others (individuals or groups). Without being present at the same moment they formed groups beyond time and space. Tim Whitmarsh (Oxford) dealt with a "mental community", the atheoi. He focused on the Late Hellenistic times where reflections in texts show that these atheoi are not formed by social interaction but by their renunciation of the gods. He argued that the doxographia of that time structured the knowledge and facilitated the formation of networks of intellectuals - unified in the negation of the gods - in Early Imperial times.

The contribution of Eric Rebillard (Ithaca) in the third session of the conference on "Encounters in public and private spaces" inquired into the strategies employed by Christians in third century Carthage to distinguish themselves from their fellow Carthaginians. Rather unexpectedly, the followers of Christ attached importance to distinction by means of dress, naming or gestures only internally. Yet, in situations among other Carthaginian citizen, these distinctions did not play any role. Those "separate worlds" did not exist socially and spatially, but only temporarily in the contexts of religious gatherings. Arja Karivieri (Stockholm) with her paper on cave sanctuaries in Attica raised the question of cult practices, their religious affiliation, (intellectual) motivation and density, especially in Late Antiquity. The increase of the objects (lamps) as opposed to the decrease in the variety in Late Antiquity and Early Byzantine times is evidence of large gatherings in those caves and/or with a higher 
frequency. Karivieri related this phenomenon to the neo-platonic philosophy and the religious groups related to it. On the other hand, the mere increase of population in that time could be the reason for a surge of activity in the caves.

Aspects of gender were the topic of the fourth session, "Gender specific strategies and situations". Here Kate Cooper (Manchester) developed further her thoughts on "subordinate members" (of a household, a group, a society) and their vulnerability. By comparing late antique female martyrs, defixiones and the kidnapping of Syrian nuns in the year 2013, she explored the possible ways women can oppose to violence and (male) dominance. Darja Šterbenc Erker (Berlin) addressed the role of the Roman matrones as powerful group in religious and thus political concerns in Augustan times. A close reading of official documents of the ludi saeculares of 17 BCE (CIL 6, 32323) reveals the disobedience of the matrons as group, who decided not to fulfill their part in the rites. Conscious negation of authority along the lines of different religious duties (mourning, ludi) of one societal group leads to a reformulation of the ritual rules of the ludi.

The fifth session was dedicated to "Textual communities", where Karen L. King (Harvard) offered an example on how to apply group style to ancient groups that formed around reading, hearing and interpreting texts. Referring to Pauline literature and the understanding of text as practice, she argued that a religion like Christianity, based on texts, varies widely through the different situations where the texts are enacted, and what practices are played out. This view allows for assessing the impact of putative texts as well. Françoise van Haeperen (Louvain-la-Neuve) interpreted epigraphical evidence (taken as speech norm) from Ostian guilds as example for groups using texts as forming and unifying element (ties and boundaries). Via these practises, van Haeperen maintained, not only did they establish their internal cohesion, but also communicated their external references (city, Imperial court). Even though highly formalized, these epigraphic documents were used in a highly refined manner by the collegae to clear their position in the social network of Ostia. Jörg Rüpke (Erfurt) questioned the concept of textual communities as strong momentum also for religious groupings, especially in times of political and cultural change. Referring to texts from different genres that span across the first centuries CE he claimed that it were more local and transient networks that formed around textual practices, rather than strong, textual communities, unified through a canon of texts. Speech norms can be detected in texts from the first century CE onwards, nonetheless, group ties and boundaries were transmitted only to a limited extent.

The focus on "Short term ritual communities" in the sixth session offered us the opportunity to look at temporarily limited groupings, how they were constituted and perpetuated. Maura K. Heyn (Greensboro) explored the signs and styles priests on Palmyrene tomb reliefs used to represent themselves by choosing distinct features of dress, gesture and attributes that set them apart from others Palmyrenians. The depictions in the tombs were used to remind of communal (religious) gatherings, thus 
strengthening both, the prestige of the deceased and the community identity of Palmyra. Aspects of time and point in time were addressed by Michael Satlow (Providence) in his contribution on the Jewish New Moon celebrations. By comparing the rules for this periodical practice from The Hebrew Bible with the ones of Late Antique Rabbinic texts, he showed how variable and flexible a calendric festival can be and the ways the importance of a ritually correct observance of the New Moon had changed. Lived religious practices and centralized rules (temple/rabbi) are highly interwoven with local variations to which Rabbis responded as having great importance. Clemens Leonhard (Münster) discussed the gradual differences of adherence to Christian groups - a characteristic of Late Antiquity. Participation and access to rituals was on a temporary basis (Eucharist); or it was only seen as a potential (Baptism). "Extraliturgical benefits such as access to informal social networks" was of more importance in the second/third century than a fully established membership, as developed in the fourth/fifth century CE. Differentiation by group styles and internal bonding was of limited interest for early Christians. Rubina Raja (Aarhus) addressed the issue of banqueting groups in Palmyra. Mirrored in the tesserae - entrance tickets to their ritual banquets - these groupings appear as temporarily, spatially and socially highly restricted and exclusive. This phenomenon - comparable to associations - allows for questioning the heuristically hampering categories of public and private cultic activities and the related static groups of a public or a private body of people. Such short term communities served as link between other social groupings in the society, thus establishing at the same time distinction and connection.

The participants engaged in a lively and highly interrelated discussion, thus narrowing down the questions that remained, the helpful sociological concepts or terminological problems. As a result most participants agreed to the suitability of a definition of groups via styles and scenes that takes account of groups as highly fluid and unstable entities of societies. However, the distinction of group from, for example, network, community or association has yet to be determined. On this definition depends how to assess the quality and types of interaction which all groupings substantially are based on. Depending on the variety and simultaneously the limitedness of ancient sources (texts, objects, spaces, reconstructed practices) their distinctive characteristics and qualities have to be clearly delineated. Moreover, the individual and his/her choices (out of a culturally given set) as an influential factor of a group's constitution must not be neglected either.

The range of methodological approaches and scholarly backgrounds offered in the fourth LAR conference inspired thoughts that will bear on the approach of Lived Ancient Religion, emphasizing ways of interaction, contrasting the authoritative rules and local practices, and focusing on situational differences.

"Beyond Duty. Interacting with Religious Professionals and Appropriating Tradition in the Imperial Era”, ERC-Tagung vom 14. bis 16. Januar 2015 im Augustinerkloster Erfurt (Georgia Petridou) 
The fifth 'Lived Ancient Religion' (henceforth LAR) conference in January 2015 focused on religious practitioners and providers of specialized religious knowledge and their interaction with lay people in the Ancient Mediterranean. A good number of our contributors (esp. Jan Bremmer, Esther Eidinow, Valentino Gasparini, Richard Gordon and Jörg Rüpke) dealt with the strategies these religious experts employed to lure in lay people (wider public and political authorities) and either take advantage of their emotional and physical needs or logically convince them about their own entitlement to power. Other contributions (like those delivered by Nicola Denzey-Lewis, AnneMarie Luijendijk, Georgia Petridou and Angela Standhartinger) concentrated more on issues of frequency of their interaction with lay people and the visibility of these religious professionals: how often did they interact with people and how accessible were they and to whom? Rubina Raja, Jörg Rüpke, Federico Santangelo and Markus Vinzent, in particular, focused on the question how easily religious knowledge and expertise lent itself to political contestation and how often religious titles and offices became part of the wider economic system of symbolic capital of prestige and honour. In this view, religious offices and titles became instruments of societal elevation rather than recognitions of religious expertise. Moreover, several of our contributors (esp. Jan Bremmer, Nicola Denzey-Lewis, Richard Gordon, Georgia Petridou, Jörg Rüpke and Annette Weissenrieder) examined further the related but thematically distinct issue of deprofessionalisation of religious expertise and wider dissemination of religious knowledge. Additional emphasis on the educational background of these religious was laid in the contributions of Anne Marie Luijendijk and Michael Swartz. Finally, the body as locus of contestation and signification of religious power was another important thematic thread that was explored in the contributions of Anja Klöckner, Valentino Gasparini, Ivana and Andrej Petrovic, Rubina Raja and Annette Weissenrieder. The last decade has seen a surge of scholarly interest in these religious professionals. Our meeting, however, was substantially different due to its unique intercultural character and its explicit focus on appropriation and contestation of religious expertise in the Imperial Era. The papers presented in LAR V examined the religious professionals, their dynamic interplay with pre-established religious schemata and authorities, as well as their proneness to religious interventionism and revisionism all around the ancient Mediterranean. A further but equally significant advantage of our meeting was its wide range of media of transmission considered here. Our contributors looked at both old and new materials, which derive not only from literary sources, but also from papyri, inscriptions, and material culture. Above all, the LAR V conference went well beyond pre-existing discussions not only in terms of the original sources, but also in terms of modern scholarly categories and terminology. In fact, problematizing the established and prima facie self-explanatory modern scholarly categories of priests and priesthood was one of the common themes that ran throughout the papers presented. Hence, we felt fully justified in adopting the rather provocative title Beyond Priesthood: Religious Entrepreneurs and Innovators in the 
Imperial Era for the resulting publication, which is edited by the organizers and has appeared with the RGVV series of De Gruyter in 2017 (open access).

„Lived Ancient Religion and Medicine”, ERC-Workshop am 28. Mai 2015 am Max-Weber-Kolleg (Georgia Petridou)

Our workshop brought together several international experts with a diverse backgrounds in classical studies, material culture, history of medicine, theology, ancient history and history of religions to look afresh at the individual as a sufferer/patient in conjunction with his personal religious/magical/alchemical (modern distinctions not ancient) beliefs/practices. More specifically, Patricia Baker (Conceptions of Salubrious Environments: Asclepia in their Natural Environments) embarked on an interdisciplinary survey of what Greeks and Romans would identify as salubrious locations in terms of their views, access to fresh air and water, and their positions away from places that were malodorous or cacophonous. For Baker, a thorough examination of these landscapes, or 'healthscapes', as she calls them, would provide us with an understanding of the desired sensual experiences sanctuaries offered that helped in the formation of health. The contribution of Jane Draycott (When Lived Ancient Religion and Lived Ancient Medicine Meet: Roman Domestic Medical Practice and its Practitioners) shifted the focus from the community and the group to the individual and the household. Draycott combined religious and medical historical approaches and examined the role that Roman private religious belief and practice played in domestic medical practice in Italy during the Late Republic and the Principate. With the paper of our keynote speaker, Richard L. Gordon (Knowing the signs: Pliny's herbarii, Lydian confession texts and somatic curses), we remained in the field of domestic medicine and herbalism and discussed the dynamics and problematics of the "folk-body". Gordon selectively discussed three different types of Imperial evidence for the "folkbody": a) Pliny's books on plant and animal remedies, b) the use of illness as an anamnesic device in the Lydian "temple script", and c) some curses that demand the forfeit of "blood" (i.e. life-force) as a punishment for theft and other wrong-doing. All of these themes, as Gordon maintained, were closely linked to religious representations. The contribution of Jessica Hughes ('Found' Objects and Lived Ancient Religion) moved the agenda of our meeting to the much promising area of material evidence and looked at yet another of the intersections of medicine and lived religion, a category of very special sanctuary dedications, which were not made explicitly to be votives, but which were 'repurposed' as offerings after having served a range of other functions, such as personal adornment and tools for work. These objects, Hughes argued, provide us with a unique opportunity to peep through the curtains and discover aspects of the individual experiences of illness and healing. The contributions of Matteo Martelli (Religion, Alchemy and Medicine in Zosimus of Panopolis' writings) and Antoine Pietrobelli (Galen's Religious Itinerary) grounded the discussion even 
more firmly on the realm of the individual. Martelli looked at the junctures of Egyptian religious practice and medicine as they are portrayed in the alchemical writings of Zosimus of Panopolis. Zosimus, as Martelli argued, criticized Egyptian religious ideas and contrasted them with a 'rational' practice of alchemy and medicine only to highlight some key aspects of his own syncretic methodological framework. Pietrobelli, on the other hand, examined thoroughly the complexities that lay behind extracts of Galen's work, which gives us glimpses into his private religious and philosophical realm. As Pietrobelli rightly argued, scholars find it difficult to comprehend how the multiple religious identities of a pagan worshipper (therapeutes) of Asclepius, a believer in a monotheistic demiurge and an avowed agnostic, could all be combined in the same person. The conceptual frame- work of Lived Ancient Religion, may in fact prove extremely helpful, Pietrobelli maintained in reconciling the singularity of Galen's religious evolution with his unique philosophical profile. The contribution of Georgia Petridou (What is Divine About Medicine? Mysteric Imagery and Bodily Knowledge in the Second Sophistic) recapped some of the themes discussed earlier and looked further into the intersections of medicine and religion in Imperial literature. Petridou asked why religious imagery and terminology drawn from mystery cults were employed to describe bodily knowledge in two of the most emblematic narratives of the second sophistic: Aelius Aristides' Hieroi Logoi and Lucian's Alexander the Pseudo-Prophet. Her argument was that those texts and many others from the same period dealt with a new kind of physiology, a physiology that is religiously experienced and religiously expressed. Finally, the crossroads between medicine and lived religion as they manifest themselves in the early Christian literature were explored by Annette Weissenrieder (Disease and Healing in a Changing World: "Medical” Vocabulary and the "Female Patient" in the Vetus Latina Mark and Luke). Weissenrieder looked at the Vetus Latina, or "Old Latin Bible”, a diverse collection of Latin biblical texts used by Christian churches probably from the second century on, and focused on the narratives of healing of "female patients", especially the bloodletting woman and Jairus' daughter in VL Mark 5 and Luke 8. She showed that along with the spread of medical knowledge beyond medical circles, there come medical designations, which are similar or strikingly different from those current in the medical discourse and are taken up in the manuscripts found and related to the so-called "African" text that is close to Cyprian and different in the so-called European text tradition. Back in 1988, Arthur Kleinmann (The Illness Narratives. Suffering, Healing and the Human Condition) defined illness as "the lived experience of monitoring bodily processes”, and thus bridged the gap between externally defined medical categories of illness and the more personal experience that illness is for the individual patient. Within the methodological framework of the LAR, illness can be thought of as a personal crisis, often reveals hidden cracks in the socio-political nexus. It offers a unique opportunity for the individual to make adjustments to pre-established political, healing and religious schemata and to create new ones. Thus, illness and its counterpart 
(healing religious and secular), this workshop argued, offer a unique insight into the 'Lived Religion' in the Graeco-Roman world.

"Seeing the Gods", Tagung vom 3. bis 4. Juni 2015 am Max-Weber-Kolleg (Marlis Arnhold)

On June 3 and 4, 2015, scholars of Classical Studies, New Testament Studies, and Religious Studies met at the University of Bonn for the international conference "Seeing the Gods. Image, Space, Performance and Vision in the Religion of the Roman Empire" conducted by Dr. des. Marlis Arnhold (Bonn), Prof. Dr. Harry Maier (Vancouver, BC), and Prof. Dr. Jörg Rüpke (Erfurt). The scope of this conference was to shed new light on the dialectics of imagination and illustration of the divine in texts and pictures. The individual contributions thus analyzed how meaning was coded and recoded in visual cues in order to create images of the divine. Not only was shown how meanings and visual cues could alter over time independently from each other, but also that the use of particular cues in specific contexts followed purposes (the one of legitimation, for instance). But also the disposition of the individual viewer towards an image of a divine being as well as his or her socio-cultural and religious background proofed crucial for the perception of an image's meaning. The conference thus revealed the strong entanglement of Christian and Non-Christian imagery on the one hand since these shared the same cultural background. On the other hand, it brought to light a number of issues, which provide potential for a continuation of the discussions: As such, the impact of the creative process in the imagemaking or the interdependency of an individual's cultural knowledge and experiences and his or her reaction to images of the divine appeared as very interesting aspects. The conference was realized with the generous support of the German Research Foundation, the Faculty of Arts of the University of Bonn, and the Max-Weber-Kolleg Erfurt, for which we would like to express our gratitude. Revised proceedings have been published with Mohr Siebeck in 2019.

\section{"Epochalisation and Periodization: The Augustan Age“, ERC-Workshop in Zusammenarbeit mit der Universität Aarhus vom 4. bis 5. April 2016 in Aarhus (Anna-Katharina Rieger)}

Epochs and periods are our tools to describe and cope with developments and trends in history. However, there is a need to critically approach these terms in order to revise the ways in which they are applied in scholarship and often hamper how we look and write about certain times, individuals, and phenomena in history. Distinguishing epochs and periods makes historical phenomena comparable and comprehensive, but it is a retrospective act creating boundaries, which inhibit to see the processual, 
transgressing elements.

In this workshop, the Augustan period as one of the best studied periods of Roman and more general Mediterranean and European history served as example to ask about a revision of the concepts of epochalisation and periodization through the lens of strategies within the religious sphere. Contributors were asked to consider a) a critique of periodization, b) innovation and tradition of religion, c) politicization of religion.

With a focus on the time between $45 \mathrm{BC}$ and $\mathrm{AD} 15$, the participants dealt with problems of the (trans-)formation of religion in the time of Octavian and later Augustus. The small circle allowed for an intensive discussion of individual papers.

Karl Galsinky ("hic nec tempora pono: Tua, Caesar, aetas") discussed concepts of periodization in the times of Augustus by looking mainly at poetry, or the involvement of people in religious affairs (ludi saeculares). The more cosmopolitical frame in the Empire lead to a memory creation linked to the emperor and oriented towards the future and not the past. Hence, the notion of saeculum becomes qualitative rather than chronological in the times of Augustus.

New insights into the recent findings of one of the earliest temples for the veneration of Augustus (Tiberian) in Ostia came with the paper of Roberta Geremia ("The temple of Rome and Augustus in Ostia: new elements for its dating”). A close revision of iconographical elements (clipeus, capricorn), entries in the fasti and historical setting under the successor of August lead her to this early dating.

With Jesper Majbom Madsen ("When their leaders became gods: Ruler cult in a Roman political context”) the roots of the emperor's worship were questioned. Against the general opinion that the emperor's worship emerged from the Hellenistic ruler cult in the Greek East - and not earlier than 29 BCE - he claimed that it started earlier referring to Roman traditions in the last years of Caesar's dictatorship.

The margins were the topic of Rubina Raja's paper on the „Creation of an epoch: Octavian, Herod and the epochalisation seen from the East”. She focused on the active role Herod played in Augustus' politics in a time when his sovereignty was not yet assured. Herod did not only copy Roman models but was in some aspects a forerunner to developments in Rome.

Christopher Hallet revised in an overview of “Octavian's renewal of Rome's earliest temples and shrines in the late 30's and early 20's BC: An Archaic Revival” the prevailing view on the "Augustan Classicism". He could show convincingly how slow architecture and sculpture was modelled along the lines of Classical Greek imagery, ornaments, and buildings, and how big and important the interest in Etruscan and Italic exempla was.

A phenomenon in Rome itself was tackled by Katharina Rieger ("Religion at grassroots, religion in Apollinic spheres: A look at some altars and bases in Augustan Rome"). Analysing the chronological range of altars and bases (of the quindecemviri and the vicomagistri), she showed how short-lived or tentative some phenomena in objects and iconography were. Only scholars' retrospective views make these objects 
being cores of the changes in art and religion, but might have had an ephemeral role in their time.

Jörg Rüpke focused on the “Augustan History of the Roman calendar” and argued that the changes in the times of Augustus opened the calendar for further meanings as well as determined it for the purposes related to Augustan politics and Roman imperialism. Hence, the Augustan phase between the Julian reform and Julio-Claudian routinization was more influential than the fixed distinction of reforms make us think.

All papers, based on variegated evidence, showed that manifold strands of religious representations, the power of marginality as well as memory and the past were present as driving forces in the pre-Augustan and Augustan time. Thus, the participants added aspects to the conditions prevailing in this time that gave politics the chance to change and use religion to a much higher degree allowing for a soft religious innovation and change of how "history" was employed by exceptional politicians like Octavian and later Augustus.

\section{“Religious Experience”, ERC-Workshop vom 19. bis 20. Mai 2016 am Max-Weber- Kolleg (Maik Patzelt)}

The Max-Weber-Kolleg Erfurt, and especially the "Lived Ancient Religion" project was pleased to host Ann Taves, a world specialist on religious experience, for a period of over three weeks, including a two-day workshop on "Religious Experience". Religious experience is a key concept of the Lived Ancient Religion approach, but simultaneously, religious experience is the most difficult concept to work with. The problem lies in the vast range of possible approaches ranging from philosophy and sociology to psychology and cognitive science. Whereas one still debated problem lies in the curious idea of having a religious experience sui generis, another line of discourse debates the impossibility of analyzing something as deeply personal as somebody's experiences. With a clear emphasis on cognitive approaches, Ann Taves' approach discusses philosophical, sociological and psychological discourses in a way that allows his- torians to rethink the aspect of religious experience expressed in their mostly very fragmentary material in these terms. Ann Taves' approach both provides methods to pinpoint the variety of religious experiences (or experiences 'deemed religious') in historical texts as well as to illuminate the various ritual strategies to that end. The first day was dedicated to Ann Taves and her recent work on religious experience and its role for constituting religious communities, such as Alcoholics Anonymous and the Latter Day Saints movement ('Mormons'). Ann Taves pointed out how experiences deemed religious serve as crucial communicative elements in forming communities. Again, her contribution helped to reconfigure how the Lived Ancient Religion project could approach religious experience. On the second day, two contributors of the Lived Ancient Religion project, Georgia Petridou and Maik Patzelt, 
illustrated the richness of the ancient material in these terms. Both reconsidered the importance of religious experience in antiquity. By introducing the hieroi logoi of Aelius Aristides, Georgia Petridou illustrated the variety of religious experiences in ancient pilgrimage. Maik Patzelt illustrated the variety of techniques for trance in ancient Rome. The lively discussions shed new light on well-known material and illuminated the way in which new concepts and methods can be fruitfully applied to the religions of the ancient world. In result, religious experience appeared as a central concern in ancient religions. A deeper investigation of religious experiences in antiquity thus remains a highly recommended task.

“Urban Religion”, ERC-Workshop in Kooperation mit dem Classics Department of Princeton University vom 2. bis 3. Juni 2016 am Max-Weber-Kolleg (Maik Patzelt)

Once again, the Lived Ancient Religion project and the Classics Department of Princeton came together in order to discuss new approaches to ancient religions. After fruitful discussions of lived ancient religion at Princeton University in January 2015, Erfurt now hosted a group of six guests from Princeton University. One further participant, Dan-el Padilla Peralta, presented his paper via Skype. For two intensive days, this workshop examined and developed the idea of urban religion in antiquity. Urban religion was seen as a specific constellation of materiality and communication that finds its expression most of all in the emergence of public spaces. From this starting point, the workshop explored religious interactions, degrees of institutionalization, innovation, imitation, and mutual influence of practices as well as identities. Whereas the first day was dedicated to Roman material, the second day concentrated on Greek and Egyptian evidence. Concerning the Roman material, three contributions (Maik Patzelt, Carolyn Tobin, and Caroline Mann) explored the problems of ritual transgression and how these transgressions could be regarded as expressions of ritual innovation, of religious and political interactions, and of new identities. Richard Neudecker and Harriet Flower dedicated their efforts to aspects of architectural strategies and the individual use of religious spaces, while Dan-el Padilla Peralta offered an insight into the broader problem of the human resources needed in the construction processes of religious architecture. The second day started with Michael Flower challenging anew the concept of religion as used in Greek sources to draw attention to key aspects of urban religion on a broader scale. This attempt was followed by archaeological approaches of Valentino Gasparini and Margaret Kurkoski who both concentrated on aspects of architectonic and representational innovation within and beyond certain communities. After Myrthe Bartels considered pseudo-Aristotelian reflections on religious epithets, Jonathan Henry pointed out the degrees of institutionalization and innovation in the field of late ancient exorcism. Common dinners helped to further discuss and develop our idea of urban religion. The workshop brought up many aspects, methodological issues, and perspectives, which provide a fruitful 
basis for further investigations of urban religion. The workshop thus served as a good basis on which to continue and increase our corporation with Princeton to further new and fruitful approaches to the religions of the ancient world beyond common dichotomies, such as private and public religion.

"Lived Religion in Metropoleis. A Comparative Approach", ERC-Tagung vom 21. bis 23. Juni 2016 im Augustinerkloster in Erfurt (Emiliano Rubens Urciuoli)

Organized through the collaboration between the Max-Weber-Kolleg Erfurt, and the Centre for Urban Network Evolutions at Aarhus University, the conference Lived Religion in Metropoleis: A comparative view (21-23 June 2016, Erfurt, Augustinerkloster) explored the mutual constitution of religious and urban spaces by focusing on big cities. Both the comparative approach on early modern and contemporary metropoleis and the cross-disciplinary (ancient history, early Christian studies, archaeology, sociology, social geography) training of the participants were capitalized for answering the following set of questions: How did urbanization processes and urban facets translate into religious agency, communication and identities within the megacities? What would ancient religion have looked like without the specific contribution of these centres to the shaping of religion and religious traditions? Are we able to narrate religious change in a way that pays sufficient attention to it? A gender- and age-balanced group of specialists, the high number of the contributors (19) advises against a fully detailed report of the conference, which deliberately shuffled the chronological order as well as the theoretical vs. historical-empirical partition of the talks, and benefited from cases studies and micro-level analyses without losing touch with its broader problematic and specific scopes. All sessions were chaired by members of the "Lived Ancient Religion" project and followed by a final discussion meant to critically assess the meeting and imagine possible future appointments for elaborating on the subject. While arguing for a more precise definition of the research object (metropoleis) and wondering whether to sharpen the overall theoretical framework, the contributors shared the feeling that a new promising field has been opened for self-centred perspectives on religions. In this sense, a follow-up conference is planned for November 2017.

“Narrating Witchcraft. Agency, Discourse and Power”, ERC-Tagung vom 30. Juni bis 1. Juli 2016 am Max-Weber-Kolleg (Richard Gordon)

Once a staple of UK African anthropology, witchcraft became a non-topic with the debate over 'magic' in the 1970s. But the irresistible rise of witch-finding movements all over sub-Saharan Africa, among many other events, made the topic of such beliefs, and their major vehicle, witchcraft narratives, an increasingly important focus of current anthropological research. Post-modern approaches to narrative mean that we no 
longer need to decide about 'truth' or 'falsehood' but can be content with negotiation, ragged ends, and variable strategies in complex social situations. Early-modern historians are exploring similar approaches to their trial material.

Given this background Esther Eidinow (Junior Fellow, Max-Weber-Kolleg Erfurt) and Richard Gordon (Associate Fellow, Max-Weber-Kolleg Erfurt), both historians of antiquity, set up an international conference at the end of the Summer semester 2016 within the framework of the ERC 'Lived Ancient Religion' project, directed by Jörg Rüpke and Rubina Raja, to explore the possible extra-value provide by a comparative perspective on such narratives. To that end, we invited ten international speakers: an African anthropologist, three early-modern historians, an expert on Kabbalah, two authorities on the ancient Near East (Babylonia, Egypt), two commentators on early Christian material, and a philologist. Given the differences between the types and extent of the primary material available in these different historical periods, the contributors played to their strengths.

Peter Geschiere (Amsterdam) emphasized the moral ambiguity of healers/witches in the territory of eastern Cameroon, the waves of new fashions and crazes of mystical protection, the ceaselessly inventive bricolage of new witchcraft narratives, and the fears of attacks emanating from one's own family expressed in the new rumours of zombie-workers. He also underlined the need, if we are to do comparative research at all, to ignore minor differences between different areas and periods and look for dominant patterns. Above all, 'witchcraft' is not an explanation, as is so often claimed, but a black hole requiring to be filled. Marion Gibson (Exeter) used two of the English witchcraft pamphlets arising from trial-proceedings, a genre that exists nowhere else, to show how variable the narratives relating to the self-same case might be. Stories of witchcraft events and the roles adopted in them by the principals are/were in constant flux in accordance with the shortterm needs of the tellers, to say nothing of the judges and the pamphlet-writers, so that there never could be a 'final' version. Alison Rowlands (Essex) used the extensive documentation from Rothenburg ob der Tauber concerning the case of Margaretha Horn (1652) to provide a memorable account of one peasant woman's long struggle to resist an accusation of witchcraft. Here again, the elusiveness of the charge, the ambivalence of every claim and every item of evidence, and the central importance of framings were beautifully brought out. Wolfgang Behringer (Saarbrücken) showed how the authors of demonological treatises manipulated narratives they found in trial records in order to fit their own truth and fully appreciated the value of such 'first-hand' mini-narratives in granting credibility to their demonological scenarios. The evidence available for the ancient Near East offers virtually no witchcraft narratives of these types, though they surely once existed, yet a comparative perspective enables us to draw out certain common themes. Thus Greta van Buylaere (Würzburg) showed that suspicion of one's own family was characteristic of witchcraftfears in Babylonia while direct accusation was avoided by 'materialising' the witch as a figurine that could then be destroyed, 
and that from the mid-second millennium the 'standard-image witch' becomes female. Svenja Nagel (Würzburg) suggested that private witchcraft attacks seem to have been adapted from temple recipes, while the very existence of textual amulets suggests that fear of witchcraft was relatively widespread. We know that wisefolk existed but cannot estimate their role, which in other societies is of key importance. In the case of the Graeco-Roman world, Esther Eidinow (Nottingham/Erfurt) raised the gender-question in relation to the trials of women, especially metics (i.e. resident but foreign) in fourth-century BCE Athens: Virilocal marriage and widespread concubinage meant that women, the Other inside, might easily be the target of accusations particularly in the aftermath of the Peloponnesian War. Richard Gordon (Erfurt) emphasised the many different forms of what we can broadly call witchcraft narratives in the Roman Empire, the value of the impalpability of 'magic', and the ability of actors in fraught situations to create narratives adapted to their strategic aims. Jan Bremmer (Groningen/Erfurt) showed how the figure of Simon Magus ballooned in the Christian imaginaire from the mid-first to the early third century acquiring ever more fantastical contours, while Almuth Lotz (Potsdam) contrasted the ability of top-class rhetors in the late-antique eastern Mediterranean to use accusations of witchcraft to emphasise their own status with the Christian saint whose intervention spreads an idealized harmony in a divided village. Perhaps the most curious case was that produced by Yuval Harari (Negev): the evidence of several curses written by Kabbalists to kill Hitler and other leading Nazis in the dangerous period of Rommel's advance on Cairo in 1942 before the first battle of El Alamein. If such curses were produced by rabbis, they were not considered 'magic' but as the effective use of divine power. This point emphasizes the relationality of all such narratives, the need for finer contextualizations, and the awareness of the levels of 'interference' that go into their construction. But, as Geschiere emphasised so forcefully, there is always the big story, the wider situation, which gives such narratives their social power. Negotiations with the Pennsylvania University Press are under way with the aim of publishing the proceedings in their Magic in History series.

\section{"Materiality of Divine Agency in the Graeco-Roman World", ERC-Workshop vom}

\section{August bis 2. September 2016 am Max-Weber-Kolleg (Anna-Katharina Rieger)}

Within the framework of the ERC Advanced Grant "Lived Ancient Religion", directed by Jörg Rüpke, a Postgraduate Workshop on the "Materiality of the Divine Agency in the Graeco-Roman World" took place between 29th August and 2nd September 2016. The Postgraduate Workshop aimed to investigate archaeological evidence and textual sources in a comparative way to unearth the multiplicity and richness with which divine agency is depicted and presented in narratives, religious practices and ideas, as well as in iconographical evidence. How well grounded in ritual action and cultural production was it to imagine the gods and goddesses in an aniconic or hybrid form? 
Why was there ever the need to communicate in writing with the gods? Why did the gods need food, clothing, and material gifts? How did curses work? What deities were able to heal, and how did they realize it? The workshop attracted more than 20 doctoral students and early career researchers from Classics, Religious Studies, Archaeology, Ancient History, and Theology to come to Erfurt. The invited guest speakers Emma Aston, Nicola Denzey Lewis, Esther Eidinow, Amy Smith, Ian Rutherford, und Greg Woolf from the University of Reading, Nottingham, London, and Brown, introduced topics like the materiality of the divine body, of tombs and the dead, the hybridity of divine beings, anatomical offerings and libations, cursing and curse tablets, the agency of images and objects. They were seconded by lectures given by Georgia Petridou, Katharina Rieger, and Jörg Rüpke from the Max-Weber-Kolleg Erfurt. The participants from the US, UK, Finland, Basque Country, Spain, Italy, Hungary, France, Austria, and Germany filled the four study days with lively discussions in a very open atmosphere. All engaged closely with the extensive methodological and thematic agenda that focused on aspects of the materiality of divine agency. Papers on concepts of the divine, on strategies of communication (divination, cursing, sacrifice) and their transformation into physically perceivable objects or texts (altars, dedications, buildings) were presented. Marginal areas of religious practices (invention of new gods and religious specialists) but also variations of epiphanies and embodiment of the deities in image and text throughout Classical Antiquity were explored in various papers. A base line in the discussion was the question what in particular the concept of "agency" might mean in various contexts, and what its employment can add to our understanding of religious processes and practices. Apart from the contacts to our colleagues from Reading, we got into contact with collaborators of the project "Empire of Faith" (University Oxford) and of the Center of Excellence "Changes in Sacred Texts and Traditions" (Finland University, Helsinki), which might be interesting for future exchanges. Many of the participants, especially those in the stage of writing their Ph.D. theses, took off with stimulating input on how to analyze religious phenomena in antiquity as preserved in texts and (image)-objects.

Klausurtagung des ERC-Projektes „Lived Ancient Religion“ vom 8. bis 9. Dezember 2016 (Jörg Rüpke)

Nach fünf erfolgreichen und ertragreichen Jahren kamen gegenwärtige und ehemalige Mitarbeiter/innen des ERC-Projektes „Lived Ancient Religion: Questioning ,Cults“ and ,Polis Religion““ am 8. und 9. Dezember 2016 im Schloss Ettersburg in Weimar zusammen, um gemeinsam in die Vergangenheit und Zukunft zu blicken. Eröffnet wurde die Klausurtagung des im Mai 2017 ausgelaufenen Projektes mit der Rekapitulation des Erreichten. Zahlreiche Publikationen, ausgerichtete Konferenzen und eine eigene Fachzeitschrift (Religion in the Roman Empire) hat das Projekt unter der Leitung von Jörg Rüpke hervorgebracht und somit nachhaltig die Forschungslandschaft 
in den einzelnen altertumswissenschaftlichen Fachgebieten geprägt. Ein Rückblick auf die verschiedenen Einzelprojekte der jeweiligen Mitglieder hat bewiesen, wie vielseitig die Suche nach gelebter antiker Religion gestaltet werden kann. Diese Erkenntnis hat alle Beteiligten dazu angeregt, das Konzept der Lived Ancient Religion weiterzuverfolgen und auszudifferenzieren. In Anbetracht dieses Erfolges verstand sich die Tagung als Wegbereiter künftiger Herausforderungen, neue Akzente der Lived Ancient Religion zu setzen und neue Perspektiven zu gewinnen. Mit diesem Ziel vor Augen wurde einhellig das Interesse bekundet, auch in Zukunft persönliche und institutionelle Kooperationen mit den jeweiligen Mitgliedern zu pflegen und auszubauen. Das jüngst unterzeichnete Memorandum for Understanding zwischen dem Max-Weber-Kolleg und dem Centre for Urban Network Evolutions in Aarhus, unter der Leitung des Projektmitglieds Rubina Raja, hat diese Bemühungen in erste Bahnen gelenkt. Das Ende des Lived-Ancient-Religion-Projektes kann vor diesem Hintergrund nur der Anfang umfassenderer Forschungen zu den Religionen von der Archaik bis zum Hochmittelalter sein. Es bleibt viel zu tun, und mit dieser Gewissheit blicken die gegenwärtigen und ehemaligen Mitarbeiter/innen erwartungsvoll in die Zukunft.

Leaving the (Disciplinary) Comfort Zone: Lived Ancient Religion AD 1 to 800, Final Conference of the ERC Advanced Grant “Lived Ancient Religion”, 3rd to 5th April 2017 (Jörg Rüpke, Rubina Raja)

With a final conference bridging time periods and disciplines, the ERC Advanced Grant “Lived Ancient Religion”, directed by Jörg Rüpke and Rubina Raja, concluded its five years of intense research. Under the topic of "Leaving the (Disciplinary) Comfort Zone: Lived Ancient Religion Ad 1 to 800”, about 25 internationally renowned colleagues were invited to Eisenach from 3rd to 5th April. The conference aimed at an implementation and adaptation of the project's results into the larger field of religious studies of the Mediterranean rather than on presenting achievements. Therefore, the invited speakers came from a variety of disciplinary contexts (Jewish Studies, Theology, Late Antiquity, Early Christian Studies) and not only from the inner circles of the LAR project. They were asked to test, criticize and contextualize definitions or results from the LAR project in their fields of research. Chronologically and topographically, topics ranged from the Mediterranean, North Africa and Europe to Western Asia, from Hellenistic times to Early Medieval times.

Among the speakers were Barbara Borg (University of Exeter), David Frankfurter (University of Boston), Nicola Denzey Lewis (Brown University), Rebecca Flemming (Cambridge), Alexia Petsalis-Diomidis (Oxford), Angela Kim Harkins (Boston College), Ian Rutherford (University of Reading), Moulie Vidas (Princeton) as well as members of the Max-Weber-Kolleg (Emiliano Urciuoli, Katharina Rieger, Richard Gordon, Maik Patzelt and Valentino Gasparini). They reflected in their contributions 
about the four main thematic fields of the conference: "A 'Thing' Called Body", "Commemorating the Moment: Individual Modification and Appropriation of Sacralized Spaces and Objects", "Experiencing the Religious" and "Switching the Code: Individual Appropriation of Religious Texts”.

Whereas the panel "Experiencing the Religious" aimed at bringing to the fore experiences underlying religious action and identifying the discourses about the dangers or values of true or false religious experiences, "Switching the Code" wanted to reconsider the techniques and procedures by which meanings, discourses and writings are performed, controlled and reproduced in religious settings and/or for theological purposes. Coming from the corner of materiality, “A 'Thing' Called Body” emphasized the situational meaning of material artefacts in religious contexts. Likewise, the panel "Commemorating the Moment" focused on the individual appropriation and modification of (mainly public) norms in the religious field, including rituals, but particularly objects and spaces, in order to disclose "micro-strategies of sacralization". In a round-table discussion Corinne Bonnet (Toulouse), Jan Bremmer (Groningen), Zsuzsanna Varhelyi (Boston) and Judith Lieu (Cambridge) commented Jörg Rüpke’s recently published book Pantheon: Geschichte der antiken Religionen (München: C. H. Beck) under the perspective of long-term developments in religious studies of the Mediterranean. They together with the vivid discussions in all four panels highlighted the benefits and the prospective potential of the "lived religion" approach, which continues by shedding light on urban space and urban religion.

The very intense and, at times, controversial discussions are published as an issue of the journal Religion in the Roman Empire 4.1 (2018) (round-table contributions) and in two volumes published in an open-access format with De Gruyter (contributions to the thematic fields of the conference, doi: 10.1515/9783110557596). 